


\title{
Impact of the elderly on household health expenditure in Bihar and Kerala, India
}

\author{
par \\ David Loutfi \\ Département de médecine sociale et préventive \\ Faculté de médecine \\ Mémoire présenté à la Faculté des études supérieures \\ en vue de l'obtention du grade de Maîtrise
}

Août 2013

(C) David Loutfi, 2013 


\title{
IDENTIFICATION DU JURY
}

\author{
Université de Montréal \\ Faculté des études supérieures
}

Cette mémoire intitulée:

Impact of the elderly on household health expenditure in Bihar and Kerala, India

\section{Présentée par: \\ David Loutfi}

a été évaluée par un jury composé des personnes suivantes :

\author{
[], président-rapporteur \\ Jean-Frédéric Lévesque, directeur de recherche \\ Subrata Mukherjee, codirecteur \\ [], membre du jury
}




\section{Résumé}

Dans le contexte d'une population vieillissante, nous avons étudié l'impact de la présence de personnes âgées sur les dépenses catastrophiques de santé (DCS), ainsi que leur impact sur trois effets reliés (le fait d'éviter des traitements, la perte de revenu, et l'utilisation de sources de financement alternatives). Nous avons utilisé les données d'une enquête du National Sample Survey Organization (Inde) en 2004, portant sur les dépenses reliées à la santé. Nous avons choisi un état développé (Kerala) et un état en voie de développement (Bihar) pour faire une comparaison des effets de la présence de personnes âgées sur les ménages. Nous avons trouvé qu'il y avait plus de DCS au Kerala et que ceci était probablement lié à la présence accrue de personnes âgées au Kerala ce qui mène à plus de maladies chroniques. Nous avons supposé que l'utilisation de services de santé privés serait lié à une augmentation de DCS, mais l'effet a varié en fonction de l'état, du présence d'une personne âgée, et du type de service utilisé (ambulatoire ou hospitalisation). Nous avons aussi trouvé que les femmes âgées au Bihar utilisait les services de santé moins qu'elle ne devrait, que les ménages ayant plus de 4 personnes ont possiblement un effet protecteur pour les personnes âgées, et que certains castes et group religieux ont dû emprunter plus souvent que d'autres groupes pour payer les frais de santé. La présence de personnes âgées, les maladies chroniques, et l'utilisation de services de santé privées sont tous liés aux DCS, mais, d'après nos résultats, d'autres groupes retardent les conséquences économiques en empruntant ou évitant les traitements. Nous espérons que ces résultats seront utilisés pour approfondir les connaissances sur l'effet de personnes âgées sur les dépenses de santé ou qu'ils seront utilisés dans des discussions de politiques de santé.

Mots clés: Dépenses catastrophiques de santé, personnes âgées, maladies chroniques, secteur privé, Inde 


\section{Summary}

In the context of an ageing population in India, we have examined the impact of the elderly on catastrophic health expenditure (CHE) and three related access impacts (avoidance of treatment, loss of income, and alternate sources of funding). We used data from the National Sample Survey Organization (India) survey on healthcare in 2004. We chose one developed state (Kerala) and one developing state (Bihar) to compare and contrast the impact of ageing on households. Our results showed that CHE was higher in Kerala and that this was likely due to more elderly that in turn have more chronic disease. We expected the use of private treatment to lead to higher levels of CHE, and while it did for some households, the impact of private treatment on CHE, varied by state, presence of elderly, and type of health service (inpatient or outpatient). We also found that elderly females in Bihar were at a disadvantage with regards to health services utilizations, that larger household size might have a protective effect on elderly households, and that some scheduled caste and Muslim households have to borrow more often than other groups in order to fund their treatment. While the elderly, chronic disease and private treatment are linked to CHE, our results suggest that other groups may simply be delaying the consequences of paying for healthcare, by avoiding treatment or borrowing money. We hope that these results be used to explore the impact of the elderly in more detail in future research, or that it contribute to health policy discussions.

Key words: Catastrophic health expenditure, elderly, chronic disease, private healthcare, India 


\section{Table of Contents}

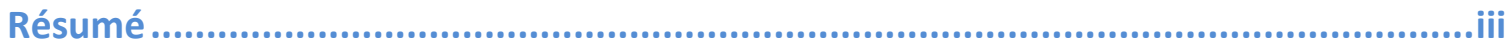

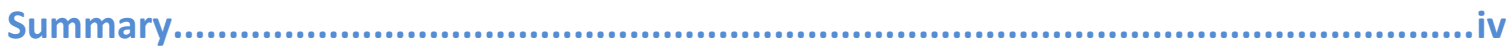

List of tables............................................................................................. vii

List of figures................................................................................................... viii

List of Abbreviations ........................................................................................... ix

Acknowledgements........................................................................................

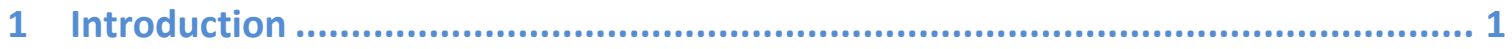

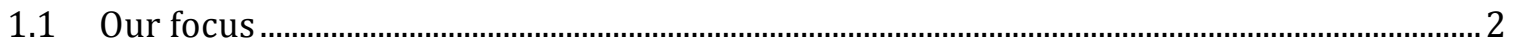

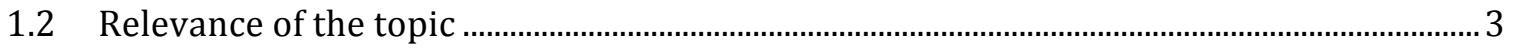

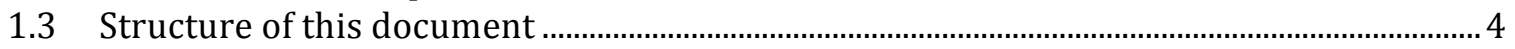

2 Literature Review ............................................................................. 5

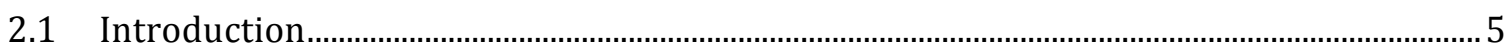

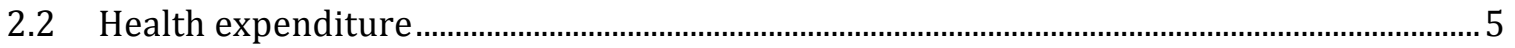

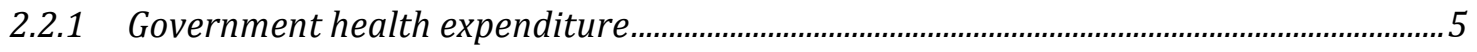

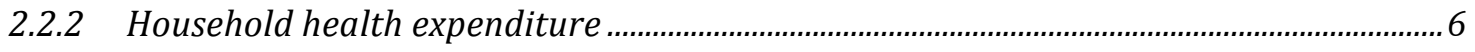

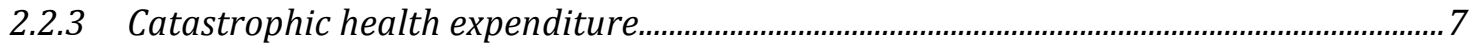

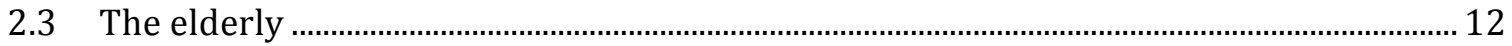

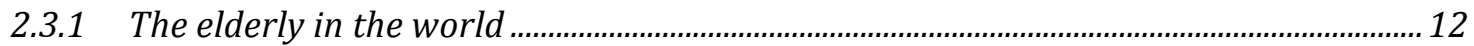

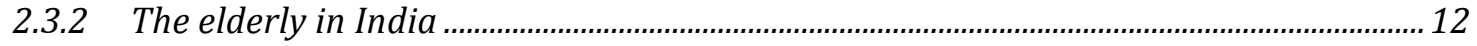

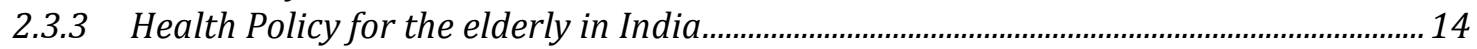

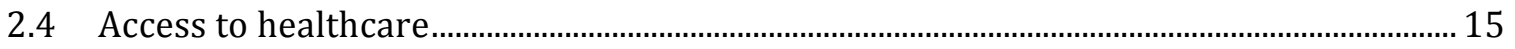

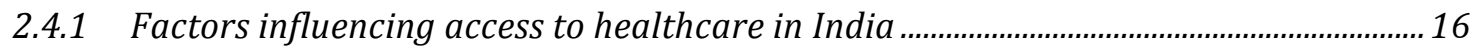

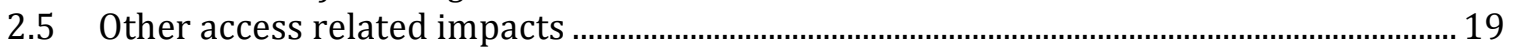

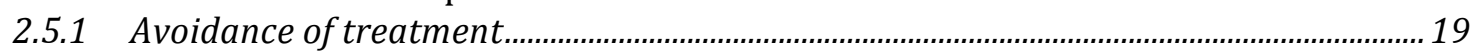

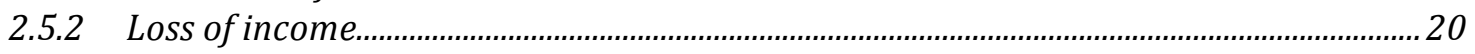

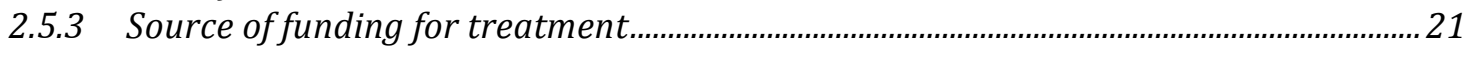

3 Conceptual framework ........................................................................ 22

4 Methodology................................................................................... 26

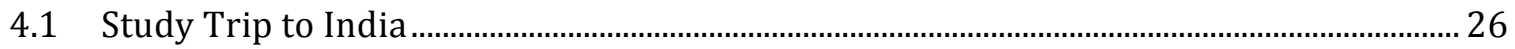

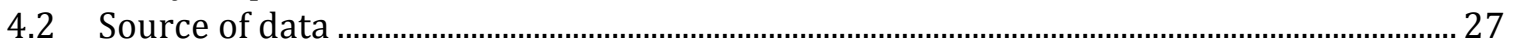

4.2.1 The National Sample Survey on Morbidity, Health care and the Aged ..........................27

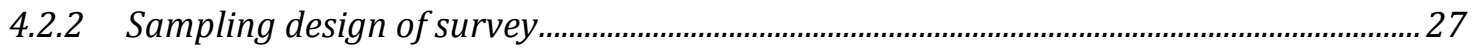

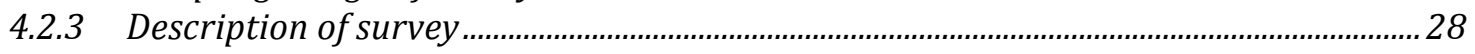

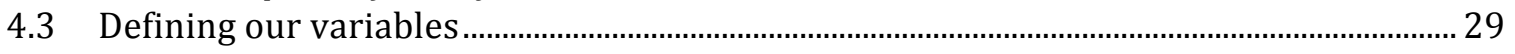

4.3.1 Primary dependent variable (Catastrophic Health Expenditure)...................................29

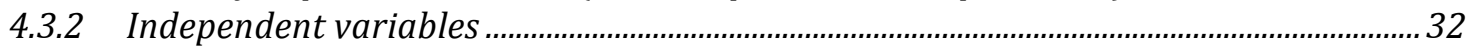

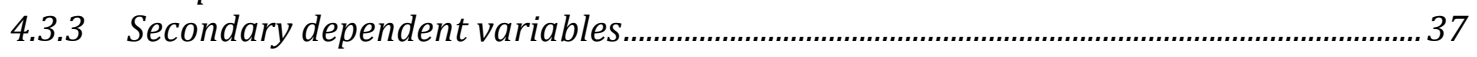

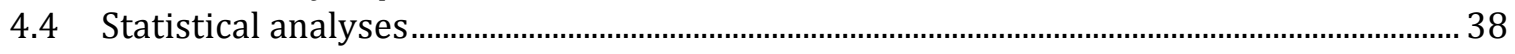

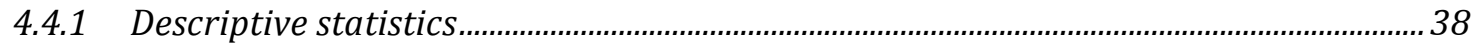

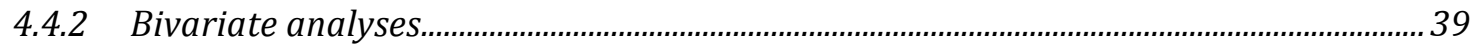

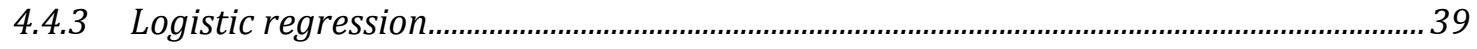

4.4.4 Analysis of secondary dependent variables ..................................................................... 39

5 Results - Article .............................................................................. 41 


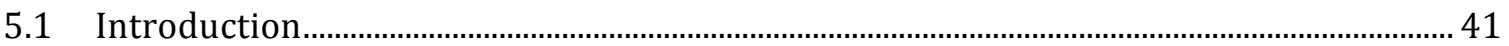

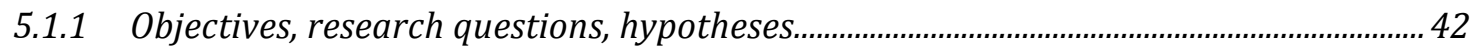

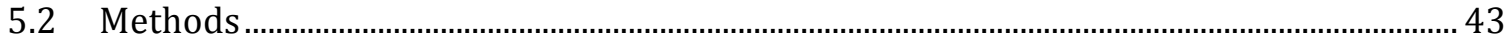

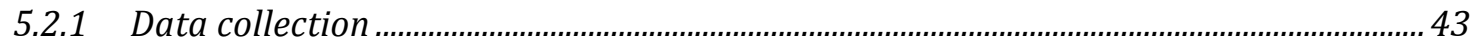

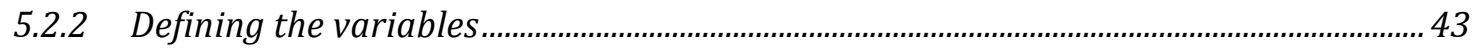

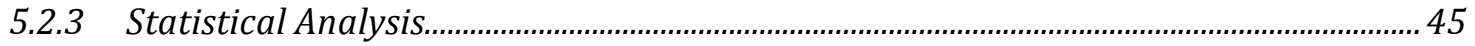

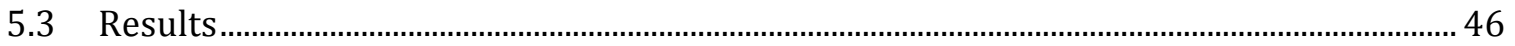

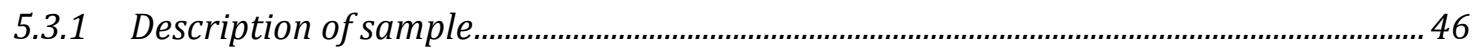

5.3.2 Level of CHE in Kerala and Bihar...................................................................................... 47

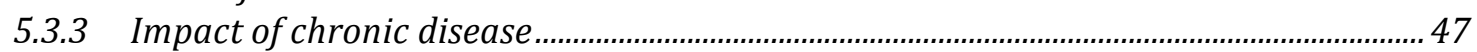

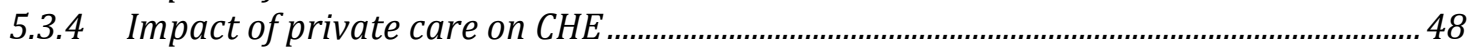

5.3.5 Logistic regression stratified by presence of elderly and state .......................................... 48

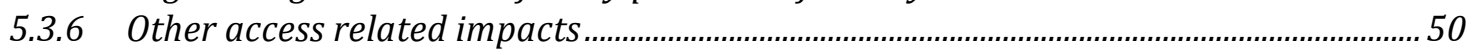

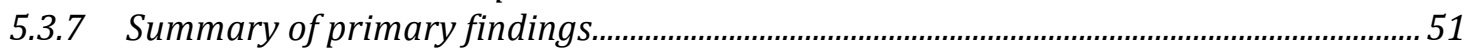

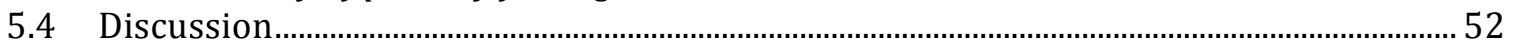

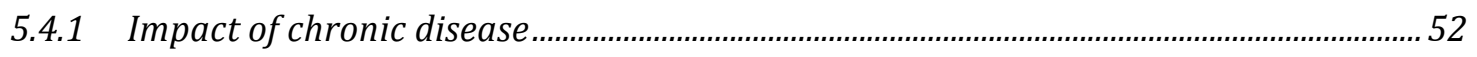

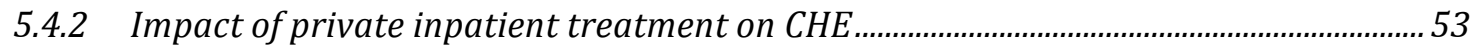

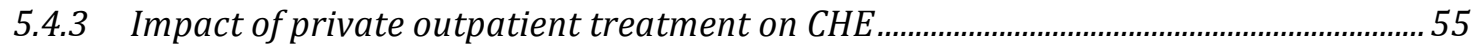

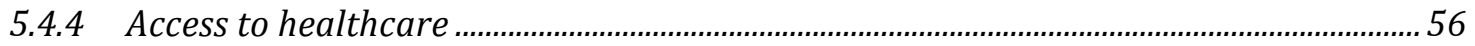

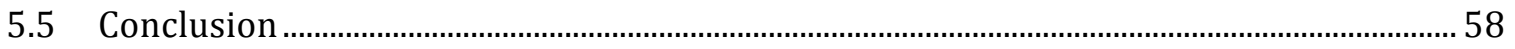

6 Additional Results ...........................................................................61

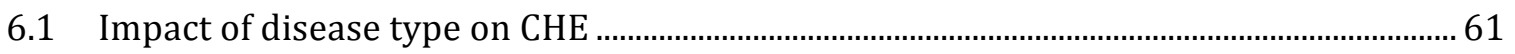

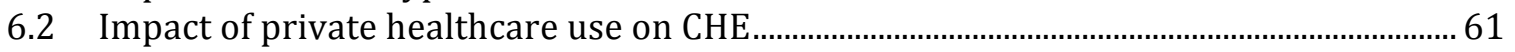

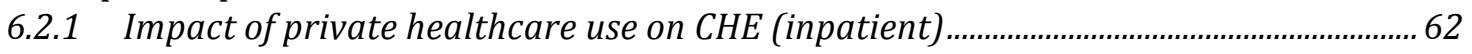

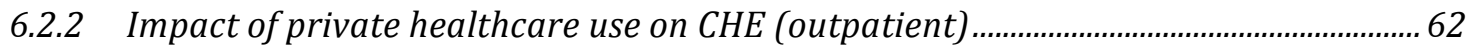

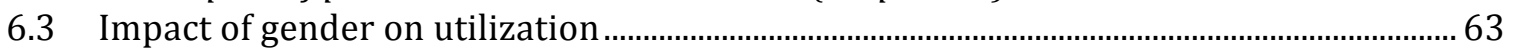

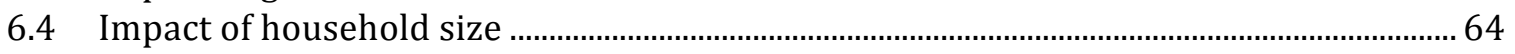

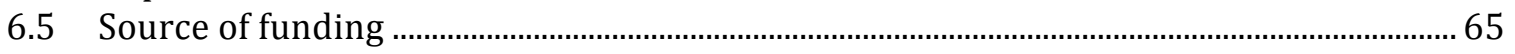

7 Discussion ..................................................................................... 66

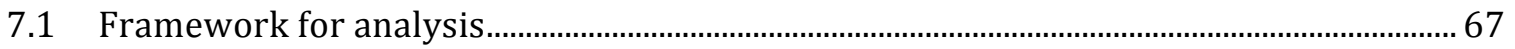

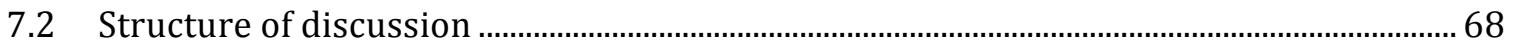

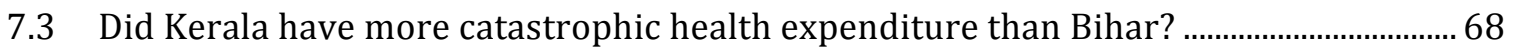

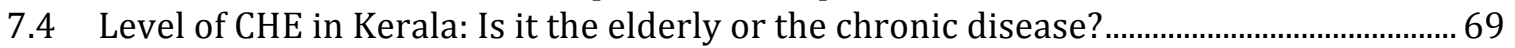

7.5 Did private healthcare use lead to increased CHE? ............................................................. 70

7.5.1 Impact of using private healthcare on CHE (all households combined)........................ 71

7.5.2 Impact of using private healthcare on CHE (stratified by presence of elderly) ........... 72

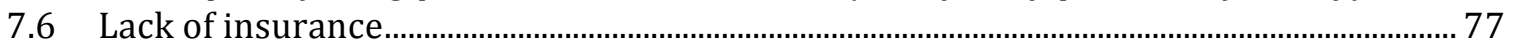

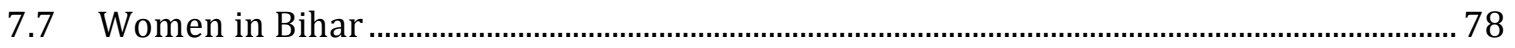

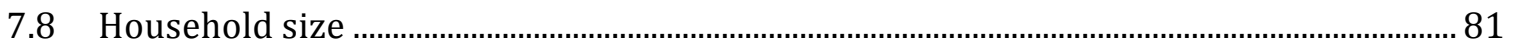

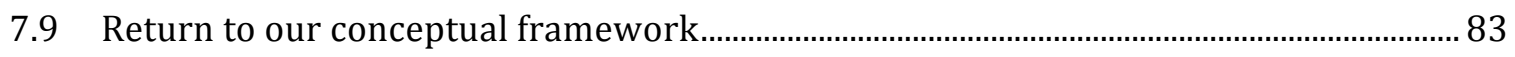

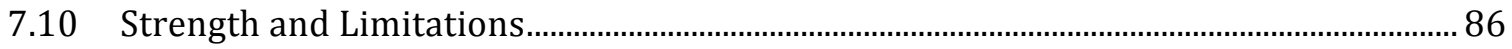

7.10.1 Limitations: Avoidance, recall period for health expenditure ........................................ 86

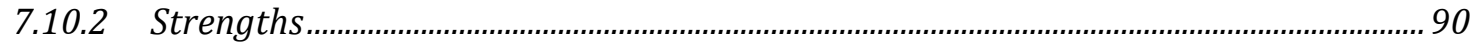

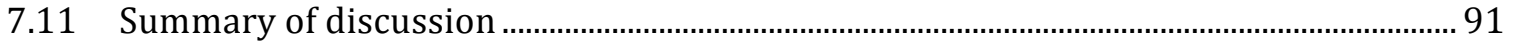

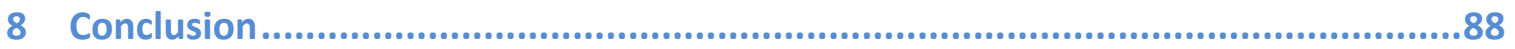

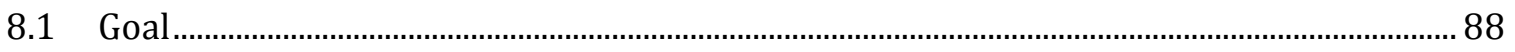

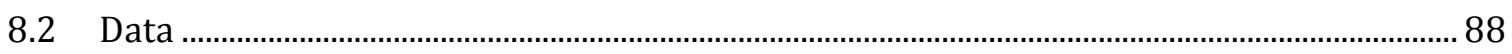

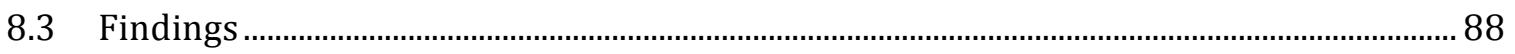

8.4 Measurement of Catastrophic Health Expenditure ................................................................. 90 
9 Appendices.................................................................................. xii

\section{List of tables}

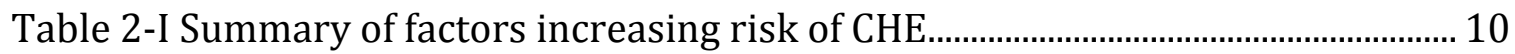

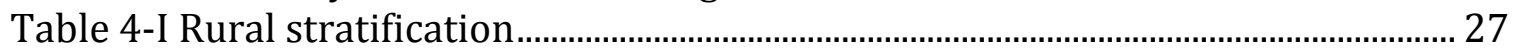

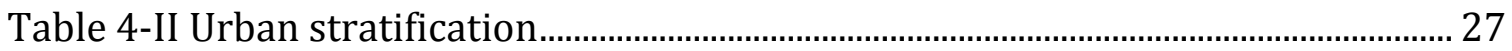

Table 4-III Second level stratification (Urban and Rural) ................................................ 28

Table 4-IV Division of Schedule 25.0 of 60th round of NSSO Survey .............................. 28

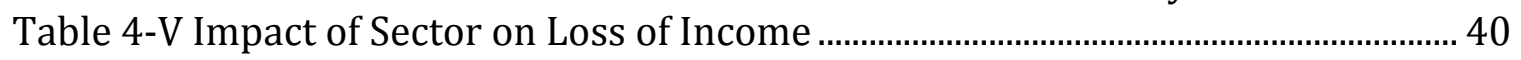

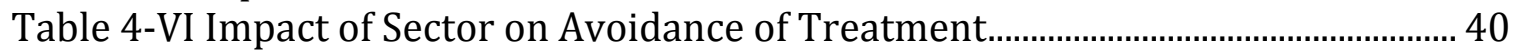

Table 4-VII Impact of Sector on Source of Funding ....................................................... 41

Table 5-I Comparison of demographic variables in Kerala and Bihar............................. 46

Table 5-II Households with catastrophic health expenditure ........................................... 47

Table 5-III Odds Ratios for Catastrophic Health Expenditure (elderly and non-

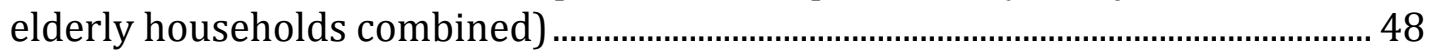

Table 5-IV Odds Ratios for Catastrophic Health Expenditure (stratified by presence

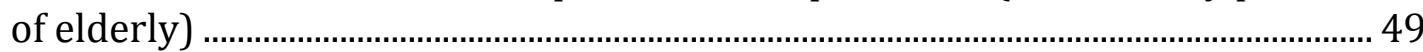

Table 5-V Impact of presence of the elderly on loss of income, avoidance, and source

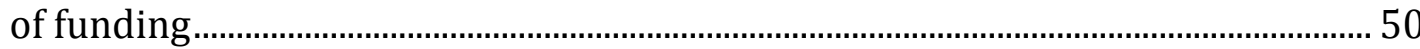

Table 5-VI Impact of presence of elderly, chronic disease, and private treatment on

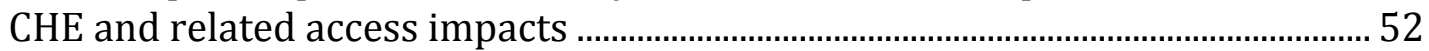

Table 5-VII Distribution of households with chronic disease ......................................... 52

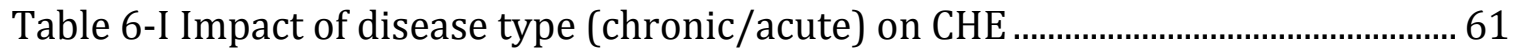

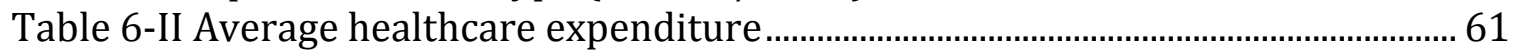

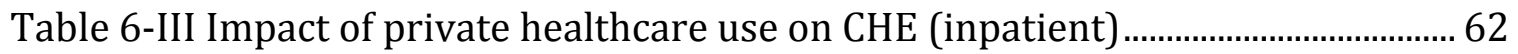

Table 6-IV Percentage of households using private healthcare (inpatient).................. 62

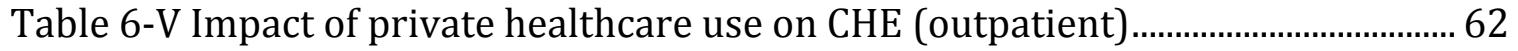

Table 6-VI Number of treatments per thousand population over the last 15 days ... 63

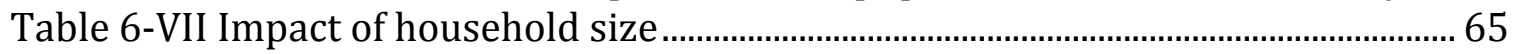

Table 7-I Impact of presence of elderly, chronic disease, and private treatment on

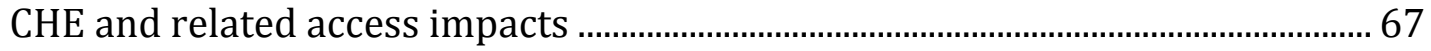

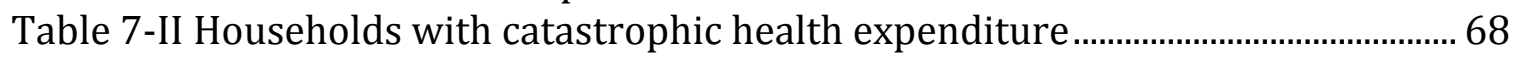

Table 7-IV Comparison of definitions of CHE (Households that incurred CHE) ......... 87

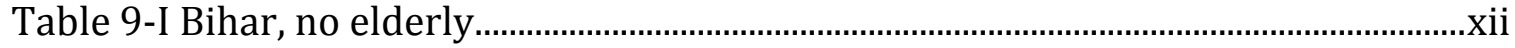

Table 9-II Bihar, elderly .......................................................................................................

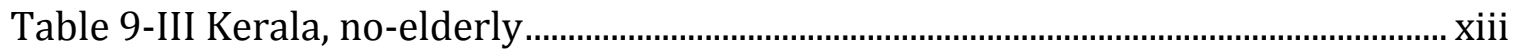

Table 9-IV Kerala, elderly ......................................................................................................... xiii

Table 9-V Percentage of households with CHE in Bihar (10\% of total household expenditure) ........................................................................................................................

Table 9-VI Percentage of households with CHE in Kerala (10\% of total household

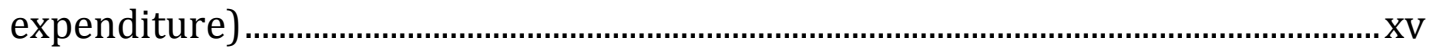




\section{List of figures}

Figure 3-1 Conceptual Framework …………………………………………………... 22

Figure 6-1 Number of treatments per thousand population over the last 15 days ... 64 


\begin{tabular}{ll}
\multicolumn{2}{l}{ List of Abbreviations } \\
BPL & Below poverty line \\
CAD & Canadian dollars \\
CHE & Catastrophic health expenditure \\
DALY & Disability adjusted life year \\
FSU & First stage units \\
GDP & Gross domestic product \\
INR & Indian rupees \\
NSS & National Sample Survey \\
NSSO & National Sample Survey Organization \\
OBC & Other Backward Castes \\
OOP & Out of pocket \\
PL & Poverty line \\
PPSWR & Probability proportional to size with replacement \\
RSBY & Rashtriya Swasthya Bima Yojna (Hindi name for a health insurance \\
scheme) & \\
SC & Scheduled Caste \\
ST & Scheduled Tribe \\
SR & Sub-round \\
SRSWOR & Simple random sampling without replacement \\
USU & Ultimate stage units \\
WHO & World Health Organization
\end{tabular}


This master's thesis is dedicated to my family. 


\section{Acknowledgements}

I would like to thank my supervisor Jean-Frédéric Lévesque for his insight and encouragement throughout the writing of this thesis. Next, my co-supervisor Subrata Mukherjee deserves special thanks for graciously hosting me for a summer and for introducing me to India and all its complexities.

I would like to thank all the staff and students at the Institute for Development Studies Kolkata, at the Center for Development Studies Thiruvananthapuram and at Université de Montréal.

Lastly, I would like to thank my family, friends, and roommates for supporting me throughout this process. 


\section{Introduction}

The world's population is estimated to have passed 7 billion in 2011. India currently has the second largest population in the world and given current population growth rates, India is expected to surpass China as the largest country in the world by 2030 (Bloom 2011).

India is undergoing a demographic and epidemiological transition. Better control of infectious diseases is leading to lower infant death rates and longer life expectancy (Jeyalakshmi et al. 2011) This leads to a population that lives longer and thus develops more chronic diseases. As people age and develop these diseases, they will require more health services and it is estimated that in 2030 almost $50 \%$ of the Indian health burden as measured by disability adjusted life years (DALYs) will be borne by the elderly (over 60 years of age) (Chatterji et al. 2008). An ageing population will thus put a strain on the health care system if it is not adapted to the changing needs of the population (Bhattacharjya 2005).

Three quarters of health expenditure in India is currently paid for privately (out-of-pocket (OOP) or private insurance) (Balarajan et al. 2011). Insurance coverage estimates vary widely including 1.6\% (Joglekar 2008), 3\% (Ellis et al. 2000), 10\% (Balarajan et al. 2011) and 25\% (Reddy, Selvaraj, et al. 2011)1. Since poorer populations generally have less health insurance, they tend to pay for health services through 0OP expenditures. For many, these expenditures can be crippling and this is known as catastrophic health expenditure (CHE). In practice a household is said to have incurred CHE if the amount of household income spent on healthcare exceeds a certain percentage (often 10\%) of total household expenditure. In India it is estimated that around 269 million people live below the poverty line (Planning Commission 2013). CHE exacerbates this problem, as 39 million people fall below

\footnotetext{
${ }^{1}$ The breadth of insurance coverage is rapidly changing in India. There is currently a project to supply all households below the poverty line with up to 30000 INR (about 550 CAD) of health insurance. While this should expand insurance coverage substantially, the project was implemented after our data was collected so the lower amounts $(1.6 \%$ or $3 \%)$ are likely more representative of our data.
} 
the poverty line each year due to these expenses (Balarajan et al. 2011). In 2004$2005,10 \%$ of urban and $14 \%$ of rural households in India incurred catastrophic health expenditure (Selvaraj \& Karan 2009).

\subsection{Our focus}

Given the ageing population of India, it is relevant to examine the impact of the elderly on catastrophic health expenditure. We have chosen to examine one developed state (Kerala) and one less-developed state (Bihar). We have chosen these two states due to their differences in economic and social development.

With regards to economic development, both states have had important economic growth in the past few years. The growth rate of the net state domestic product (NSDP) from 2000 to 2009 was 7.8\% in Kerala and 9.0\% in Bihar, compared with $7.1 \%$ in India as a whole. Though Bihar is experiencing strong growth, its per capita income is still the lowest in the country. Many workers in Bihar lack job security and social security due to the large informal sector. Using NSSO data, Naik estimates that $94 \%$ of the workforce in Bihar is in the informal sector, while only $63 \%$ of the workforce is in the informal sector in Kerala (Naik 2009). Further, in 2004-2005, poverty rates in Bihar were $41.4 \%$ and $15 \%$ in Kerala (Institute of Applied Manpower Research (India) 2011).

While social or human development is difficult to measure, Huq and Sen have developed the human development index (HDI) in order to ascribe one number to describe the human development of an area. It combines measures of life expectancy, literacy, and gross domestic product to produce one number ranging from zero to one that can be used to compare different areas. The HDI in India is 0.467 and this puts it a medium level of human development. However, this masks a difference between Indian states. The HDI in Kerala is 0.790 , which is comparable to countries such as Mexico and Chile. In Bihar, the HDI is much lower at 0.367. This is similar to countries such as Zimbabwe and Ethiopia (Institute of Applied Manpower Research (India) 2011). Literacy rates are also higher in Kerala (94\%) than Bihar (62\%) (Office of the Registrar General and Census Commissioner, India 2011) and higher literacy has also been linked to higher utilization of health services (Grosse \& Auffrey 1989). 
We would expect the presence of an elderly person in the household to increase the probability of CHE due to their increased use of health services. However, different states in India are at different stages of the demographic transition. For example, the percentage of elderly is substantially higher in Kerala (11.24\%) than it is in Bihar (5.58\%). Further, given the differences in access to healthcare and development, we expect the impact of the elderly on health expenditure to differ in these two states. For example, the elderly in Bihar might be less of an economic burden on their households simply because they cannot reach any health services. Therefore, we have examined the impact of the presence of elderly people on the economic consequences of healthcare on households in both states using data from the National Sample Survey of India, 60 $0^{\text {th }}$ round (NSS) carried out in 2004.

One limitation in many studies of catastrophic health expenditure is that its definition (as health expenditure as a proportion of total expenditure) does not cover all households that the concept aims to include. There are three specific cases in which this measure of CHE is incomplete. First, households could choose to avoid treatment altogether, knowing that it would be too expensive. Second, a household could lose income, either due to the sick person not working, or due to another family member taking time off work to help treat them. Third, households may choose to sell assets in order to pay for healthcare. This may enable them to avoid catastrophic health expenditure in the short term but may have longer-term consequences on the household. We will thus examine catastrophic health expenditure and these three related consequences to develop a more complete view of the impact of these increased healthcare needs due to an ageing population.

\subsection{Relevance of the topic}

This topic is important because the aging population of India combined with poor health infrastructure (lack of universal health insurance and often limited access to health care at affordable price ) will likely cause an increase in health payments and thus CHE. This can significantly affect the living standards of many families and will push many into poverty and worsen the state of those who are already poverty stricken (Balarajan et al. 2011). Kerala is further along in the demographic and epidemiological transitions and is more developed than Bihar. 
Understanding the current impact of the elderly on Kerala should help educate us on the potential challenges and solutions available to Bihar in the future. As well, poor health can have adverse economic effects through reduced productivity, and poor economic development is linked to poorer health (Sahn 2012). To avoid this vicious circle that could keep Bihar in an underdeveloped state, we should strive to understand the links between the current population structure and health expenditure. More generally, deepening our understanding of the factors causing CHE will allow policy makers to promote various initiatives and policies that could reduce CHE (Pal 2010).

\subsection{Structure of this document}

This thesis is divided into five parts. First, we review the literature on catastrophic health expenditure in the world and in India in particular. Second, we discuss the frameworks used in our conceptualization and analysis. Third, we examine the methodology used to analyze our data. Fourth, we present our results in the form of an article. Last, we discuss our findings in the context of an ageing population before concluding. Supplementary results of our can be found in the appendices. 


\section{Literature Review}

\subsection{Introduction}

In this literature review, we first give some context with regards to health expenditure before discussing what has been studied about catastrophic health expenditure in the world and in India. Given that the impact of the elderly is our focus, the next section discusses literature covering the state of ageing in the world, and then in India, with some discussion of current policies regarding the elderly in India. Next we discuss some of the factors that affect access in the Indian context. We end with a review of literature covering some of the other potential economic consequences of falling sick, such as avoiding treatment, losing income, or using alternate sources of funding.

\subsection{Health expenditure}

\subsubsection{Government health expenditure}

A country the size of India necessarily has huge health expenditure. In the years 2004-05, health expenditure was approximately 24 billion Canadian dollars and is $4.25 \%$ of GDP. Of this amount, only about $20 \%$ is paid for by the public sector, while most of the rest is paid out of pocket by households when they fall ill (Government of India, Ministry of Health and Family Welfare 2009). Unlike many developed countries, there is very little coverage by health insurance, with estimates ranging from 1.6\% to 25\% (Joglekar 2008; Ellis et al. 2000; Balarajan et al. 2011; Reddy et al. 2011). This means Indian citizens will fall in one of three categories. First, those who can afford healthcare pay and receive treatment. Second, those who have less money spend a large proportion of their income on treatment and have to forgo other essential items (Wagstaff \& Doorslaer 2003). Third, those who can't afford it at all avoid treatment altogether and suffer the consequences. This is due to the lack of government spending on healthcare both by the central and by state governments in India. A comparison with nearby countries shows that government 
health spending account for only $17.3 \%$ of total health spending in India while this rose to $28.1 \%$ and $26.3 \%$ for Bangladesh and Nepal, respectively. The proportion of government spending in developed countries such as Canada (69.8\%), the USA (44.7\%), and the UK (86.3\%) was much higher (Government of India, Ministry of Health and Family Welfare 2009). In 2003-04, only 4.97\% of the state government's budget was spent on healthcare. In Bihar, this was slightly lower at $4.84 \%$ and slightly higher in Kerala at 5.42\%. Unfortunately, these percentages have been decreasing (from $7.02 \%$ in $1985-86$ to $4.97 \%$ in 2003-04) (Ghuman \& Mehta 2009). The central government spent only $2 \%$ of its budget on healthcare (Bhaumik 2013). Public health expenditure is less than 1\% of GDP and this is partially due to the economic liberalization policy introduced in 1991 (Ghuman \& Mehta 2009). Finally, public health expenditure accounts for only $19.67 \%$ of total health expenditure, while the private sectors accounts for $78.05 \%$, with the rest being attributed to external flows (e.g. NGOs) (Government of India, Ministry of Health and Family Welfare 2009).

\subsubsection{Household health expenditure}

As private health insurance is extremely limited, households have to spend a large amount on healthcare should they fall sick. Indeed, it was estimated that $80 \%$ of health expenditure was paid for out-of-pocket in 2006 (Bhattacharjya \& Sapra 2008). Inpatient care, outpatient care or the cost of medication can each impose a substantial burden on household (Saksena et al. 2010). Unfortunately, paying for healthcare is sometimes a choice that households have to pass up. As such, higher healthcare expenditure is often not an indication of the amount of illness but rather the ability to pay. We can take the obvious examples of healthcare expenditure by households in the United States and in India. We expect Americans to have better health despite higher health expenditure. This concept can be expanded to compare states within India. A more developed state like Kerala has higher household health expenditure than a less developed state such as Bihar (Sen 2002). This expenditure is something that is worthwhile in that it improves people's health. However, the downside to the treatment is the economic impact on the household. Massive health 
expenditure can impact household spending on other essential items and when this expenditure becomes too large, we call it catastrophic health expenditure (CHE).

\subsubsection{Catastrophic health expenditure}

Catastrophic health expenditure is a concept that has often been used in designing policy to protect households or individuals from the economic impacts of health expenditure. The goal is to set a threshold above which we can say that households are spending too much of their income on healthcare. Once these households are identified, policy can then be designed to protect these households. Wyszewianski describes a few different definitions of CHE (Wyszewianski 1986). He first mentions a 1979 definition that considers health expenditure to be catastrophic if it exceeds a fixed amount (2000.00 USD used in the Long-Ribicoff catastrophic health insurance bill). This definition is necessarily incomplete since some households would be expected to be able to pay 2000.00 USD without suffering much, while for other families this would be a much larger part of their income.

Many authors have defined CHE as a percentage of income. Feldstein proposed $10 \%$ of income spent on healthcare as being catastrophic (Feldstein 1971). This is an improvement over the use of a fixed amount, but still does not completely address the fact that $10 \%$ of a rich household's income may not force them to make any significant changes, but poorer households may need this $10 \%$ to pay for essential subsistence items. As a solution, different thresholds for different levels of income have been proposed (Wyszewianski 1986). Finally, given the arbitrary nature of defining catastrophe, people have used different thresholds such as $5 \%$, $10 \%, 15 \%$ or $20 \%$.

Since the conceptual definition of CHE involves an amount that causes a change in the household's lifestyle, some authors have used a household's capacity to pay rather than their total income as the denominator. Capacity to pay is defined as the household's income minus their spending on essential items such as food $\mathrm{Xu}$, Klavus, et al. 2003). If the amount spent on healthcare exceeds a certain percentage of a household's capacity to pay, then this is considered catastrophic. If a poor household spends most of its income on food, but spends all the rest on healthcare, this definition considers it catastrophic, while the previous ones do not. There are 
many definitions of CHE and defining catastrophe is necessarily arbitrary to a certain extent. However, it is useful as a concept for policymakers and a consistent definition is useful in that context. Some literature in the Indian context defines CHE as $10 \%$ of total household expenditure (a proxy for income (Xu, Klavus, et al. 2003)) (O'Donnell et al. 2005; Selvaraj and Karan 2009) this is the definition that we will use, keeping in mind its limitations.

\subsubsection{CHE in the world}

Catastrophic health expenditure is a concept that has been studied in many different contexts around the world. Its primary use is to examine the economic impact of healthcare on households with the goal of helping to improve health policy.

In 1986, Wyszewianski studied the characteristics of American families who incurred CHE. He found that these households were often low-income, headed by an unemployed person, or headed by an elderly person (Wyszewianski 1986). In 2003 Wagstaff studied the impact of paying for healthcare in Vietnam and found that the primary cause was not inpatient spending, but rather outpatient spending. Further, he found that the poor were often pushed further into poverty but that the non-poor were less often pushed below the poverty line (Wagstaff \& Doorslaer 2003). In a 2005 working paper, O'Donnell et al. studied 6 Asian countries or territories (Bangladesh, Hong Kong, India, Sri Lanka, Thailand, and Vietnam) to find the determinants of CHE (defined as $10 \%$ of total household expenditure). They show that larger household size in Bangladesh, Hong Kong and Thailand increase CHE while larger household size decreases CHE in India. Households in a rural area, lack of access to safe drinking water, and lack of a sanitary toilet were also linked to increased CHE. They also show that CHE increases as household expenditure (a proxy for income) increases ( $O^{\prime}$ Donnell et al. 2005). This suggests that richer households often incur more CHE. In a 2003 study of Zambia, Hjortsberg showed that economic status and geographical access to healthcare (e.g. distance) were the main determinants of increased health expenditure (Hjortsberg 2003). In 2006, a study in Burkina Faso by Su showed that low economic status, utilization of modern healthcare, number of illness episodes, and presence of a household member with a chronic illness were the main determinants of CHE (defined with multiple 
thresholds of $20 \%, 30 \%, 40 \%$, and $60 \%$ of non-food expenditure) (Su et al. 2006). In 2006 study of Vietnam, Thuan et al. showed that chronic illnesses were a main determinant of CHE (defined as $40 \%$ of capacity to pay) and that these chronic illnesses were more prevalent in poorer sections of the population. They also showed that CHE was most often due to repetitive visits for more common illness rather than accidents or one-time expenditures (Thuan et al. 2006). Knaul et al. also showed in 2007 that in Mexico, households with elderly members or children incurred more CHE (defined as 30\% of non-food expenditure). Surprisingly they showed that household size increased excessive spending on healthcare, but decreased CHE. This is perhaps due to rich families being able to support a large family and thus also have the means to pay for healthcare. They also show that access to social security and higher education of the head of household are linked to decreased CHE (Knaul et al. 2007). In 2009, Gotsadze et al. studied CHE in Georgia and showed that hospitalization, presence of chronic illness and low economic status of the household were all linked to CHE (defined as $40 \%$ of capacity to pay). They also note that the low amount of prepayment (e.g. insurance) is likely increasing CHE (Gotsadze et al. 2009). In 2011, Knaul et al. studied CHE in twelve Latin American and Caribbean countries (Argentina, Bolivia, Brazil, Chile, Colombia, Costa Rica, Dominican Republic, Ecuador, Guatemala, Mexico, Nicaragua, and Peru). Though there was variation across the countries, CHE (defined using 30\% of capacity to pay) was linked to low-income, rural residence, presence of elderly, and lack of insurance (Knaul et al. 2011). Most recently, in 2012, Li et al. studied the impact of universal health insurance on CHE (defined as $40 \%$ of capacity to pay) in China. Their results indicate that hospitalization, presence of an elderly person, chronic illness, and living in a rural or poor area increased the likelihood of incurring CHE. Interestingly, they also showed that health insurance might increase CHE if its breadth of coverage is insufficient since it can increase utilization rates ( $\mathrm{Li}$ et al. 2012). Finally, in 2003, Xu et al. summarized the results of CHE studies in 59 countries. They found that low capacity to pay, lack of insurance, and availability of health services requiring payment were the main causes of CHE (Xu, Evans, et al. 2003). 
Table 2-I Summary of factors increasing risk of CHE

\begin{tabular}{|c|c|c|}
\hline Factor & Article & Country \\
\hline Presence of elderly & $\begin{array}{l}\text { Wyszewianski, } \\
\text { Knaul, Li }\end{array}$ & $\begin{array}{ll}\text { USA, } & \text { Mexico, Latin } \\
\text { America, } & \text { Caribbean, }\end{array}$ \\
\hline $\begin{array}{l}\text { Increased number of } \\
\text { Children }\end{array}$ & Knaul & Mexico \\
\hline Low and high Income status & $\begin{array}{l}\text { Wyszewianski, } \\
\text { Wagstaff, Hjortsberg, } \\
\text { Su, Thuan, Gotsadze, } \\
\text { Knaul, Xu }\end{array}$ & $\begin{array}{l}\text { USA, Vietnam, Zambia, } \\
\text { Burkina Faso, Georgia } \\
\text { Latin America, Caribbean }\end{array}$ \\
\hline Unemployment & Wyszewianski & USA \\
\hline $\begin{array}{l}\text { Increased outpatient } \\
\text { spending }\end{array}$ & Wagstaff & Vietnam \\
\hline Increased inpatient spending & $\begin{array}{l}\text { Wagstaff, Gotsadze, } \\
\text { Li }\end{array}$ & Vietnam, Georgia, China \\
\hline $\begin{array}{l}\text { Household size (large and } \\
\text { small) }\end{array}$ & O’Donnell, Knaul & $\begin{array}{l}\text { Bangladesh, Hong Kong, } \\
\text { India, Sri Lanka, Thailand, } \\
\text { and Vietnam, Mexico }\end{array}$ \\
\hline $\begin{array}{l}\text { Geographic distance } \\
\text { (urban/rural) }\end{array}$ & $\begin{array}{l}\text { O’Donnell, } \\
\text { Hjortsberg, Knaul, Li }\end{array}$ & $\begin{array}{l}\text { Bangladesh, Hong Kong, } \\
\text { India, Sri Lanka, Thailand, } \\
\text { and Vietnam, Zambia, } \\
\text { Latin America, Caribbean, } \\
\text { China }\end{array}$ \\
\hline Lack of safe water & O'Donnell & $\begin{array}{l}\text { Bangladesh, Hong Kong, } \\
\text { India, Sri Lanka, Thailand, } \\
\text { and Vietnam }\end{array}$ \\
\hline Lack of sanitary toilet & O’Donnell & $\begin{array}{l}\text { Bangladesh, Hong Kong, } \\
\text { India, Sri Lanka, Thailand, } \\
\text { and Vietnam }\end{array}$ \\
\hline Presence of chronic illness & $\begin{array}{l}\text { Su, Thuan, Gotsadze, } \\
\mathrm{Li}\end{array}$ & $\begin{array}{l}\text { Burkina Faso, Vietnam, } \\
\text { Georgia, China }\end{array}$ \\
\hline Use of modern medical care & $\mathrm{Su}$ & Burkina Faso \\
\hline Number of illness episodes & $\mathrm{Su}$, Thuan & Burkina Faso, Vietnam \\
\hline Lack of social security & Knaul & Mexico \\
\hline Poor education & Knaul & Mexico \\
\hline $\begin{array}{l}\text { Lack of or presence of } \\
\text { Insurance }\end{array}$ & Knaul, Xu, Li & $\begin{array}{l}\text { Latin America, Caribbean, } \\
\text { China, Study of } 59 \\
\text { countries }\end{array}$ \\
\hline Availability of health services & $\mathrm{Xu}$ & Study of 59 countries \\
\hline
\end{tabular}




\subsubsection{CHE in India}

Now let us examine CHE in the Indian context. There is a large range of development in India, and many different authors in many different states and contexts have studied CHE. In 2005, George studied CHE in Kerala and found that as many as $25 \%$ to $30 \%$ of households in Kerala incurred CHE at the $10 \%$ threshold level. It is the highest rate of CHE of all states in India and the author attributes this to higher utilization and better access to healthcare (George 2005). In 2009, Gupta studied the impact of health expenditure on poverty estimates. Poverty lines are defined for rural and urban areas in each state based on the cost of basic nutritional requirements. They found that inclusion of health expenditure as necessary expenditure increased poverty estimates by $3.6 \%$ and $2.9 \%$ for rural and urban areas respectively. The adjustment to poverty estimates is important as some healthcare is now considered essential in the same way that food is (Gupta 2009). van Doorslaer showed that 78 million additional people in Asia would be considered poor if healthcare spending was deemed essential (van Doorslaer et al. 2006). Also, in 2009, Selvaraj studied the change in Indian healthcare spending from 1986 to 2005. They show that utilization of public health services has diminished in this period and that the average cost of hospitalization is increasing. Their analysis shows that approximately $13 \%$ of households incurred CHE (defined as $10 \%$ of total household expenditure) in India in 2004. Furthermore, they show an increase in the number of people being pushed below the poverty line due to this out-of pocket expenditure. While 26 million people were pushed below the poverty line in 199394, 39 million people were pushed below the poverty line in 2004-05 (Selvaraj \& Karan 2009). In 2010 Pal examined the factors that affect CHE. She found that economic well-being, safe cooking methods, female heads of household, and higher education were linked to reduced CHE, while households size, number of elderly, number of children, and lower social status were linked to increased probability of CHE (defined as 40\% of capacity to pay).(Pal 2010). Mondal et al. studied CHE in West Bengal in 2010. They found that around 25\% of the population incurred CHE (defined as $40 \%$ of capacity to pay), and that the rural population was more vulnerable to CHE than the urban population. They also found that the type of 
treatment (public/private), chronic illness, hospitalization, multiple minor illnesses, and institutional birth deliveries often lead to CHE. One important finding is that medical care for repeated minor illnesses was a greater contributor to CHE than chronic illness or hospitalization (Mondal et al. 2010). In 2010, Ghosh studied CHE (defined as $10 \%$ of total household expenditure) across the whole of India and found that the amount of CHE ranged from about 3.5\% in Assam to over 30\% in Kerala. The author also found an increase in out-of-pocket health expenditure from 1994 to 2005 as well as higher expenditure for more developed states (Ghosh 2010).

\subsection{The elderly}

Our primary interest is the impact of the elderly on health expenditure so here we examine the state of ageing in the world and in India. In many developed countries elderly are defined as being 65 and older, with some countries such as Japan considering even higher ages. Many developing countries, including India, define the elderly as being 60 or older.

\subsubsection{The elderly in the world}

In developed countries, the proportion of elderly in the population is increasing substantially. Good control of infectious diseases has caused a decrease in death rate, and subsequently birthrates, while good control of chronic diseases is causing people to live longer. This ageing of the population has many effects on households, the economy and the healthcare system. Of interest to us is the impact on healthcare spending. As the population ages, they will develop more chronic diseases and these diseases tend to be more expensive to treat. In developed countries the global burden of disease (measured in Disability Adjusted Life Years (DALYs)) due to chronic diseases will increase from 85\% in 2002 to $89 \%$ in 2030 while in developing countries, it will increase from $44 \%$ to $54 \%$ over the same time period (Kinsella \& He 2009, p.58). These changes are also occurring in developing countries, although to a lesser extent.

\subsubsection{The elderly in India}

Over the past 60 years, the number and proportion of elderly in India has increased substantially. The number of elderly has increased from 19.1 million in 
1951 to 77 million in 2001 and is projected to reach 140 million by 2021. This is almost 5 times the population of Canada or half the population of the USA. Not only is the absolute number increasing, but the proportion of elderly in the total population is also increasing. In $1951,5.4 \%$ of the population was above 60 , and by 2001 this had increased to 7.4\%. By 2026, 12.4\% of the population is expected to be above the age of 60 (Jeyalakshmi et al. 2011). As well, by the year 2042, the number of elderly is expected to exceed the number of children (Chatterji et al. 2008). This will mean that there will be fewer people of working age available to support the elderly in the long run. However, in the short run, there will be fewer children for parents to support, so in theory there should be more resources available to support the elderly (Bloom 2011). Nonetheless, a large proportion of the elderly (70\% of women and $30 \%$ of men) are totally dependent on others for economic support (Jeyalakshmi et al. 2011).

The sex ratio is also changing. While there were 1028 females per 1000 males in 1951, in 2001, there were only 972 females per 1000 males. Despite this decrease, female life expectancy is increasing. Male life expectancy was higher until about 1980 (unlike most developed countries) but since then female life expectancy has surpassed it. During the period of 2002-06, life expectancy was 62.6 years for males and 64.2 for females (Jeyalakshmi et al. 2011).

Nonetheless, the elderly population is far from homogeneous. As an example, let us look at literacy rates, which will likely impact earning, and potentially health expenditure. Only $50 \%$ of elderly males and $20 \%$ of elderly females were literate through formal schooling by 2007 (Jeyalakshmi et al. 2011). As well, the 2001 census shows that elderly males are substantially more literate than elderly females. Further it shows that the urban population is more literate than the rural one (Kinsella \& He 2009, p.96). Given these differences in the elderly population, we would expect some difference in health expenditure by gender and by region.

The risks associated with an ageing population only lead to problems given certain conditions. Much of the developed world has an older population than India and will not have to deal with the same consequences. This is primarily due to access to healthcare and to financial protection from its costs. Ageing populations in 
developed countries do have a major impact, though it tends to be on government expenditure, as the government must pay for pensions and healthcare for the elderly. This differs from developing countries where less than $11 \%$ of elderly Indians have a pension (Uppal \& Sarma 2007) and only about 6\% have health insurance as of 2007. Recent government initiatives have increased this percentage closer to 25\% (Reddy et al. 2011). Therefore, the burden of ageing in India will fall largely on households.

Traditionally, the family support system has been relatively strong in India. Extended families would live together and the elderly would live with their adult children. This is gradually changing however, and means that the elderly are increasing isolated. In fact, the number of elderly living alone has increased from $2.4 \%$ to $5 \%$ from $1992-93$ to $2005-06$ and the number of elderly living only with a spouse has almost doubled from $6.6 \%$ to $13.7 \%$ in the same time period (Kumar et al. 2011).

Contrary to many developed countries, many of the elderly still work in developing countries. This is likely due to a lack of social security, and a lack of an ability to save during their lifetime. In fact, about $40 \%$ of the elderly population in India still works (Jeyalakshmi et al. 2011).

\subsubsection{Health Policy for the elderly in India}

There are a number of government ministries that have policies relating to the elderly. The Ministry of Social Justice and Empowerment is the primary government agency that deals with programs and policies for the elderly. The Ministry of Health and Family Welfare also plays an important role, having set up two institutes of ageing and geriatric departments in many medical colleges. The Ministry of Rural Development contributes programs such as a pension scheme that benefits the elderly residing in households below the poverty line. As well, the Ministry of Railways and the Ministry of Civil Aviation have discounts, while the Ministry of Finance has different tax exemptions for the elderly. The department of Pensions and Pensioner Grievances works to provide information on pensions and to adjust the amounts should the need arise. There is also an Inter-Ministerial Committee on Older Persons whose responsibility it is to conceive and coordinate 
an Action Plan on any ageing related issues. This committee was created through the National Policy on Older Persons (NPOP). Put in place in 1999, this is an overarching policy to structure policy and programs for the elderly. Some of its stated aims include providing care, protection and healthcare and to promote awareness regarding the elderly. The highest body created by the NPOP is the National Council for Older Persons. It is comprised of members from government, NGOs, citizens and retired person associations and experts in field such as law, medicine and social security. In 2007, the Maintenance and Welfare of Parents and Senior Citizens Act was enacted to provide the elderly with a secure, dignified and productive life. Finally, article 41 of the constitution requires the government to provide for the elderly, while article 47 requires them to ensure proper nutrition of its citizens (including the elderly) (Jeyalakshmi et al. 2011). Clearly, there are a number of initiatives, programs and policies that address the issue of ageing. However, many of these central government policies are enacted by the individual states, and these states are enacting these policies at different rates. Further, states have their own policies regarding the elderly. These policies are a step in right direction, though they will need to be properly implemented to achieve the desired results.

\subsection{Access to healthcare}

Access to healthcare varies substantially from place to place. There are a number of factors (education, gender, social norms, public vs. private treatment, distance to health facility, etc.) that can affect whether people can access the healthcare they need.

Our two states of interest are at different levels of development and so we expect that access will vary considerably and that the factors that affect access will also vary. For example, the private insurance status of a person might have a considerable effect on their utilization of services in the United States, but this same factor would have very little influence in Canada.

Variations in access will lead to differences in utilization and health expenditure. Below, we examine some factors that can impact access to healthcare in India. 


\subsubsection{Factors influencing access to healthcare in India}

\subsubsection{Health and human infrastructure in Kerala and Bihar}

Compared with the rest of the country, Kerala has relatively good access to healthcare. In fact, in Kerala there are 7060 people served per government doctor whereas the average in India is 13531 people served per government doctor (Central Bureau of Health Intelligence 2010b). Furthermore, there are 1089 people per government hospital bed in Kerala while there are 2012 people per bed in India (Central Bureau of Health Intelligence 2010a).

In contrast with Kerala, access to healthcare in Bihar is relatively poor. There are 23174 people served per government doctor, compared with 13531 in India as a whole (Central Bureau of Health Intelligence 2010b). Similarly, there are 4163 people per hospital bed in Bihar, compared with 2012 people per bed in the whole of the country (Central Bureau of Health Intelligence 2010a).

\subsubsection{Public/private healthcare}

Public healthcare is theoretically free in India, though this is rarely true in practice. Private healthcare is very widespread and its use is increasing, particularly in Kerala (Institute of Applied Manpower Research (India) 2011; Kutty 2000). However, there is a wide range of private services available. There are healthcare professionals with formal training and there are many without (Das 2011; Bhat 1999). Many of the poor are now choosing private services because of their better reputation despite the cost (Roy \& Howard 2007). Private healthcare is a potential contributor to catastrophic health expenditure.

\subsubsection{Gender}

Females tend to have more healthcare needs and will use more healthcare in areas where access is good, though this difference tends to diminish with age (Evashwick et al. 1984; Macintyre et al. 1996). By many indicators, females in Kerala are particular well off, when compared to the rest of the country. The female-male ratio is 1058 females per 1000 males in Kerala and only 921 females per 1000 males in Bihar (Government of Kerala 2001). A rise in this ratio in Kerala is not necessarily due only to the better treatment of women in the state but also to the ageing 
population of Kerala, where one expects to see more elderly females than males due to higher life expectancy of females (Chacko 2003).

The overall literacy rate was 91\% in Kerala and only 48\% in Bihar in 2001 (Government of Kerala 2001). Further, job availability is improving for educated women in Kerala, encouraging women to stay in school longer and a bachelor's degree is often seen as an important step to finding an educated husband (Chacko 2003). Examining the gender difference in more depth, we see that the literacy rates in Kerala were $94 \%$ for males and $88 \%$ for females. On the other hand, only $60 \%$ of males and 34\% of females were literate in Bihar (Government of Kerala 2001). This gap of $6 \%$ between males and females in Kerala is the smallest in the country. A large part of this is due to volunteer women who were part of a campaign to reduce illiteracy in Kerala in 1990 (Chacko 2003). Low literacy amongst women in Bihar is also linked to lower employment, and diminished ability to use health services (Government of Kerala 2001). As such, we expect this better literacy in Kerala to have an impact on utilization of health services and thus catastrophic health expenditure.

\subsubsection{Social Factors (caste, religion)}

Scheduled caste, scheduled tribe, and other backward castes are groups that were traditionally discriminated against. While affirmative action is supposed to minimize this, the groups are still very much at a disadvantage. They are often landless, less literate, and poorer (Kurian 2007). As well, many scheduled tribe households have been displaced for economic development (Kurian 2007). In Bihar, about $25 \%$ of households are SC or ST while in Kerala only $12 \%$ are SC or ST (NSS 2004). This difference is partially due to Bihar being composed almost exclusively of Hindus (e.g. Christians are more prevalent in Kerala and are rarely SC). Bihar thus has a large group of disadvantaged households to cope with. While the majority of the population in Kerala is Hindu (57\%), there are also large populations of Christians (19\%) and Muslims (23\%). The Hindus in Kerala are known for their traditional matriarchal system, and this is thought to be an important reason for the place of women in the state, though this system has been in decline since about 1925 when the British transitioned to a system of individual inheritance as opposed 
to inheritance through the female line (Chacko 2003). The social structures present in each state are indicators of disadvantaged households and while it is not the caste itself that would lead to higher health expenditure, it is the systematic discrimination against these groups that could have an impact on catastrophic health expenditure.

\subsubsection{Urban/Rural differences}

Both urban and rural households can be mired in poverty for different reasons. In urban areas, overcrowding, the spread of infectious diseases, and environmental hazards are of particular concern, while rural households contend with isolation and lack of government services (Mehta \& Shah 2001). Kurian notes an increasing urban-rural divide due partially to economic growth in urban centers. Many of the poor in India live in rural areas working in agriculture or the informal sector. Thus, many of them are not benefiting from the growth seen in urban areas (Kurian 2007). Rural households, who are often poorer than urban ones, often have fewer health facilities nearby, and cannot use health services as easily.

\subsubsection{Migration}

Another issue facing households in Bihar is the migration of male workers outside of the state. Many migrate to large cities around India where they often find work in construction or as rickshaw pullers or security guards. This places the women in a difficult situation who must now handle the tasks that were previously split between men and women (Datta \& Rustagi 2012). This increase in tasks has also had an impact on upper caste women, who used to stay home, but now have to go out to work. A further consequence of male migration outside of Bihar is the increased difficulty that women have in getting credit (Datta \& Rustagi 2012). For the lower castes in particular, this can mean incurring debt or having to forgo important purchases such as for healthcare. In Kerala, there is also significant migration for work though this is often outside of India and to Gulf countries in particular. Large incomes in these countries are being sent back as remittances and in the 90 s, amounted to $24 \%$ of state income (Kannan \& Hari 2002). This increased household incomes for many poor households in Kerala (Prakash 1998). Migration 
can thus have a positive impact by allowing households to pay for healthcare like in Kerala or a negative impact, where households in Bihar might have to avoid treatment or incur debt.

\subsection{Other access related impacts}

While catastrophic health expenditure is a serious consequence, its measurement does not fully cover the concept for which it was designed. An ideal measurement of CHE would be one that followed a family's expenditure over a few years in order to examine the short and long-term economic consequences of illness (Chuma \& Maina 2012). The measurement of CHE defined as a percentage of health expenditure over total households expenditure is only an approximate measure. It is estimated that the chosen threshold is one at which households would have to forgo other important expenditures. With a longitudinal study, this could be addressed directly. It is for this reason that we have added secondary dependent variables (avoidance of treatment, loss of income, and alternate source of funding) to our analysis. For example, some households are able to pay for healthcare through their income and savings but many households have to borrow money or sell valuable assets to cover their costs (Kabir et al. 2000; Russell 1996; R. Sauerborn et al. 1996). Some households also reduce their consumption to lower their costs (Tibaijuka 1997). Increasing debt to pay for healthcare can have serious consequences as the burden of payment can be passed from one generation to the next (Corbett 1989). These secondary dependent variables allow us to gain a better understanding of the economic consequences of illness, which is the intended goal of a measure of CHE.

\subsubsection{Avoidance of treatment}

The literature on avoidance of treatment is limited as it is difficult to measure. Much of the data available is only on people who went to a health professional for care. Some of those would avoid treatment on learning the cost, but there are also many who would never reach a healthcare professional. The first problem is identifying a healthcare need. Many of the most vulnerable households (the poor and uneducated) have poor health literacy. If these households don't report a healthcare need, it becomes impossible to determine whether they avoided required 
treatment. One survey asked households about symptoms and then extrapolated unmet healthcare needs (J.-F. Levesque et al. 2013). Many studies simply report the number of people who avoided treatment from amongst those who reported some illness. In her article on the medical poverty trap, Whitehead outlines a number of studies such as in Jamaica and India that did just that (Whitehead et al. 2001). She further discusses a report on poverty in Kyrgyzstan that indicates that many of the poor and those living in rural areas cannot afford treatment due to the cost and so forgo necessary treatment (World Bank 1999). This avoidance is also seen in rural China (Wu 1997). Avoidance of treatment is difficult to measure but it is not the only economic consequence of falling sick.

\subsubsection{Loss of income}

Loss of income is another potential economic consequence of falling ill or of having a family member fall sick. Should an economically active person of a household develop a chronic disease, this can have long-term consequences for the household and can change the dependency ratio of the household (Corbett 1989). McIntyre summarizes many articles discussing indirect costs of healthcare such as loss of income and the source of funding used (savings, borrowing, etc.). She notes the difficulty in comparing studies due to different types of indirect costs. There can be loss of income from the person who falls sick, or loss of income of the family member who helps with the caregiving. As well, the female contribution of a household's activities is often unaccounted for. A study in Burkina Faso showed that women had less leisure time during certain seasons (R Sauerborn et al. 1996) and these contributions to the household are often not considered. Further, there can be long term loss of income due to years of life lost (McIntyre et al. 2006). A study in Bangladesh showed that loss of income due to the father being sick was linked to poorer nutritional status for the children (Pryer et al. 2004). Another study in Bangladesh showed that loss of income was often substantially larger than direct healthcare costs (Pryer 1989). 


\subsubsection{Source of funding for treatment}

Many households are not able to pay for healthcare using their income and savings. They often have to borrow with high interest, ask family and friends for contributions or sell valuable assets to cover the costs. A study of Gujarat and Rajasthan showed that due to poor government health services, households were forced to use private services and fund these by selling assets and borrowing (Dogra 1988). In Vietnam, 36\% of poor households had to borrow to fund their treatment, while only $4.5 \%$ of the rich had to borrow. Further, over $60 \%$ of the poor were in debt, and $30 \%$ of all households identified health costs as the principal reason for being in debt (Ensor \& San 1996). In Cambodia, about 20\% of households had to borrow and about 10\% reduced consumption of food, while in Uganda, households had to borrow or sell assets to pay for treatment (Whitehead et al. 2001). A study of four countries in Africa (Kenya, Guinea, Burundi and Nigeria) found that many households were able to pay for healthcare that was expensive relative to their income through contributions from friends and family. The authors note that this is a testament to the strength of the community but that it is particularly devastating for the households that fall through this social safety net (McPake et al. 1993). In Bangladesh, around $40 \%$ of households had to borrow money for maternity care (Nahar \& Costello 1998). A study in Ghana showed that rural households borrowed more than urban ones to fund treatments though overall coping mechanisms (sale of assets, borrowing) were similar (Mock et al. 2003).

CHE, loss of income, avoidance of treatment, and using other sources of funding such as selling assets or borrowing can all lead households into poverty (Whitehead et al. 2001) and escaping this poverty trap can be very difficult (Kabir et al. 2000). Despite strong community bonds in many developing countries, social security is of benefit for all households in order to prevent poverty. A number of studies show the importance of our secondary dependent variables. Keeping the impact of these variables in mind will inform us in our analysis of CHE and its effects on households in Kerala and Bihar. 


\section{Conceptual framework}

Access to healthcare is a complex and multifaceted concept. Factors influencing access often include availability of services, use of health services, and user characteristics (Penchansky \& Thomas 1981; Levesque, et al. 2013b).Below is a framework by Lévesque et al. (2013) combining and restructuring many of the factors into a pathway of access with contributions from supply side factors (above) and demand side factors (below).

\section{Figure 3-1 Conceptual Framework}

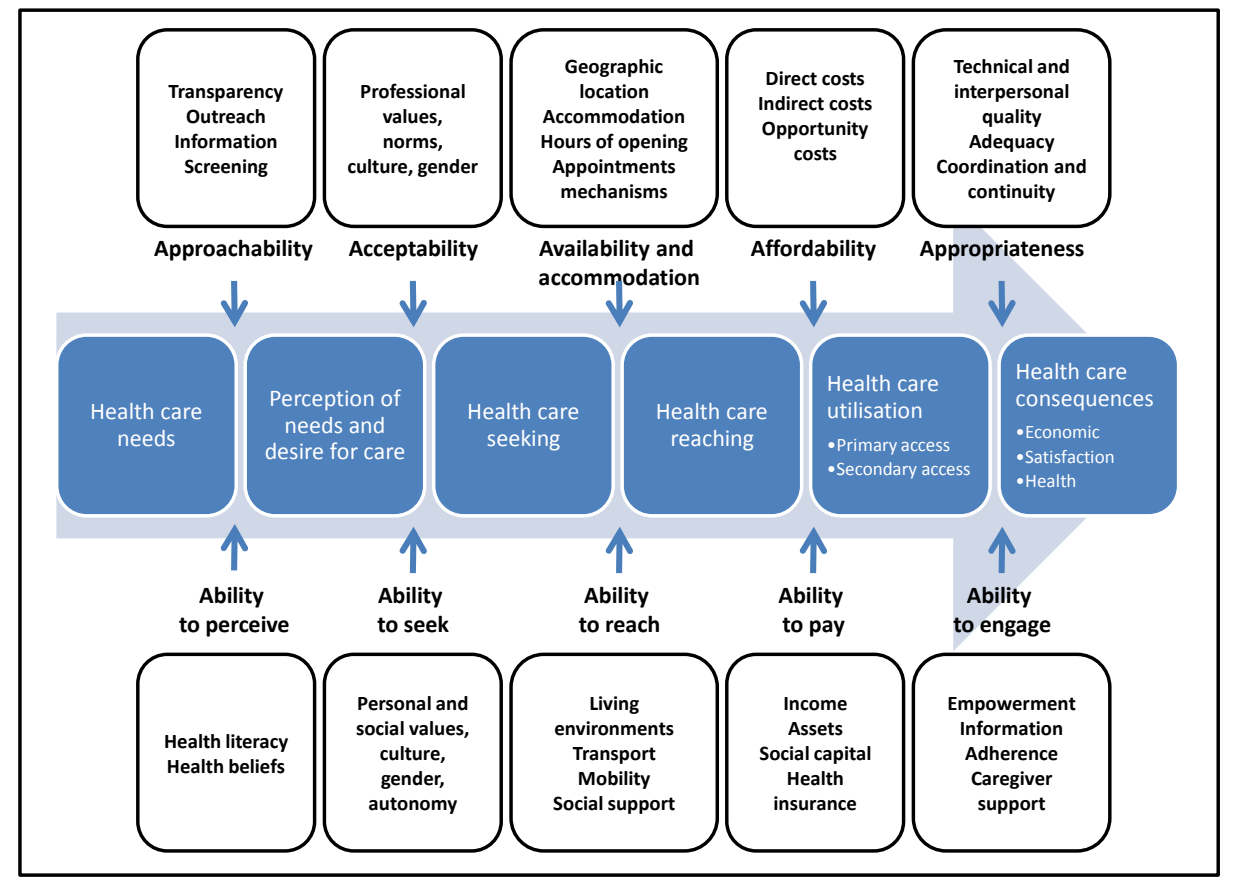

This conceptual framework involves a pathway of access to healthcare starting from healthcare needs and continuing to healthcare consequences. This access framework is at the interface between supply and demand side factors. There are five dimensions of accessibility of services, and five abilities of persons on the demand side, which can both contribute to influencing access. The five dimensions of accessibility of services are accessibility (information, screening, etc.), acceptability (culture, gender, etc.), availability and accommodation (opening hours, 
geographic location, etc.), affordability (direct, indirect and opportunity costs), and appropriateness (technical quality, coordination, etc.). The five abilities are the ability to perceive (health literacy), the ability to seek (personal values, autonomy, etc.), the ability to reach (transport, mobility, etc.), the ability to pay (income, insurance, etc.), and the ability to engage (adherence, health information, etc.). These are factors on the supply and demand side of access that contribute to people's progression along the pathway to access and act at different areas along the pathway such as the perception of healthcare needs, the seeking of healthcare, and the utilization of healthcare services (Levesque, et al. 2013b). This framework illustrates that access to care has many dimensions. Health expenditure is dependent on access while access can be impacted by factors such as gender and cultural norms and financial availability. This framework enables us to keep a larger picture in mind during the discussion and analysis.

Our data set allow us to measure some but not all aspects outlined in this framework. First, the number of elderly will influence the healthcare needs of the household, as they tend to have more diseases. Other factors that we are able to measure and that influence the perception of need and decision to seek treatment are level of education, caste, and religion. Factors that can influence the decision to receive treatment as well as the quality of the treatment are economic status, the presence of health insurance, the location or physical access to health centers, and the type of treatment (public/private) sought. The main consequence of healthcare needs in our analysis is healthcare expenditure. However, there can also be a loss of income or different sources of funding such as the sale of household assets, which can have long-term effects on a household's welfare. Lastly, some households may choose to avoid treatment based on cost or perceived severity of the disease and this could lead to a worsening health status. Our data set will thus allow us to examine some factors affecting access, but the conceptual framework provides a larger view beyond that provided by our data set alone.

The principle objective of this research is to examine the effects of the presence of elderly people on household health expenditure and we will use this framework to examine our hypotheses outlined here: 
1. Households with elderly will be more likely to incur CHE

2. Households with elderly will have more chronic disease that will increase their likelihood of incurring CHE

3. Households with elderly will be particularly vulnerable to the consequences of consulting private sources of care given the high cost of treating chronic disease in this sector.

We expect that variation in the three factors will lead to higher CHE in Kerala than Bihar. 


\section{Methodology}

Our objective was to assess the economic impact of elderly people on households in Kerala and Bihar. We examined catastrophic health expenditure as well as avoidance of treatment, loss of income and alternative sources of funding. This section describes the methods employed to do this. The topics covered in this section are a study trip to India, the source of data, the definition of our variables, and the statistical analyses.

\subsection{Study Trip to India}

With the purpose of better understanding the Indian context, a study trip to India was carried out from June to September 2012.

Once the selection of the two states (Bihar and Kerala) had been carried out, trips to each of these states were undertaken. In July 2012, a trip to the Centre for Development Studies Thiruvananthapuram in Kerala was carried out. Here the research topic was discussed with staff and students and previous theses on CHE and access to health care only available in their library were examined. In September 2012, a trip to the Asian Development Research Institute in Bihar was carried out. A meeting with researchers studying development economics was carried out to understand the particular context and challenges related to Bihar in light of better interpreting the data.

The majority of the data analysis was carried at the Institute of Development Studies Kolkata, in West Bengal, where staff was experienced in dealing with large NSSO databases. Preliminary results of analysis were presented to staff and students at IDSK in order to receive comments and suggestions.

The exposure to the Indian context was of vital importance in understanding the data. As an example, it was important to understand that the variety of private healthcare providers could vary from poorly equipped alternative healthcare providers to extremely well equipped and modern facilities and that this would likely have an impact on health spending. It was this type of comprehension that was gained from the trip to India, and that was useful in understanding and proposing hypotheses for some of the results of our analysis. 


\subsection{Source of data}

\subsubsection{The National Sample Survey on Morbidity, Health care and the Aged}

The data for our study is from the National Sample Survey Organization's (NSSO) survey on morbidity, health care and the condition of the aged from January to June $2004\left(60^{\text {th }}\right.$ round). This particular survey is carried out every ten years by the NSSO and so the data used is the most recently available. The NSSO is a national level government organization set up in 1950 to carry out surveys to be used in socio-economic planning and policymaking. This survey covers utilization and costs of healthcare as well as the condition of the elderly. It includes a detailed breakdown of the costs associated with healthcare and so is well suited to our needs.

\subsubsection{Sampling design of survey}

The survey used a multistage stratified sampling design. The first stage units (FSUs) were villages for rural areas and NSS urban frame blocks for urban areas. The ultimate stage units (USUs) were households. The list of villages and urban frame blocks is from the 1991 census.

Stratification for FSUs was carried out separately for urban and rural areas. In rural areas, each district was treated as a separate stratum. However, special strata were created for two situations. If there were more than 50 villages of less than 50 people in a state, a stratum was created. Also, if there were more than 4 villages of more than 15000 people, another stratum as created.

\section{Table 4-I Rural stratification}

\begin{tabular}{|c|c|}
\hline Stratum 1 & Villages between 0 and 50 people \\
\hline Stratum 2 & Villages of more than 15000 people \\
\hline Strata $4,5,6$, etc. & Each district was considered a separate stratum \\
\hline \multicolumn{2}{|c|}{$\begin{array}{l}\text { In urban areas, each town of more than 1,000,000 inhabitants had its own stratum, } \\
\text { while the smaller towns were assigned strata according to the table below. }\end{array}$} \\
\hline Stratum 1 & All towns with population less than 50,000 \\
\hline Stratum 2 & All towns with population between 50,000 and 199,999 \\
\hline
\end{tabular}




\begin{tabular}{ll}
\hline Stratum 3 All towns with population between 200,000 and \\
999,999
\end{tabular}

Strata 4, 5, 6, etc. Each town with a population of 1,000,000 or more

FSUs were then selected with probability proportional to size with replacement (PPSWR) with the exception of stratum 1 in the rural sector and all strata in the urban sector, which were sampled using simple random sampling without replacement (SRSWOR). Villages or urban frame blocks that were too large were further subdivided and selected at random.

Stratification for second stage units was carried out as per the table below, ensuring adequate representation of households with children, elderly, and people that are ill.

Table 4-III Second level stratification (Urban and Rural)

\begin{tabular}{ll}
\hline Stratum 1 & Households with at least one member hospitalized in the last \\
& year
\end{tabular}

Stratum $2 \quad$ Households with at least one child below the age of 5

Stratum 3 Households with at least one member 60 years or older

Stratum 4 Remaining households

Four households were selected from the first stratum and 2 households from each of the other strata for a total of 10 households who were then asked to answer questions from the household survey (National Sample Survey Organisation 2005).

\subsubsection{Description of survey}

Schedule 25.0 of the $60^{\text {th }}$ round of NSSO survey covers morbidity and healthcare. It is divided into 14 blocks as per the table below.

Table 4-IV Division of Schedule 25.0 of 60th round of NSSO Survey

\begin{tabular}{ll}
\hline Block 0 & Descriptive identification of sample household \\
Block 1 & Identification of sample household \\
Block 2 & Particulars of field operation \\
Block 3 & Household characteristics \\
Block 4 & Demographic particulars of household members \\
Block 5 & Particulars of household members who died during the last 365 \\
\hline
\end{tabular}


days

$\begin{array}{ll}\text { Block } 6 & \text { Particulars of economic independence and ailments on the date } \\ \text { of survey for persons aged } 60 \text { years and above } & \text { Particulars of medical treatment received as inpatient of a } \\ \text { hlock 7 } & \text { Eospital during the last } 365 \text { days } \\ \text { Block } 8 & \text { of henses incurred for treatment of members treated as inpatient } \\ \text { Block 9 } & \text { Particulars of spells of ailment of household members during the } \\ \text { Block 10 } & \text { Expenses incurred during the last } 15 \text { days for treatment of } \\ & \text { members (not as inpatient of hospital) and source of finance } \\ \text { Block 11 } & \text { Particulars of immunisation of children (0 - } 4 \text { yrs.), pre-natal } \\ & \text { care and post-natal care for ever married women of age below } \\ & 50 \text { years during the last } 365 \text { days }\end{array}$

Block 12 Remarks by investigator

Block 13 Comments by supervisory officer

The blocks of interest to us were block 1 (covering sector, sub-round, state and others), block 3 (caste, religion, monthly expenditure, and others), block 4 (covering individual level characteristics such as age and presence of insurance), block 7 (details of inpatient services), block 8, (details of costs of inpatients services, loss of income and sources of funding), block 9 (details of outpatient services and on avoidance of treatment) and block 10 (details of costs of outpatients services, loss of income and sources of funding). These blocks gave us sufficient information to determine household expenditure, household health expenditure, avoidance of treatment, loss of income, alternate sources of funding, as well as to define our independent variables.

\subsection{Defining our variables}

\subsubsection{Primary dependent variable (Catastrophic Health Expenditure)}

For our purposes, a household is said to have incurred catastrophic health expenditure if they have spent more than $10 \%$ of their household consumption 
expenditure on healthcare. There are two parts of this variable to define: the numerator (health expenditure) and the denominator (household consumption expenditure).

\subsubsection{Numerator (health expenditure)}

The numerator includes 3 types of health expenditure: inpatient expenditure, outpatient expenditure and other expenditure.

Inpatient expenditure includes all expenditure related to hospitalization, including diagnostic tests, bed charges, blood and oxygen charges, transport costs, and others. We have subtracted any reimbursements a household may have received (such as through insurance) in order to include only out-of-pocket inpatient expenditure.

Outpatient expenditure includes costs related to treatment outside of a hospital and includes the same as other costs as for inpatient expenditure (diagnostic tests, transports costs, etc.). Again, we have subtracted and reimbursements received in order to include only out-of-pocket outpatient costs.

Other expenditure includes any treatment the household has paid for in an informal setting.

\section{Combining inpatient and outpatient spending}

In the NSS survey, households are asked for their inpatient expenditure over the last 365 days and for their outpatient and other expenditure over the last 15 days. This was thus problematic to combine. The concept of catastrophic health expenditure is one of catastrophe due to large health spending. As such, you cannot separate inpatient and outpatient expenditure. You cannot ask if there was catastrophic health expenditure due only to inpatient spending, as it is the final catastrophic outcome from all health expenditure that is of interest.

There were two options for combining inpatient and outpatient expenditure with different recall periods. First we considered running a regression to predict how much households spend on outpatient expenditure in order to impute a value to different household based on their income level, urban/rural status, state and other important variables. However, so many households in our sample are below the poverty line, particularly in Bihar, that imputing any amount of outpatient 
expenditure would likely lead to CHE. When we did this, our amounts of CHE became inflated (26\% in Bihar, and 63\% in Kerala compared with 16\% in Bihar and $39 \%$ in Kerala using our method). Many households likely avoid treatment altogether, and so it seemed unrealistic to impute these values of outpatient expenditure to all households. Furthermore, the use of a regression to predict and impute values of spending was not seen in the literature reviewed. The second option was simply to multiply the 15 day outpatient expenditure by $365 / 15$ to make the reference period one year in order to be able to add it to inpatient expenditure. This is the option we chose. This means that for households that had health expenditure in the last 15 days we are assuming they had that same expenditure every two weeks for the whole year. Similarly, for households that had no health expenditure in the last 15 days, we are assuming they had no outpatient health expenditure for the whole year. While this is unlikely, it was seen as better than the regression method, which imputed values to all households and so inflated our CHE numbers. Our method likely indicated CHE in households where there was none but also likely indicated no CHE where there was some. We were thus able to combine inpatient and outpatient expenditure to have yearly total household expenditure.

To summarize, inpatient and outpatient expenditure had to be combined in order to evaluate the concept of CHE, as the concept we are interested in is one of catastrophe on a household due to any health spending. Given the need to combine spending, the question becomes how best to do this. Since inpatient and outpatient spending had different reference periods these needed to be adjusted to match the reference period of the denominator of CHE (household expenditure). We could use either a regression to predict spending based on certain household characteristics or simply multiply household expenditure by $(365 / 15)$ in order to change the reference period to one year. We did not use the regression method since it had not been used in the literature and also because the amount of CHE that was predicted using the regression was much higher than that observed in the literature. As well it was thought that while our method could have an impact on the prevalence of CHE that we calculated, the effect on factors that could influence CHE would be minimal. While it would have been interesting to pursue the regression method, as, in theory, 
it would predict a household's health spending more precisely than multiplying by (365/15), it was thought that it was beyond the scope of this master's project to develop and justify this regression method not seen in the literature on CHE. Given these difficulties associated with the use of the regression method, the simpler method of multiplying by (365/15) was preferred.

\subsubsection{Denominator (household expenditure)}

The denominator includes all household expenditure over the last 30 days. This was then multiplied by 365/30 to make the reference period one year.

We were then able to put total yearly households health expenditure over total yearly household expenditure and if this was more than $10 \%$, we considered it to be catastrophic.

\subsubsection{Independent variables}

\subsubsection{Religion and Caste}

Religion and caste were reclassified as one religio-caste variable with the four following categories: Scheduled Tribe, Scheduled Caste, Muslim, and Others. This variable represents a type of social vulnerability. ST, SC and Muslims all face a certain amount of discrimination; therefore we combined religion and caste to form this one variable. There is little overlap between the two categories. However, when a Christian was classified as ST, for example, we chose the most socially vulnerable category for our new variable (ST in this case). Our data included 4 households that were both Muslim and SC or Muslim and ST. As previously, these households were put into the most socially vulnerable category. ST was given precedence over Muslim, while Muslim was given precedence over SC. One household had no information about religion or caste so that household was excluded from analyses. This variable will permit us to examine the impact of social discrimination on CHE.

\subsubsection{Household education}

A common problem with analyzing household survey data relates to the level of education. The level of education is often collected at the individual level as part of the household roster, as it was with our NSS data. The question then becomes: 
whose education matters in terms of household level outcomes? A very common approach is to use the education of the head of household as the education level of the household. Jolliffe considers multiple methods for determining a household level of education (Jolliffe 2002). He considers using the education of the head of household or the highest level of education of anyone in the household. He proposes that we consider two households, the first in which no one has any formal education and the second in which everyone except the head of household has a high school level of education. Using the head of household method, both of these households would have the same level of household education. Another method often used is the average education level of a household (Jolliffe 2002). We have not used this method because of the difficulty of creating an average using the categorical variable at our disposal. Using the most educated person in the household has been done to predict household income and has been shown to be more accurate than the head of household method (Jolliffe 2002). We chose to use the education level of the most educated person in the household as the most educated person will often make managerial decision (Jolliffe 2002), which, in our case, could mean choosing what type of healthcare to use, or whether or not to use said healthcare. Thus in our construction of this variable each household was given an education level equivalent to the education level of the most educated household member.

\subsubsection{Source of treatment (Public - Private)}

The source of treatment was divided into two types of treatment, inpatient and outpatient.

For inpatient services, we classified all visits to a hospital by an individual as either public or private. Then households were classified as either public or private based on use by the individuals in the household. Almost every household used either public or private treatment exclusively though $4 \%$ did use both private and public providers for their inpatient treatments. We have classified households with public and private visits according whether they used any private treatment or only public treatment. Households that used both were thus classified as private users. This was done since private care is often more expensive and it is the impact of the cost that interest us. 
For outpatient treatment, we again classified individuals as using private or public services. Then households were classified as using any private treatment, using only public treatment, or not receiving any treatment at all. Similar to the inpatient case, we examined the average cost of public treatment and of private treatment. At the household level, public treatment costs an average 1752 rupees, but private treatment costs an average of 2749 rupees.

\section{Combining source of treatment for inpatient and outpatient services}

We have examined inpatient and outpatient source of treatment separately. Could they not be combined into one variable indicating whether a household prefers private or public services? We have decided to examine source of funding for inpatient and outpatient separately because of conceptual differences. Inpatient spending tends to be much larger than outpatient spending since diseases requiring inpatient care are generally more severe. As an example, a disease requiring inpatient treatment might cost 1000 INR in a private hospital and only cost 500 INR in a public hospital. On the other hand, a disease requiring only outpatient treatment might cost 100 INR in a private clinic and only 50 INR in a public clinic. While private treatment is double in both cases, it is clear that some households might be able to afford private treatment for outpatient treatment while private treatment for inpatient diseases could be too expensive. As such households might use both private and public treatment depending on the disease. This is why classifying a household as either a user of public or private treatment exclusively is problematic. Since our main outcome of interest is catastrophic health expenditure, it is conceivable that using private inpatient treatment could be linked to CHE while using private outpatient treatment might not. In our data, over $90 \%$ of households used either private or public treatment exclusively for outpatient care, and over $95 \%$ of households used either private or public treatment exclusively for inpatient care so there is not much concern over households using both public and private services in the analysis. The second reason for the separation of inpatient and outpatient services is that outpatient services can be a significant contributor to CHE on their own (George 2005; Li et al. 2012; Mondal et al. 2010). These practical 
considerations of how households spend their income have lead us to examine inpatient and outpatient sources of funding separately in our analysis.

\subsubsection{Income status}

We have classified all households according to their level of expenditure. Expenditure is often used as a proxy for income (Hjortsberg 2003; Wagstaff \& Doorslaer 2003). Households were either classified as poor (below the poverty line), middle income (between the poverty line and three times the poverty line) or rich (expenditure greater than three times the poverty line). The definition of the poverty line was key to this classification. We used the official poverty lines from the Indian government in the years 1999 and 2005 (Bandyopadhyay 2010). We then adjusted these to find the poverty line in 2004. Given the different costs of living in Bihar and Kerala and the differences in rural and urban areas, we used 4 different poverty lines (urban Bihar, rural Bihar, urban Kerala, rural Kerala). Poverty lines are given in terms of an amount per capita per month. These were thus adjusted for each household based on the household size and were then put over one year. Each household was then compared to the poverty line for their state, sector (urban/rural) and household size. Following that households were classified into our three expenditure categories.

\subsubsection{Insurance}

Health insurance is an important variable to us in the conceptualization of our problem. Given that the ageing population is leading to an increase in the number of chronic diseases, this is only problematic if there is limited health insurance or lack of access. Otherwise, the increase in chronic disease would not be an issue of concern. We would have liked to examine the impact of health insurance on catastrophic health expenditure. However the coverage of insurance is extremely low in India. In our data set, only 3\% of households have any form of health insurance. Given the way our analysis was stratified by state and age structure of households, this small amount of insurance made it difficult to include in the regression analysis and so it was excluded. 


\subsubsection{Children under 5}

The number of children under 5 was included as a potential predictor of CHE since they tend to be more vulnerable and can have more healthcare needs.

\subsubsection{Elderly}

Households were defined as having no elderly or one or more elderly. The presence of elderly was only used in the bivariate analysis. It was not required in our multivariate analysis because our regressions were stratified by presence of elderly.

\subsubsection{Household size}

Household size was included as a predictor variable because large household size can lead to increased healthcare needs. On the other hand, it could also increase household income.

\subsubsection{Chronic disease}

Chronic disease is an important predictor variable given that the prevalence of chronic diseases is increasing in India (Reddy et al. 2005).

For the purpose of the bivariate analyses of our secondary dependent variables, we classified households as having no disease, only acute disease or any chronic diseases. Households that had both acute and chronic diseases were classified under any chronic disease since it is the chronic diseases that tend to be more expensive and are more likely to lead to CHE.

For the purpose of our multivariate analysis, we used the number of hospitalizations due to chronic disease as our variable. One would expect CHE to increase as hospitalization due to chronic disease increased.

\subsubsection{Sub-round}

The survey was carried out in two sub-rounds. The first was from January to the end of March and the second was from April to the end of June. Health expenditure could theoretically differ in the sub-rounds due to differences in weather (e.g.: monsoon could lead to more malaria) and to differences in working 
habits (during the harvest period, people are not always able to seek out healthcare.)

\subsubsection{Secondary dependent variables}

\subsubsection{Loss of income}

We have defined loss of income due to illness as a combination of loss of income due to use of outpatient healthcare and loss of income due to use of inpatient healthcare. The former is taken over a reference period of 15 days while the latter is taken over 365 days. This loss of income is self-reported by individuals. Loss of income is given for each individual disease event (e.g. hospitalization, visit to doctor, etc.). These were summed for each household and then imported to the household level data set. However, there were missing data points for households that did not have any disease events. If we try to sum a household with loss of income due to inpatient care with a household that has a missing data point for loss due to outpatient care, STATA will create a missing data point for our new variable. Therefore, we changed some missing values to zero for those households that had losses from either outpatient or inpatient care. Our final variable consists of the sum of income lost from inpatient and outpatient expenditure for each household.

\subsubsection{Avoidance of treatment}

Avoidance of treatment is a variable that captures households who should have received treatment but did not. There are two possible values to the variables: having any avoidance at all, or having none. We have defined it at the household level and so it includes all households in which there was an individual that avoided treatment at least once.

\subsubsection{Source of funding}

Source of funding is a variable designed to identify households that might find it difficult to pay for healthcare and would have incurred catastrophic health expenditure if not for some other source of funding. The questionnaire categorizes the sources of funding into 4 categories: income and savings, borrowing, contributions from friends and relatives, and other. Income and savings is all 
spending that comes directly from household income or previous savings. Borrowing includes all spending from a moneylender or other formal institution. Contributions from friends and relatives is similar to borrowing but only includes those contributions that came from a more informal system (friends and family). Other includes any funding that comes from other sources and often includes the sale of ornaments, draught animals and other physical assets. Each household's spending was categorized into these four categories in order to obtain the percentage of funds from each category. Income and savings was considered to be a safe source of funding, while the other three could have long-term impacts on households.

This category is of interest because households that had to borrow or sell assets might not suffer any immediate catastrophe, but they might have longer-term consequences. A household might sell borrow money to treat an elderly person, but in the process of paying of their loan with interest, they could have to forgo sending a child to school. Similarly, if a household had to sell livestock to pay for healthcare, they might no longer have the means to bring in sufficient income for the household. Households that borrowed from friends and family are more likely to have greater flexibility in paying the loan back. This social support system is a benefit of the larger extended families in India and it can compensate partially for the lack of governmental support. However, it does not cover everybody and if a household has to go into debt to pay for healthcare, the longer term consequences can be just as problematic as incurring catastrophic health expenditure. While the consequences of borrowing or selling assets are not clear-cut, it does become more likely that these households will face similar financial consequences eventually.

\subsection{Statistical analyses}

\subsubsection{Descriptive statistics}

Descriptive statistics were carried out at in individual level and a household level for both Kerala and Bihar to get a sense of the distribution of variables. 


\subsubsection{Bivariate analyses}

Bivariate analyses for association between variables were done for all of our previously mentioned variables. These analyses were done 4 times (for elderly and non-elderly households in Kerala and Bihar). Variables considered significant ( $p$ $\leq 0.20$ ) were kept for multivariate analysis. All of our variables were significant at the $20 \%$ level in at least one of the four scenarios, except for insurance (see appendix II). Pearson's $\chi^{2}$ test was used to test differences in proportions.

\subsubsection{Logistic regression}

In order to determine what variables had a direct impact on CHE, we ran four logistics regressions. The regressions were for non-elderly households in Bihar, elderly households in Bihar, non-elderly households in Kerala and elderly households in Kerala. The dependent variable was CHE with a threshold of $10 \%$ of total household expenditure. We added our independent variables to the model by block. We categorized our variables into three blocks. The first block was household demographic characteristics and included the number of children under 5, household size, dummy variables for caste, education, expenditure level, and sector (urban/rural). The second block was disease and treatment related variables and included the number of chronic disease events (hospitalizations, visits to the doctor) and the source of treatment for inpatient and outpatient services (public or private). The third and last block included only the variable sub-round. Blocks were added one at a time, keeping only significant variables in between rounds. Expenditure level (poor/middle income/rich) was added to our final model because of its conceptual importance in determining CHE, despite its lack of significance. As well, variables that were significant in one model were added to all other models to ensure comparability of the models.

\subsubsection{Analysis of secondary dependent variables}

\subsubsection{Loss of income}

The mean loss of income for each category of interest was calculated. These were then tested using a Wald test. For example, we calculated average loss of income for urban households and average loss of income for rural households to see 
if there was a significant difference. See table 4-V for example. This was carried out for each of our independent variables.

Table 4-V Impact of Sector on Loss of Income

\begin{tabular}{llllll}
\hline & & \multicolumn{2}{l}{ Bihar (95\% CI) } & \multicolumn{2}{l}{ Kerala (95\% CI) } \\
\hline \multirow{3}{*}{ Sector } & \multirow{4}{*}{ Urban } & No Elderly & Elderly & No Elderly & Elderly \\
& $473(262-$ & $448(144-$ & $681(184-$ & $272(113-$ \\
& & $684)$ & $753)$ & $1177)$ & $431)$ \\
& Rural & $792(-133-$ & $560(368-$ & $462(371-$ & $408(315-$ \\
& & $1717)$ & $752)$ & $554)$ & $500)$ \\
& $\mathrm{p}>\mathrm{z}$ & $\mathrm{p}=0.5094$ & $\mathrm{p}=0.5427$ & $\mathrm{p}=0.3971$ & $\mathrm{p}=0.1475$ \\
\hline
\end{tabular}

\subsubsection{Avoidance of treatment}

Having defined all households as having some avoidance or none, we then calculated the proportion of households that avoided treatment for each category of our independent variables and the difference were tested using a Wald test. See table 4-VI for example:

Table 4-VI Impact of Sector on Avoidance of Treatment

\begin{tabular}{|c|c|c|c|c|c|}
\hline & & \multicolumn{2}{|l|}{ Bihar } & \multicolumn{2}{|l|}{ Kerala } \\
\hline & & No Elderly & Elderly & No Elderly & Elderly \\
\hline Sector & Urban & $\begin{array}{l}11.49 \% \\
(5.8-21.5)\end{array}$ & $\begin{array}{l}22.83 \% \\
(10.56- \\
42.57)\end{array}$ & $\begin{array}{l}18.41 \% \\
(12.57- \\
26.16)\end{array}$ & $\begin{array}{l}9.26 \% \\
(6.22- \\
13.57)\end{array}$ \\
\hline & Rural & $\begin{array}{l}18.1 \% \\
(13.47- \\
23.9)\end{array}$ & $\begin{array}{l}20.81 \% \\
(15.15- \\
27.9)\end{array}$ & $\begin{array}{l}17.71 \% \\
(14.29- \\
21.73)\end{array}$ & $\begin{array}{l}17.25 \% \\
(14.41- \\
20.51)\end{array}$ \\
\hline
\end{tabular}

\subsubsection{Source of funding}

To analyze this variable, we showed what percentage of funding came from each of the 4 categories. Since we had the amount spent from each category at the household level, we took the amount for each of the 4 categories and divided it by the total amount. This gave us the percentage spent from each category at a household level. We then took the average of these percentages in the analysis of our dependent variables. For example, we could then calculate the average percentage spent from income and savings for urban and rural households separately. This could then tell us if certain categories of our independent variables 
had greater expenditure from sources that could be considered risky (such as borrowing). See 4-VII below for example:

Table 4-VII Impact of Sector on Source of Funding

\begin{tabular}{|c|c|c|c|c|}
\hline & & $\begin{array}{l}\text { Variable sub- } \\
\text { category }\end{array}$ & $\begin{array}{l}\text { Bihar }(95 \% \\
\text { CI) }\end{array}$ & $\begin{array}{l}\text { Kerala (95\% } \\
\text { CI) }\end{array}$ \\
\hline \multirow[t]{8}{*}{ Sector } & Urban & Income and savings & $69 \%(62-75)$ & $61 \%(56-66)$ \\
\hline & & Borrowing & $21 \%(15-27)$ & $26 \%(22-30)$ \\
\hline & & Friends and relatives & $7 \%(5-10)$ & $9 \%(6-11)$ \\
\hline & & Other (selling assets) & $3 \%(1-5)$ & $5 \%(2-7)$ \\
\hline & Rural & Income and savings & $57 \%(54-60)$ & $56 \%(53-59)$ \\
\hline & & Borrowing & $30 \%(28-33)$ & $30 \%(27-33)$ \\
\hline & & Friends and relatives & $9 \%(7-10)$ & $10 \%(8-12)$ \\
\hline & & Other (selling assets) & $4 \%(3-5)$ & $3 \%(2-4)$ \\
\hline
\end{tabular}

For example, in this table we could then test whether urban households in Bihar borrow less than rural households in Bihar (21\% vs. 30\%), using a Wald test.

All analyses were carried out using Stata 11.

Finally, the analysis was done with our conceptual framework (figure 3-1) in mind. It shows how our variables have an impact on access to healthcare, which, in turn, can have an impact on the short and long-term consequences of falling sick (CHE, avoidance of treatment, loss of income and source of funding).

The logistic regression was our primary analysis of health expenditure, and the three secondary dependent variables were used to improve our understanding of the economic consequences of seeking and receiving treatment. 


\title{
5 Results - Article
}

\section{Impact of the elderly on household health expenditure in Bihar and Kerala, India}

Authors: David Loutfi, Jean-Frédéric Lévesque, Subrata Mukherjee

Note: DL led the analysis and drafted the manuscript as part of his Master's thesis. JFL and SM provided comments and suggestions for the analysis and manuscript.

\begin{abstract}
:
In the context of an ageing population in India, we have examined the impact of the presence of the elderly on household catastrophic health expenditure (CHE) and three related access impacts (avoidance of treatment, loss of income, and use of alternate sources of funding). We used data from the 2004 National Sample Survey Organization (India) survey on healthcare. We chose one developed state (Kerala) and one developing state (Bihar) to compare and contrast the impact of ageing on households. Our results showed that the rate of CHE was higher in Kerala and that this was likely due largely to more elderly who in turn have more chronic disease. We expected the use of private treatment to lead to higher levels of CHE, and while it did for some households, the impact of the use of private treatment on CHE varied by state, presence of elderly, and type of health service (inpatient or outpatient). We also found that elderly females in Bihar were at a disadvantage with regards to health services utilization, that larger household size might have a protective effect on elderly households, and that some scheduled caste and Muslim households have to borrow more often than other groups in order to fund their treatment. While the elderly, chronic disease and private treatment are linked to CHE, our results suggest that other groups may simply be delaying the economic consequences of paying for healthcare, by avoiding treatment or borrowing money. These results can be used to explore the impact of the elderly in more detail in future research, and contribute to health policy discussions.
\end{abstract}

\subsection{Introduction}

India has the second largest population in the world and this population is undergoing a demographic and epidemiological transition. Better control of infectious diseases is leading to lower infant death rates and longer life expectancy (Jeyalakshmi et al. 2011). This leads to a population that lives longer and develops more chronic diseases. As people age and develop these diseases, they will require more health services and it is estimated that in 2030 almost $50 \%$ of the Indian health burden as measured by disability adjusted life years (DALYs) will be borne by the elderly (Chatterji et al. 2008). An ageing population will thus put a strain on the 
health care system if it is not adapted to the changing needs of the population (Bhattacharjya 2005). Three quarters of health expenditure in India is currently paid for privately (out-of-pocket (OOP) or private insurance) (Balarajan et al. 2011). Insurance coverage estimates vary widely including 1.6\% (Joglekar 2008), 3\% (Ellis et al. 2000), 10\% (Balarajan et al. 2011) and 25\% (Reddy et al. 2011). Poorer populations generally have less health insurance thus they tend to pay for health services through OOP expenditures. For many, these expenditures can be crippling and this is known as catastrophic health expenditure (CHE). In practice a household is said to have incurred CHE if the amount of household income spent on healthcare exceeds a certain percentage (often 10\%) of total household expenditure. This is a major problem in India, where 39 million people fall below the poverty line each year due to these expenses (Balarajan et al. 2011). In 2004-2005, 10\% of urban and $14 \%$ of rural households in India incurred catastrophic health expenditure (Selvaraj \& Karan 2009). Further, poor health can have adverse economic effects through reduced productivity, and in turn, poor economic development is linked to poorer health (Sahn 2012).

Given the ageing population of India, we have examined the impact of the elderly on catastrophic health expenditure. We would expect the presence of an elderly person in the household to increase the probability of CHE due to their increased use of health services. However, different states in India are at different levels of development and at different stages of the demographic transition. For example, the number of elderly is substantially higher in Kerala (11.24\%) than it is in Bihar (5.58\%). Further, given the better access to healthcare in Kerala, we expected the impact on health expenditure to differ in these two states. Therefore, we examined the impact of the presence of elderly people on household health expenditure in both states using data from the National Sample Survey of India, $60^{\text {th }}$ round (NSS). Deepening our understanding of the factors causing CHE will allow policy makers to promote various initiatives and policies that could reduce CHE ( $\mathrm{Pal} 2010$ ).

\subsubsection{Objectives, research questions, hypotheses}

The principle objective of this research is to examine the effects of the presence of elderly people on household health expenditure. 
The hypotheses are:

1. Households with elderly will be more likely to incur CHE

2. Households with elderly will have more chronic disease that increases their likelihood of incurring CHE

3. Households with elderly will be particularly vulnerable to the consequences of consulting private source of care given the high cost of treating chronic diseases in this sector.

As Kerala has more elderly, and is considered to have a relatively high level of private health services, we therefore expect more CHE in Kerala than Bihar

\subsection{Methods}

\subsubsection{Data collection}

We used data from the health and morbidity survey ( $60^{\text {th }}$ round) conducted by the National Sample Survey Organization (NSSO) from January to June 2004. The NSSO is a government department in India responsible for collecting data on a number of different topics at a countrywide level. This particular survey is carried out every ten years by the NSSO and so the data used is the most recently available. The NSSO used a two-stage stratified sampling design. First stage units were villages in rural areas and urban frame survey blocks in urban areas. Second stage units were households. The data was collected over two three-month sub-rounds (January - March and April - June). The survey covered household expenditure, illness and the elderly.

\subsubsection{Defining the variables}

This study has one main dependent variable (catastrophic health expenditure) and one main independent variable (presence of an elderly person in the household) as well as secondary dependent variables (loss of income, source of funding, and avoidance of treatment) and independent variables (education, urban-rural status, etc.). 


\subsubsection{Dependent variable:}

We define catastrophic health expenditure as household health expenditure exceeding $10 \%$ of total household consumption expenditure. This threshold of $10 \%$ has been chosen since some think is the threshold at which the household is forced to give up basic needs (Wagstaff \& Doorslaer 2003)

Though we define CHE as a percentage of household expenditure, it has previously been given other operational definitions. Others have used a fixed dollar amount or other percentages of household income (5\%, 20\%) (Wyszewianski 1986). Our measure (10\% of household expenditure) is widely used in the Indian context (Pal 2010; George 2005; Devadasan et al. 2007), which is why we have chosen to use it. Some define CHE not as a proportion of total household expenditure but as a proportion of capacity to pay (Xu et al. 2003), which is the amount that a household has left over after purchased necessities (such as food). If capacity to pay is used as the denominator, a higher proportion (such as $40 \%$ ) is generally required as the threshold for catastrophe. Despite the threshold being somewhat arbitrary, it nonetheless allows us to identify many households that spend a large amount on health care costs that, in turn, can impact the living standards of households.

\subsubsection{Other dependent variables}

We have included three secondary dependent variables to help gain a better understanding of the impact that illness has on households.

1. Loss of income

The measure of catastrophic health expenditure is limited in that it does not take into account the amount of income lost to the household due to the illness, both from the patient not being able to work and from other household members not working in order to help take care of the patient.

2. Source of funding for treatment

Some households might not incur catastrophic health expenditure because they sell off important assets. While this avoids short-term catastrophe, this might cause financial problems in the future such as not being able to send a child to school.

3. Avoidance of treatment 
CHE only tells us who incurred catastrophe amongst those who spent money. It does not tell us anything about those who avoided treatment altogether because they could not afford it. Our variable includes households in which an individual went to a hospital and was recommended treatment but did not choose to receive it. It does not include all households with individuals who could have needed treatment, but never reached a health center.

These 3 additional dependent variables will allow us to paint a more complete picture of the financial and access related impact of healthcare expenditure.

\subsubsection{Independent variables:}

The presence of an elderly person in the household is determined by asking the respondent for the list of family members living in the household as well as their ages. Households are then categorized by number of elderly people. An elderly person is defined as being sixty or older, as is standard for governmental purposes in India. The other independent variables are the following: education level, caste, religion, presence of chronic diseases, economic status, urban-rural status, public vs. private treatment, number of elderly, and number of children under 5.

\subsubsection{Statistical Analysis}

\subsubsection{Analysis for CHE}

Bivariate analysis was carried out to choose variables for our multivariate analysis. All of our independent variables listed above were significant (20\% level) in the bivariate analysis, except for insurance and so were kept for the multivariate. Insurance status was dropped due to its low prevalence, despite being conceptually important. The multivariate analysis was done using a logistic model that included the effects of our independent variables on the likelihood of incurring CHE. The main dependent variable was binary (presence or absence of CHE). Dummy variables were constructed for our categorical variables. The variables were added to the model by block. Block 1 consisted of demographic variables such as caste and education. Block 2 consisted of disease and treatment variables, and block 3 
included our other variable (sub-round). Significant variables, and conceptually important variables were kept in our final models.

\subsubsection{Analysis for secondary dependent variables}

We carried out a bivariate analysis to examine how each of our three secondary dependent variables varied in relation to the independent variables. The bivariate analyses of these three variables were used to complement the main logistic regressions on CHE.

Analysis was done using Stata 11.

\subsection{Results}

\subsubsection{Description of sample}

The total number of households in our survey was 7003, with 4174 from Bihar and 2829 from Kerala. Table 5-I compares demographic variables between the two states. In Bihar, $23.70 \%$ of households had one or more elderly person, while in Kerala this increased to $38.96 \%$ of households. In Kerala $57.03 \%$ of households had a member with a secondary education or higher, while in Bihar, this fell to $25.45 \%$. With regards to the locations of households, $11.06 \%$ and $27.25 \%$ of households lived in urban areas in Bihar and Kerala respectively. The percentages of households that reported having a member with a chronic illness were $7.24 \%$ and $42.58 \%$ in Bihar and Kerala respectively.

\section{Table 5-I Comparison of demographic variables in Kerala and Bihar}

\begin{tabular}{|c|c|c|c|}
\hline Variable & Categories & Bihar & Kerala \\
\hline \multirow{4}{*}{$\begin{array}{l}\text { Education (of the most } \\
\text { educated household } \\
\text { member) }(n=7001)\end{array}$} & Illiterate & $31.15 \%$ & $2.08 \%$ \\
\hline & $\begin{array}{l}\text { Primary and below } \\
\text { (literate) }\end{array}$ & $28.03 \%$ & $8.58 \%$ \\
\hline & Middle & $15.36 \%$ & $32.30 \%$ \\
\hline & Secondary and above & $25.45 \%$ & $57.03 \%$ \\
\hline \multirow[t]{4}{*}{ Caste $(n=7003)$} & Scheduled tribe & $1.23 \%$ & $1.48 \%$ \\
\hline & Schedules caste & $23.73 \%$ & $10.68 \%$ \\
\hline & Other backward caste & $55.80 \%$ & $53.60 \%$ \\
\hline & Other & $19.22 \%$ & $34.25 \%$ \\
\hline
\end{tabular}




\begin{tabular}{|c|c|c|c|}
\hline \multirow[t]{3}{*}{ Religion (n=7002) } & Hindu & $85.53 \%$ & $61.99 \%$ \\
\hline & Muslim & $14.17 \%$ & $17.68 \%$ \\
\hline & Other & $0.29 \%$ & $20.33 \%$ \\
\hline \multirow[t]{2}{*}{$\begin{array}{l}\text { Chronic diseases } \\
(\mathrm{n}=7003)\end{array}$} & $\begin{array}{l}\text { Presence of chronic } \\
\text { disease in the } \\
\text { household }\end{array}$ & $7.23 \%$ & $42.58 \%$ \\
\hline & $\begin{array}{l}\text { Presence of chronic } \\
\text { disease in an elderly } \\
\text { person }\end{array}$ & $3.5 \%$ & $20.21 \%$ \\
\hline $\begin{array}{l}\text { Insurance and/or } \\
\text { reimbursement } \\
(\mathrm{n}=7003)\end{array}$ & $\begin{array}{l}\text { Presence of insurance } \\
\text { and/or reimbursement }\end{array}$ & $0.3 \%$ & $4.04 \%$ \\
\hline \multirow[t]{3}{*}{ Poverty $(n=7003)$} & $\begin{array}{l}\text { Households below } \\
\text { poverty line (BPL) }\end{array}$ & $41.32 \%$ & $14.00 \%$ \\
\hline & $\begin{array}{l}\text { Middle income (Above } \\
\text { PL and below } 3 \text { times } \\
\text { PL) }\end{array}$ & $57.4 \%$ & $71.87 \%$ \\
\hline & $\begin{array}{l}\text { Rich (Above } 3 \text { times } \\
\text { PL) }\end{array}$ & $1.27 \%$ & $14.12 \%$ \\
\hline \multirow[t]{2}{*}{ Elderly $(\mathrm{n}=7003)$} & $\begin{array}{l}1 \text { or more elderly } \\
\text { person in the } \\
\text { household }\end{array}$ & $23.7 \%$ & $38.96 \%$ \\
\hline & $\begin{array}{l}\text { Absence of elderly } \\
\text { people in the } \\
\text { household }\end{array}$ & $76.3 \%$ & $61.04 \%$ \\
\hline \multirow[t]{2}{*}{ Sector $(n=7003)$} & Urban & $11.06 \%$ & $27.25 \%$ \\
\hline & Rural & $88.94 \%$ & $72.75 \%$ \\
\hline
\end{tabular}

\subsubsection{Level of CHE in Kerala and Bihar}

Our bivariate analysis revealed that CHE was more common in Kerala (39.39\%) than in Bihar (15.99\%). As well, households with elderly were more likely to have incurred CHE in both states (table 5-II).

Table 5-II Households with catastrophic health expenditure

\begin{tabular}{lll}
\hline & Bihar & Kerala \\
\hline No Elderly & $14.11 \%$ & $31.96 \%$ \\
Elderly & $22.05 \%$ & $51.03 \%$ \\
Total & $15.99 \%$ & $39.39 \%$ \\
\hline
\end{tabular}

\subsubsection{Impact of chronic disease}

Our bivariate analysis indicated that households with elderly had more CHE. However, our multivariate analysis showed that once chronic disease was added to 
the model, the presence of elderly became insignificant (table 5 -III). This suggests that it is not merely the presence of elderly that leads to more CHE; rather, it is the fact that elderly tend to have more chronic disease that leads to more CHE in households with elderly.

Table 5-III Odds Ratios for Catastrophic Health Expenditure (elderly and nonelderly households combined)

\begin{tabular}{|lll|}
\hline Variables & Bihar & Kerala \\
\hline & OR $(95 \% \mathrm{CI})$ & OR $(95 \% \mathrm{CI})$ \\
\hline Number of elderly & $1.13(0.89-1.43)$ & $1.04(0.85-1.27)$ \\
\hline Middle Income (ref=poor) & $0.89(0.62-1.26)$ & $1.05(0.72-1.52)$ \\
\hline Rich (ref=poor) & $0.44(0.15-1.27)$ & $0.56^{* *}(0.32-0.97)$ \\
\hline $\begin{array}{l}\text { Chronic disease (ref=no chronic } \\
\text { disease in household) }\end{array}$ & $2.42^{*}(1.91-3.08)$ & $1.62^{*}(1.42-1.85)$ \\
\hline $\begin{array}{l}\text { Private treatment (inpatient) } \\
\text { (ref=public) }\end{array}$ & $2.21^{*}(1.37-3.56)$ & $1.85^{*}(1.37-2.50)$ \\
\hline Sub-round (ref=sr 1) & $0.72(0.52-1.01)$ & $0.87(0.65-1.16)$ \\
\hline Pseudo - R2 & 0.0790 & 0.0814 \\
\hline
\end{tabular}

* significant at $1 \%,{ }^{* *}$ significant at $5 \%$

Note: Variables in this table are only the ones included in our final model. Excluded for non-significance are the number of children under 5, household size, socio-religious status, education, sector, and outpatient source of treatment.

\subsubsection{Impact of private care on CHE}

Analysis of all households (table 5-III) in each state showed that use of private treatment led to more CHE when using inpatient services but not when using outpatient services. Private treatment would be expected to lead to more CHE so our inpatients results are unsurprising. However, the lack of impact of private outpatient services is unexpected. We suspect that this is linked to our method of extrapolating 2 -week outpatient expenditure to one year by multiplying by 26 . This has led to high outpatient expenditure for both public and private services, meaning they are both likely to cause CHE, leading to a lack significance of this variable. We seem to have a threshold effect where having any outpatient expenditure is strongly linked with CHE.

\subsubsection{Logistic regression stratified by presence of elderly and state}

Further multivariate analysis stratified by presence of elderly revealed a more complicated picture. 
Table 5-IV Odds Ratios for Catastrophic Health Expenditure (stratified by presence of elderly)

\begin{tabular}{|c|c|c|c|c|}
\hline Variables & $\begin{array}{l}\text { Bihar non- } \\
\text { elderly }\end{array}$ & Bihar elderly & $\begin{array}{l}\text { Kerala non- } \\
\text { elderly }\end{array}$ & Kerala elderly \\
\hline & OR (95\% CI) & OR (95\% CI) & OR (95\% CI) & OR (95\% CI) \\
\hline $\begin{array}{l}\text { Middle Income } \\
\text { (ref=poor) }\end{array}$ & $0.57(0.19-1.72)$ & $0.31(0.05-2.18)$ & $1.10(0.48-2.51)$ & $0.78(0.38-1.58)$ \\
\hline Rich (ref=poor) & $0.17(0.01-2.08)$ & $\begin{array}{l}\text { Omitted by Stata } \\
\text { due to small } \\
\text { sample size }\end{array}$ & $\begin{array}{l}0.31^{* *}(0.10- \\
0.92)\end{array}$ & $0.50(0.18-1.37)$ \\
\hline $\begin{array}{l}\text { Chronic disease } \\
\text { (ref=no chronic } \\
\text { disease in } \\
\text { household) }\end{array}$ & $1.89(0.96-3.72)$ & $0.57(0.32-1.00)$ & $\begin{array}{l}1.38^{* *}(1.06- \\
1.78)\end{array}$ & $\begin{array}{l}1.21^{* *}(1.02- \\
1.44)\end{array}$ \\
\hline $\begin{array}{l}\text { Private treatment } \\
\text { (inpatient) } \\
\text { (ref=public) }\end{array}$ & $\begin{array}{l}11.62^{* *}(1.60- \\
84.52)\end{array}$ & $0.53(0.10-2.74)$ & $1.08(0.55-2.10)$ & $\begin{array}{l}3.01^{*}(1.60- \\
5.64)\end{array}$ \\
\hline $\begin{array}{l}\text { Private treatment } \\
\text { (outpatient) } \\
\text { (ref=public) }\end{array}$ & $0.83(0.10-6.73)$ & $\begin{array}{l}3.33(0.78- \\
14.16)\end{array}$ & $\begin{array}{l}2.94 *(1.50- \\
5.73)\end{array}$ & $0.97(0.50-1.87)$ \\
\hline $\begin{array}{l}\text { Sub-round (ref=sr } \\
\text { 1) }\end{array}$ & $1.06(0.32-3.54)$ & $\begin{array}{l}0.12^{* *}(0.02- \\
0.81)\end{array}$ & $1.09(0.60-1.97)$ & $1.08(0.64-1.81)$ \\
\hline Pseudo - R2 & 0.1869 & 0.1388 & 0.0806 & 0.0544 \\
\hline
\end{tabular}

* significant at $1 \%, * *$ significant at $5 \%$

Note: Variables in this table are only the ones included in our final model.

Excluded for non-significance are the number of children under 5, household size, socio-religious status, education, and sector.

Our results show that being rich protects from CHE in non-elderly household in Kerala. They also show that chronic disease was linked to higher CHE in Bihar and Kerala (table 5-III), but that when stratified by elderly (table 5-IV), chronic disease only had an impact in Kerala. Finally, the sub-round significantly reduced likelihood of CHE but only in elderly households in Bihar. Mean health expenditure was not shown to vary substantially between sub-rounds and so the impact seen here could just be a type- 1 error. Private inpatient treatment led to more CHE in Bihar amongst households without elderly while it lead to more CHE in Kerala only amongst households with elderly. With regards to private outpatient services, our previous analysis (table 5-III) did not show any impact. However, once we stratify our analysis by presence of elderly, we reveal a more complicated picture. The use of private outpatient treatment seems to lead only to more CHE in non-elderly households in Kerala. 


\subsubsection{Other access related impacts}

In order to gain a better understanding of the access related impacts of falling sick, we analyzed loss of income, avoidance of treatment, and source of funding.

With respect to the impact of the elderly on these variables, table $5-\mathrm{V}$ shows that households with elderly did not lose more income nor did they avoid treatment more often than households without elderly. However, in both Kerala and Bihar, households without elderly tended to borrow more often in order to pay for healthcare.

Table 5-V Impact of presence of the elderly on loss of income, avoidance, and source of funding

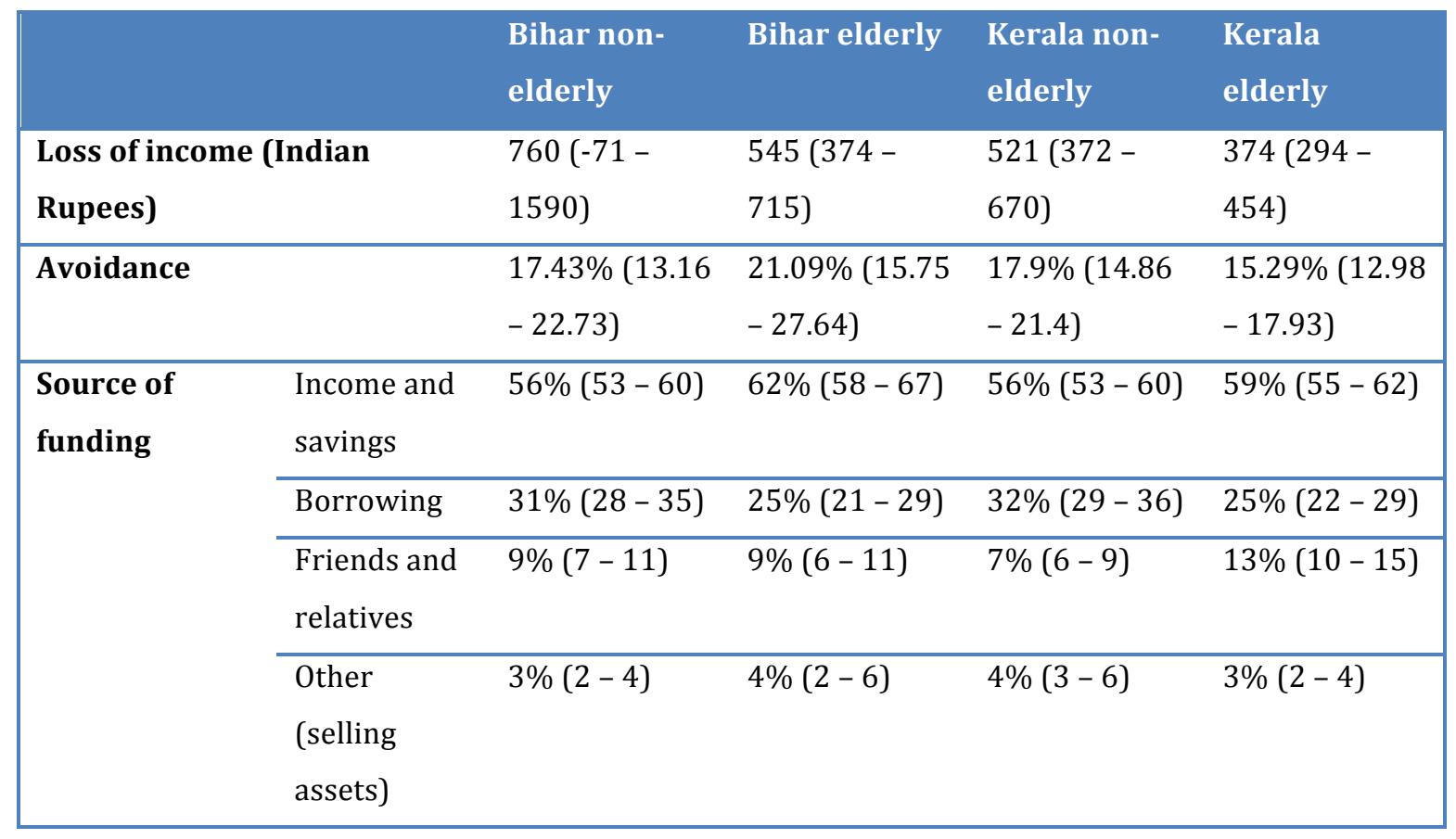

\subsubsection{Loss of income}

Our results also showed that households from higher castes, with better education, or of better economic class lost more income due to illness. All these variables are linked to income. Loss of income did not appear to be a large concern for the poor given that they have low incomes and therefore cannot lose large absolute amounts. 


\subsubsection{Avoidance of treatment}

Avoidance of treatment was linked to larger households, more children under 5, rural location, lack of education, and poverty. However, there were no clear trends linked to the elderly.

\subsubsection{Source of funding (savings, borrowing, etc.)}

Our results did not show that education or socio-religious class had an impact on CHE, but they show that education impacted the source of funding used to pay for health services. Better-educated households tended to fund their treatment through income and savings while illiterate households had to borrow more often or sell assets in order to fund their treatment. This is an important result since it is an indication that these less well-educated households will have economic consequences in the future.

Socio-religious status also provides some interesting insight into how households pay for funding. In Bihar, scheduled tribe households without elderly and Muslim households with elderly both had to borrow more often than other groups in order to fund their healthcare. Interestingly, in the present study, there was no difference in sources of funding across socio-religious groups in Kerala (including castes), perhaps indicating more equitable access to health services.

Larger households also tended to fund their treatment more through income and savings and less through borrowing, contributions from friends and relatives or selling assets.

Note: The tables of the analysis of our three secondary dependent variables were very lengthy and so were not included in this paper. However, more detailed results are available from the author upon request.

\subsubsection{Summary of primary findings}

Our hypotheses mention the potential impact of the elderly, chronic disease, and private care on CHE and its related impact. Table 5-VI summarizes our results regarding these three specific variables. 
Table 5-VI Impact of presence of elderly, chronic disease, and private treatment on CHE and related access impacts

\begin{tabular}{ll}
\hline Elderly & $\begin{array}{l}\text { Households with elderly had more CHE though they did not } \\
\text { have to borrow as often to fund their treatment indicating that } \\
\text { they likely avoided long-term consequences. Presence of } \\
\text { elderly had no impact on loss of income or avoidance of } \\
\text { treatment. }\end{array}$ \\
Chronic disease & $\begin{array}{l}\text { Households with more chronic disease incurred more CHE. } \\
\text { Further, in some cases, they avoided treatment or had to } \\
\text { borrow more often than households with acute diseases. This } \\
\text { could worsen the impact of chronic disease on households. } \\
\text { Chronic disease had no impact on loss of income. }\end{array}$ \\
Private treatment & $\begin{array}{l}\text { Using private treatment led to increased CHE for many } \\
\text { households, though there are exceptions, which we discuss } \\
\text { below. Private treatment had no impact on loss of income, } \\
\text { avoidance of treatment, or source of funding. }\end{array}$ \\
\hline
\end{tabular}

\subsection{Discussion}

Here we review some of our results and suggest some explanations. Following that, we discuss our results in the larger context of access to healthcare.

\subsubsection{Impact of chronic disease}

Our analysis revealed that households with elderly had more CHE though this was likely largely due to the increased prevalence of chronic disease in these households. The table below shows the distribution of elderly and non-elderly households with chronic disease.

Table 5-VII Distribution of households with chronic disease

\begin{tabular}{lllllll}
\hline Households & $\begin{array}{l}\text { Bihar } \\
\text { disease })\end{array}$ & \multicolumn{1}{l}{ with } & chronic & $\begin{array}{l}\text { Kerala } \\
\text { disease })\end{array}$ & \\
\hline without elderly & $17.75 \%$ & with chronic & \\
with elderly & $58.95 \%$ & $54.18 \%$ & & \\
\hline
\end{tabular}

This indicates that households with elderly are more likely to have a chronic disease. The repetitive treatments associated with chronic disease make them more costly than acute diseases. Given that households with elderly are more likely to have a chronic disease and that chronic diseases are more expensive to treat than acute ones, the increased CHE in elderly households is likely linked to the increased 
presence of chronic diseases. While the elderly could choose more expensive care and so incur CHE directly, much of the impact of the elderly on CHE is through increased prevalence of chronic disease.

\subsubsection{Impact of private inpatient treatment on CHE}

Elderly households in Kerala incur more CHE if they use private inpatient treatment, while only non-elderly households in Bihar incur more CHE for using private inpatient treatment. Below are a few factors that could explain these findings.

First, private treatment is very widespread in India accounting for $82 \%$ of outpatient visits and 58\% of inpatient expenditure (Sengupta \& Nundy 2005). In Kerala public treatment (2400 INR) costs about half as much as private treatment (4959 INR). Further, elderly households in Kerala use private inpatient care more than non-elderly household ( $71 \%$ vs. $64 \%$ ), and households in Bihar use it at roughly the same rate. Given that private treatment is more expensive than public treatment in Kerala and that the elderly use this more expensive private care more often than non-elderly, we would expect that private treatment would have an impact on CHE in elderly households in Kerala.

Second, our regression controls for the presence of chronic disease but not the type of chronic disease. Given that certain diseases are more expensive to treat than others, it could be that that an increased prevalence of a more expensive disease among the non-elderly population is leading to these results (more CHE in non-elderly households in Bihar than in elderly ones). While a full analysis of disease-specific costs was not carried out in this research, this would be an interesting area to explore.

The high costs of treatment in Bihar also suggest that treatment is being sought for expensive diseases. This points to under-utilization of treatment in Bihar. Further, the lack of impact of private care amongst the elderly also suggests underutilization by the elderly, in particular. If the elderly were using health services (public and private) for cheaper diseases as well, we might notice a difference between the costs. An in depth analysis of utilization would help in the interpretation of this result. 
In Kerala in particular, the impact of private care on CHE could be linked to the growing problem of mental health. The higher prevalence of mental illness in Kerala (5.87\%) as compared with the national average (2\%) could be contributing to increased costs of private treatment in Kerala. It should be noted that the awareness of mental health issues is likely much higher in Kerala and so the prevalence of diagnosed mental illness could be very different from the actual prevalence. The move away from the joint family model in Kerala is isolating seniors, which can lead to depression (Pilania et al. 2013). As well, the female to male ratio in Kerala is 1254:1000, higher than the rest of the country (1029:1000) (Kumar \& Devi 2010). This is relevant since females have been shown to be more likely to have mental health concerns in India (Kamble et al. 2012). Mental illness is often comorbid with other diseases and can worsen their outcomes (Moussavi et al. 2007). The impact of mental illness on other diseases could be leading to particularly high expenditure amongst the elderly in Kerala, particularly when using private healthcare. Private inpatient care is about twice the cost of public inpatient care (table 6-II. In a private healthcare facility, this increased expenditure could lead to increased CHE. This explanation related to mental health is a hypothesis that could be explored further, though no analysis on the topic was carried out directly in this research.

These are possible explanations for the impact of private care on the elderly in Kerala. However, the lack of impact of CHE due to private care among non-elderly in Kerala is difficult to explain. One possibility is the length of treatment. Elderly often have longer stays in hospital than the non-elderly. Private treatment is very widespread in Kerala and many clinics have one or two beds, should they need to keep a patient overnight. While intended as outpatient treatment, this type of visit would be recorded as inpatient treatment due to the overnight stay. However, the short period of stay (more likely among non-elderly) would lower the cost of private inpatient care that we calculated. This would make the cost of private outpatient care more similar to public care. Therefore, this short-term hospitalization could mask the difference between private and public treatment for inpatient services. 
Alternatively, this could simply be a type-2 error (i.e. our data does not show the impact of private care even though it should).

\subsubsection{Impact of private outpatient treatment on CHE}

Private outpatient treatment only increased the likelihood of CHE in nonelderly households in Kerala.

Here we consider the widespread use of alternative medicine in India. For example, a study of rural Madhya Pradesh showed that up to $65 \%$ of people identified as doctors had no formal medical training (Das 2011). A study of hypertensive patients in Chandigarh showed that $63.9 \%$ of patients used some sort of complementary or alternative medicine, the most common one being ayurveda (Shafiq et al. 2003).

Private healthcare providers include expensive clinics and hospitals as well as cheap alternative treatment, such as ayurveda, acupuncture, aromatherapy, herbal therapy, meditation, and naturopathy. Given that alternative medicine is often cheaper than modern medicine, poorer populations, such as in Bihar, likely use this type of treatment more often. Using private alternative medicine in Bihar might cost a similar amount to public care and so the impact of private care on CHE would not be seen in our data. Our data showed that the mean cost of public outpatient care in non-elderly households in Bihar is 745 INR while private care costs 429 INR, on average. Similarly, in elderly households in Bihar, public care costs 590 INR on average while private care was cheaper at 545 INR. Since we expect use of alternative care to be higher in Bihar, the lower cost associated with private care could be linked to more informal treatment or alternative care. Comparatively, in Kerala, private health services are very widespread, part of the formal sector and so often, more expensive than public healthcare. Mean cost of public outpatient use in Kerala amongst the non-elderly was 175 INR, while it was 303 INR in the private sector. Amongst elderly it was 234 INR for public use, and 425 INR for private use. We thus expect private care to lead to more CHE and we see that this is the case with non-elderly households. However we don't see this with the elderly and that is difficult to explain. One possibility is that since the absolute cost of treatment for both public and private care is more expensive amongst the elderly, elderly 
households might be incurring CHE regardless of whether they use public or private health services while, non-elderly households might only incur CHE when they use private care. To verify these hypotheses it would be useful to examine the use of alternative medicine by age group to verify if elderly/non-elderly or rich/poor use it more or less often.

It should also be noted that health-spending patterns in each state could vary substantially. While this was not measured in our survey, government spending on healthcare is likely higher in Kerala (better infrastructure and higher utilization of public sector). Furthermore, due to disparities in income, households in Kerala are likely more able to afford healthcare. The poor in Bihar are poorer than the poor in Kerala and this lack of available income in Bihar could be linked to lower CHE. Therefore, the higher level of CHE in Kerala is partially a reflection of better financial status of households in that state.

\subsubsection{Access to healthcare}

CHE is only a concern for households or individuals that can access healthcare. Access is a multifaceted concept and includes geographical, financial, and cultural access amongst others (Levesque et al. 2013). Our independent variables have an impact on access in different ways and the level of access, in turn, creates certain consequences (CHE, loss of income, avoidance of treatment, alternate source of funding).

We saw that the presence of elderly did indeed lead to more CHE, but that this was likely due to increased chronic disease in this population. These diseases will likely lead to greater demand for access to treatment. However, the availability of health services will determine what type of service is chosen (private or public) and this choice will in turn have an impact on cost, and eventually CHE. While we expected that the choice of private treatment would lead to more CHE, this wasn't always the case due, potentially, to the diversity of private providers and the ways in which they are used (short stays, mostly for cheaper services). As an example of the range of quality of health providers, a study of rural Madhya Pradesh showed that up to $65 \%$ of people identified as doctors had no formal medical training (Das 2011). 
We then examined other independent variables and saw their effects on our outcomes. We saw that household size might have an impact on the decision to seek treatment as large households provide a sort of social security which meant that they would not have to borrow as often, potentially reducing the long term impact of using and paying for health services. While strong community bonds, such as in the joint family system, can provide an informal sort of social security (McPake et al. 1993), previous research has shown that increased household size can lead both to increased CHE (in India) and to decreased CHE (in Bangladesh, Hong Kong and Thailand) (O'Donnell et al. 2005). More research would be needed to understand the impact of household size on the short and long term economic consequences of illness. Similarly, better-educated households and certain castes were also likely protected from these long-term consequences due to a diminished need to borrow to pay for treatment. This is unsurprising given that ST, SC and OBC households are often landless, less literate and poorer (Kurian 2007). These results suggest that while smaller household size, lower education, and lower castes do not contribute directly to increased $\mathrm{CHE}$, there are potential long-term consequences, due to an increased need to borrow.

Broadening our scope, we next consider factors beyond our analysis that could have an impact on access. The change in access will, in turn, have an impact on CHE and our three secondary dependent variables.

First we consider the fact that we did not have data examining health literacy. Knowledge of healthcare needs could be an important determinant of the choice to seek care. Second, cultural acceptability is an important concern in some states in India, where women are often at a disadvantage. Third, health services need to be geographically accessible. While the impact of living in a rural area was not shown in our multivariate analysis, it is possible that a more direct measure of distance to health services would show value. Fourth, having a certain amount of social support allows people, especially women, to leave the home and seek care. Our results did show that large households tended to borrow money less often, perhaps indicating that they had the financial freedom to seek treatment without forsaking important expenses, such as children's education. Last, we consider financial accessibility, the 
part of access that was the primary focus of our analysis. It is an important determinant of access and of CHE. However, in order to understand CHE, we need to understand a broad range of factors that can have an impact. It is not merely a matter of providing insurance or making health services cheaper. While these would undoubtedly be beneficial, we also need to consider the case of women, the plight of certain castes, the education level of households, and the physical distance to health services.

While the elderly do have an important impact on healthcare needs and this can lead to CHE, a number of factors must be considered in order to help households avoid CHE.

Our analysis was able to incorporate some aspects of the conceptual framework, notably certain parts of affordability, ability to pay, abilities to perceive and seek (cultural access) and ability to reach. On the other hand, we were not able to fully measure all aspects of these dimensions of access. Our analysis shows that many of the variables that we measured have an impact on access, though a study using all the variables from the framework could be illuminating. As a first example, we were not able to measure the quality of healthcare providers (appropriateness). Use of cheaper healthcare providers might allow households to avoid CHE in the near future, though there are potential harmful effects of using lower quality health services. Treatment might not be as effective, and so these households might have to contend with poor health and new health expenses in the long term. A measure of quality of care could help identify these households. As a second example, we did not have a good measure of the ability to perceive a need for treatment. Some households might not be aware of a need for treatment. This is challenging to measure as it could require a physical exam as well as specific questions related to symptoms of various illnesses. However, a measure of need would help identify households that would otherwise be ignored by our measures of CHE or avoidance.

\subsection{Conclusion}

Our results are in line with others that suggest that an ageing population is leading to larger health expenditure for households. A large part of this is due to chronic disease. With regards to health policy, our results show that this problem 
must be addressed from several angles in order to prevent or minimize CHE in the future, for states such as Bihar. First, preventative measures such as healthy eating, reduced smoking, and an active lifestyle will help prevent chronic diseases in the long-term. Second, healthcare needs to become more financially accessible. Improving the infrastructure of public health services and regulating the cost of private health services will help in this direction. As well, expanding insurance coverage, either through government programs or through affordable private insurance could be beneficial to people's health, even if it increases CHE when first implemented. This could help certain groups (SC and Muslims) that tend to borrow more, as they are likely to suffer long-term consequences from borrowing. Third, cultural accessibility needs to be addressed. For example, the promotion of women's health could be emphasized in Bihar. Fourth, the joint family model is likely providing a certain amount of financial security for the elderly, and the trend away from this could be detrimental to them. Finally, other factors not covered in our analysis should also be kept in mind. These include improved geographical accessibility (e.g.: health services availability in rural areas), improved understanding of health needs through improved health education, and appropriate follow-up to treatment to ensure adherence, avoiding relapses or worsening of certain conditions. Improving access to health services can increase CHE, though if financial access (cheaper services or insurance) is improved simultaneously, this can help compensate for the increased CHE while improving life expectancy.

\section{References :}

Balarajan, Y., Selvaraj, S. \& Subramanian, S.V., 2011. Health care and equity in India. Lancet, 377(9764), pp.505-515.

Bhattacharjya, P., 2005. Implications of an Ageing population in India: Challenges and Opportunities. In Living to 100 and Beyond Symposium. Orlando, Florida, USA: Society of Actuaries. Available at: http://www.silverinnings.com/docs/Ageing\%20Indian/Implication $\% 20 \mathrm{of} \%$ 20Ageing\%20population\%20in\%20India.pdf.

Chatterji, S. et al., 2008. The Health Of Aging Populations In China And India. Health Affairs, 27(4), pp.1052-1063. 
Das, J., 2011. The Quality of Medical Care in Low-Income Countries: From Providers to Markets. PLoS Med, 8(4), p.e1000432.

Devadasan, N. et al., 2007. Indian community health insurance schemes provide partial protection against catastrophic health expenditure. BMC Health Services Research, 7(1), p.43.

Ellis, R.P., Alam, M. \& Gupta, I., 2000. Health insurance in India: prognosis and prospectus. Economic and Political Weekly, pp.207-217.

George, A.T., 2005. Good Health at Low Cost. Economic and Political Weekly, pp.2488-2491.

Jeyalakshmi, S., Chakrabarti, S. \& Gupta, N., 2011. Situation Analysis of The Elderly in India. Available at: mospi.nic.in/mospi_new/upload/elderly_in_india.pdf [Accessed July 4, 2012].

Joglekar, R., 2008. Can Insurance Reduce Catastrophic Out-of-Pocket Health Expenditure?, East Asian Bureau of Economic Research. Available at: http://ideas.repec.org/p/eab/laborw/22367.html [Accessed May 18, 2012].

Kamble, S.V. et al., 2012. Mental Health status of elderly pesons in rural area of India. Indian Journal of Basic \& Applied Medical Research, 1(4), pp.309-312.

Kumar, N.A. \& Devi, D.R., 2010. Health of Women in Kerala: Current Status and Emerging Issues, Centre for Socio-economic \& Environmental Studies.

Moussavi, S. et al., 2007. Depression, chronic diseases, and decrements in health: results from the World Health Surveys. Lancet, 370(9590), pp.851-858.

Pal, R., 2010. Analysing Catastrophic OOP Health Expenditure in India: Concepts, Determinants and Policy Implications, Indira Gandhi Institute of Development Research.

Pilania, M. et al., 2013. Elderly depression in India: An emerging public health challenge. The Australasian Medical Journal, 6(3), pp.107-111.

Reddy, K.S. et al., 2011. A Critical Assessment of the Existing Health Insurance Models in India.

Sahn, D.E., 2012. Health, Poverty and Economic Growth: An Introduction. African Development Review, 24(4), pp.267-269.

Selvaraj, S. \& Karan, A.K., 2009. Deepening Health Insecurity in India: Evidence from National Sample Surveys since 1980s. Economic and Political Weekly, XLIV(40), pp.55-60.

Sengupta, A. \& Nundy, S., 2005. The private health sector in India. BMJ : British Medical Journal, 331(7526), pp.1157-1158. 
Shafiq, N. et al., 2003. Prevalence and pattern of use of complementary and alternative medicine (CAM) in hypertensive patients of a tertiary care center in India. International journal of clinical pharmacology and therapeutics, 41(7), pp.294-298.

Wagstaff, A. \& Doorslaer, E. van, 2003. Catastrophe and impoverishment in paying for health care: with applications to Vietnam 1993-1998. Health Economics, 12(11), pp.921-933.

Wyszewianski, L., 1986. Families with Catastrophic Health Care Expenditures. Health Services Research, 21(5), pp.617-34.

$\mathrm{Xu}$, K. et al., 2003. Household catastrophic health expenditure: a multicountry analysis. The Lancet, 362(9378), pp.111-117. 


\section{Additional Results}

In this section, we present additional results that were not mentioned in the article but which we still consider relevant. A brief description of the results is provided in this section; however, the implications of these additional results are covered more fully in the discussion, where we discuss their importance in relation to our primary results and analyses.

\subsection{Impact of disease type on CHE}

Table 6-I Impact of disease type (chronic/acute) on CHE

\begin{tabular}{lll}
\hline Disease type & Bihar (\% with CHE) & Kerala (\% with CHE) \\
\hline Acute & $52.74 \%$ & $45.04 \%$ \\
Chronic & $67.58 \%$ & $60.47 \%$ \\
\hline
\end{tabular}

This table shows the impact of disease type on presence of CHE. The presence of chronic disease in linked to increased prevalence of CHE in both states.

\subsection{Impact of private healthcare use on $\mathrm{CHE}$}

Our regressions showed that private inpatient treatment lead to higher rates of CHE than public treatment while private outpatient treatment did not when examining elderly and non-elderly households combined. The average cost for each of these categories was examined in order to understand how this could occur (table 6-II). Table 6-II Average healthcare expenditure

\begin{tabular}{lllll}
\hline $\begin{array}{l}\text { Time } \\
\text { frame }\end{array}$ & $\begin{array}{l}\text { Public } \\
\text { inpatient }\end{array}$ & $\begin{array}{l}\text { Private } \\
\text { inpatient }\end{array}$ & $\begin{array}{l}\text { Public } \\
\text { outpatient }\end{array}$ & $\begin{array}{l}\text { Private } \\
\text { outpatient }\end{array}$ \\
\hline Bi-weekly & N/A & N/A & 249 rupees & 403 rupees \\
Year & 3785 rupees & 9018 rupees & 6053 rupees & 9801 rupees \\
\hline
\end{tabular}

This table shows that the difference between public and private inpatient spending (over a year) is larger than the difference between public and private outpatient spending. This could be related to our methodology (i.e. multiplying outpatient spending by 365/15) and likely has an impact on the measurement of CHE. The 
smaller the difference between public and private spending (as with our outpatient spending) the less likely we are to see the impact of private treatment on CHE. The implications of this are explored further in the discussion.

Next we examined the impact of private treatment stratified by presence of elderly and it revealed a more complicated picture.

\subsubsection{Impact of private healthcare use on CHE (inpatient)}

Table 6-III Impact of private healthcare use on CHE (inpatient)

\begin{tabular}{lll}
\hline Households & Bihar & Kerala \\
\hline Non-Elderly & Private causes more CHE & No impact \\
Elderly & No impact & Private causes more CHE \\
\hline
\end{tabular}

Private treatment was linked to more CHE in non-elderly households in Bihar though it had no impact in households with elderly. Conversely, private treatment was linked to more CHE in households with elderly in Kerala but not in households without elderly. In order to explain this we explored two factors: the choice of public and private providers and the cost of treatment of illnesses. Table 6-IV shows the households that used private healthcare in each state.

Table 6-IV Percentage of households using private healthcare (inpatient)

\begin{tabular}{lll}
\hline Households & Bihar & Kerala \\
\hline Non-Elderly & $84.78 \%$ & $63.60 \%$ \\
Elderly & $85.22 \%$ & $70.61 \%$ \\
\hline
\end{tabular}

This confirms the widespread use of private treatment and its particularly high prevalence in Bihar.

We also examined the average cost of illness in each state and found that in Kerala public treatment ( 2400 INR) costs about half as much as private treatment (4959 INR) while in Bihar the average public treatment (8315 INR) costs a similar amount to private treatment (7422 INR).

\subsubsection{Impact of private healthcare use on CHE (outpatient)}

Table 6-V Impact of private healthcare use on CHE (outpatient)

\begin{tabular}{lll}
\hline Households & Bihar & Kerala \\
\hline Non-Elderly & No impact & Private causes more CHE \\
\hline
\end{tabular}




Elderly No impact $\quad$ No impact

Here we note that for outpatient treatment, private treatment is linked to more CHE only for households without elderly in Kerala.

In order to explain this we looked at the average cost of treatment. Our data showed that the mean cost of public outpatient care in non-elderly households in Bihar is 745 INR while private care costs 429 INR, on average. Similarly, in elderly households in Bihar, public care costs 590 INR on average while private care was cheaper at 545 INR. Comparatively, in Kerala, private health services are very widespread, part of the formal sector and so often, more expensive than public healthcare. Mean cost of public outpatient use in Kerala amongst the non-elderly was 175 INR, while it was 303 INR in the private sector. Amongst elderly it was 234 INR for public use, and 425 INR for private use. It is important to note that average private treatment is more expensive than public treatment in Kerala but not in Bihar. We suggest that there may be a link to the use of cheaper alternative medicines in the private sector in Bihar and this is explored in the discussion.

\subsection{Impact of gender on utilization}

The table and chart below compare utilization in Kerala and Bihar amongst elderly and non-elderly for males and females. It shows lower utilization rates than expected for elderly females in Bihar.

Table 6-VI Number of treatments per thousand population over the last 15 days

\begin{tabular}{llllllll}
\hline \multicolumn{3}{l}{ Non-Elderly } & \multicolumn{3}{l}{ Elderly } \\
\hline & Male & Female & Total & Male & Female & Total & $\begin{array}{l}\text { Ratio } \\
\text { (elderly } \\
\text { to non- } \\
\text { elderly) }\end{array}$ \\
Bihar & 38 & 40 & 39 & 145 & 126 & 137 & $\mathbf{3 . 5}$ \\
Kerala & 178 & 198 & 189 & 634 & 683 & 662 & $\mathbf{3 . 5}$ \\
\hline $\begin{array}{l}\text { Ratio } \\
\text { (Bihar } \\
\text { to }\end{array}$ & $\mathbf{4 . 7}$ & $\mathbf{5 . 0}$ & $\mathbf{4 . 8}$ & $\mathbf{4 . 4}$ & $\mathbf{5 . 4}$ & $\mathbf{4 . 8}$ & \\
Kerala) & & & & & & & \\
\hline
\end{tabular}


Figure 6-1 Number of treatments per thousand population over the last 15 days

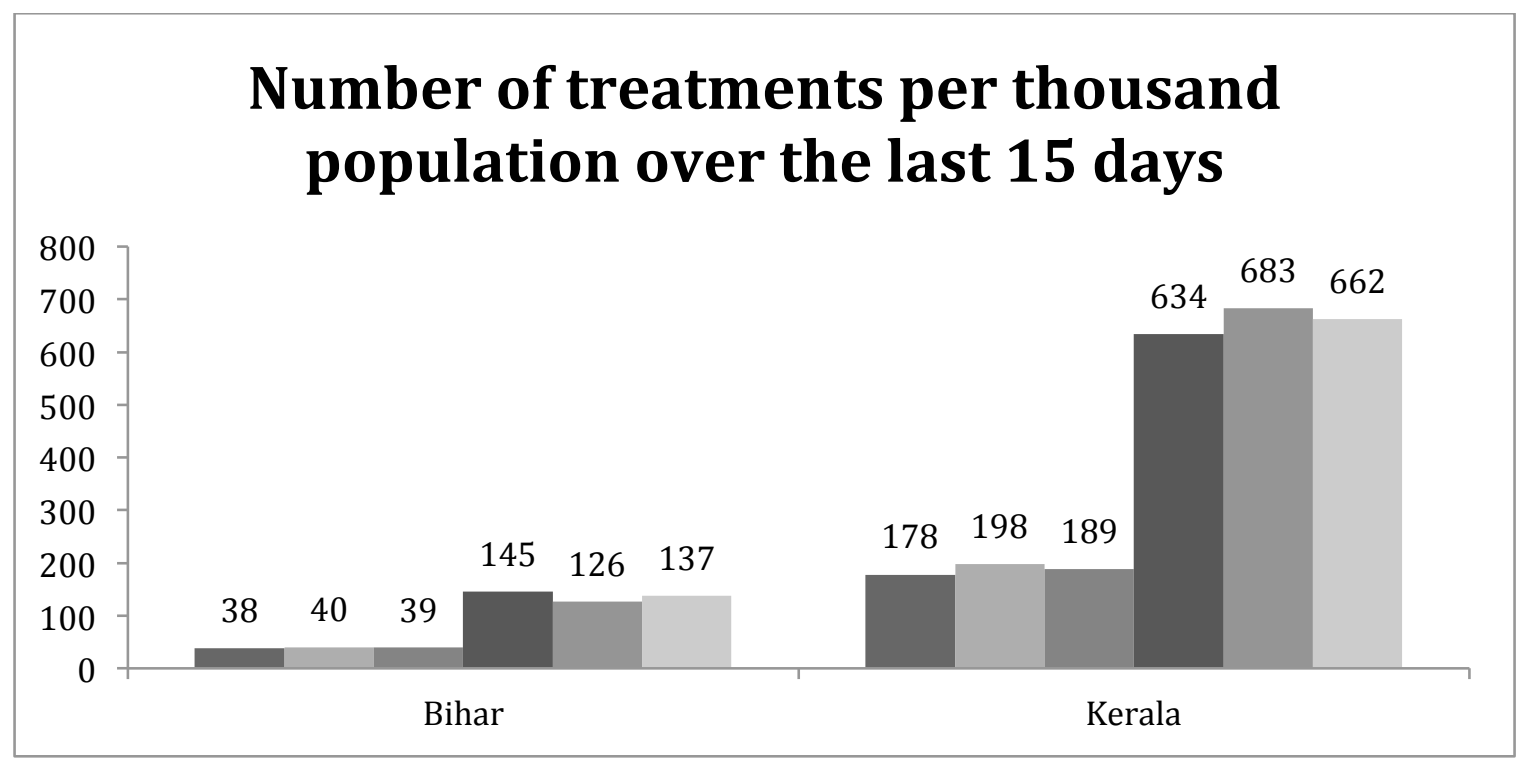

Note: See table 6-IX for legend

Three key observations stand out from this chart. The first is that utilization in Kerala is almost 5 times higher in Kerala than Bihar across all categories. This is expected due to better availability of health services as well as higher literacy, which is linked to higher utilization (Grosse \& Auffrey 1989). The second point of interest is the comparison of utilization between non-elderly and elderly. In Kerala, female elderly use healthcare more than male elderly. Although in general, females are expected to use health care services more than males, this difference in use should diminish with age (Evashwick et al. 1984), and so it is not clear why elderly females in Kerala use more health care services than males. At the very least, we expect women to use health services at same rate as males. Next, amongst non-elderly in Kerala, females still use healthcare more often. This is expected as non-elderly female adults tend to use more health services than non-elderly males (Evashwick et al. 1984). We explore potential explanations for this in the discussion.

\subsection{Impact of household size}

Household size can have an impact both in the likelihood of incurring disease (simply by having more people in the household that can fall sick) and also on 
household income as there are more potential income earners. It is therefore difficult to predict its impact on CHE.

Table 6-VII Impact of household size

\begin{tabular}{|c|c|c|c|c|}
\hline & Bihar & & Kerala & \\
\hline & Avoidance & $\begin{array}{l}\text { Source of } \\
\text { funding }\end{array}$ & Avoidance & $\begin{array}{l}\text { Source of } \\
\text { funding }\end{array}$ \\
\hline Non-Elderly & No impact & No impact & No impact & No impact \\
\hline Elderly & No impact & $\begin{array}{l}\text { Larger } \\
\text { households } \\
\text { use their } \\
\text { income and } \\
\text { savings more } \\
\text { than smaller } \\
\text { households. }\end{array}$ & $\begin{array}{l}\text { Larger } \\
\text { households } \\
\text { avoid } \\
\text { treatment } \\
\text { more often } \\
\text { than smaller } \\
\text { households }\end{array}$ & $\begin{array}{l}\text { Smaller } \\
\text { households } \\
\text { require more } \\
\text { funding from } \\
\text { friends and } \\
\text { family than } \\
\text { larger } \\
\text { households }\end{array}$ \\
\hline
\end{tabular}

Summarized in the table above are the variables on which household size had an impact, namely, avoidance of treatment and source of funding for treatment. Household size had no impact on catastrophic health expenditure or on loss of income. This table shows that larger households with elderly in Bihar and Kerala did not have to borrow from friends and family as much as small households. In Kerala, larger households also avoided treatment more often than small households. These results are likely linked to the joint family model that provides a sort of informal social security for larger households, a concept that is developed in the discussion.

\subsection{Source of funding}

An examination of the households that had to use alternative sources of funding can help illuminate our discussion of CHE. Our results did not show that education or socio-religious class had an impact on CHE, but they show that better educated households had better sources of funding in Kerala and Bihar in both elderly and non-elderly households. Better-educated households tend to fund their treatment through income and savings while illiterate households have to borrow more often or sell assets in order to fund their treatment. This is an important result since it is an indication that these less well-educated households will likely suffer economic consequences in the future. 
Socio-religious status also provides some interesting insight into how households pay for healthcare. In Bihar, scheduled tribe households without elderly and Muslim households with elderly both had to borrow more often than other groups in order to fund their healthcare. Interestingly, in the present study, there was no difference in sources of funding across socio-religious groups in Kerala (including castes), indicating more equitable access to health services. This is in distinction to other studies which have shown that scheduled tribe, scheduled caste and Other Backward Castes (OBC) households in Kerala are at a disadvantage when compared to other castes with respect to access to quality healthcare (Mukherjee et al. 2011; Mohindra et al. 2006).

\section{Discussion}

In this section, we discuss some of the more interesting points revealed through our analysis in terms of the differences between households with elderly and those without. This section discusses which factors affect catastrophic health expenditure and its related economic impacts: avoidance of treatment, loss of income, and use of alternate sources of funding.

The principle objective of this research was to examine the effects of the presence of elderly people on household health expenditure.

The hypotheses were:

1. Households with elderly will be more likely to incur CHE

2. Households with elderly will have more chronic disease that will increase their likelihood of incurring CHE

3. Households with elderly will be particularly vulnerable to the consequences of consulting private sources of care given the high cost of treating chronic diseases in this sector.

We expected that these 3 points would lead to higher CHE in Kerala than Bihar. The table below summarizes the results of our analyses with respect to these three points. 
Table 7-I Impact of presence of elderly, chronic disease, and private treatment on CHE and related access impacts

\begin{tabular}{ll}
\hline Elderly & $\begin{array}{l}\text { Households with elderly had more CHE though they did not } \\
\text { have to borrow as often to fund their treatment indicating that } \\
\text { they likely avoided long-term consequences. Presence of } \\
\text { elderly had no impact on loss of income or avoidance of } \\
\text { treatment. }\end{array}$ \\
Chronic disease & $\begin{array}{l}\text { Households with more chronic disease incurred more CHE. } \\
\text { Further, in some cases, they avoided treatment or had to } \\
\text { borrow more often than households with acute diseases. This } \\
\text { could worsen the impact of chronic disease on households. } \\
\text { Chronic disease had no impact on loss of income. }\end{array}$ \\
Private treatment & $\begin{array}{l}\text { Using private treatment led to increased CHE for many } \\
\text { households, though there are exceptions, which we discuss } \\
\text { below. Private treatment had no impact on loss of income, } \\
\text { avoidance of treatment, or source of funding. }\end{array}$ \\
\hline
\end{tabular}

These results suggest that the presence of elderly can increase the likelihood of CHE and other access related consequences, though the impact of chronic disease is the most strongly linked with CHE and other consequences. Private treatment often led to more CHE though this appears to be modified by many factors such as the diversity of private providers in India, which we discuss below. Further, the impact of elderly, chronic disease, and private treatment on households is probably greater than that measured by CHE alone given the impact shown by our secondary dependent variables.

\subsection{Framework for analysis}

Returning to our conceptual framework (figure 3-1), it shows various factors that can impact access to healthcare as well as its consequences (CHE, avoidance of treatment, loss of income, alternate sources of funding). We have analyzed the impact of these factors and in this chapter; we explain the results of this analysis. Presence of the elderly in a household can impact healthcare needs, which, through the pathway of our framework, can lead to various consequences such as CHE. Chronic disease, one such healthcare need, can also lead to increased need for treatment and potentially CHE. The type of treatment (public or private) is also likely to have an impact on CHE or our other related consequences. We expect that 
these factors will differ in Kerala and Bihar and so will lead to differences in CHE, loss of income, source of funding, and avoidance of treatment.

\subsection{Structure of discussion}

In the first part of our discussion, we cover the results summarized in table 7-I. We discuss the impact of these three factors on CHE and our other access related consequences. In the second part of the discussion, we cover other parts of our conceptual framework (e.g. insurance, household size, etc.) that could have had an impact on our measures. Next, we examine the results through our framework more directly, before ending with strengths and weaknesses of this study.

\subsection{Did Kerala have more catastrophic health expenditure than Bihar?}

We expected that Kerala would have more CHE than Bihar. We thought this would be due to an older population, more chronic disease, and better access to health services including a higher rate of private health care utilization in Kerala. The table below shows that households in Kerala incurred more CHE than households in Bihar, and that this held true for households with or without elderly. Table 7-II Households with catastrophic health expenditure

\begin{tabular}{lll}
\hline & Bihar & Kerala \\
\hline No Elderly & $14.11 \%$ & $31.96 \%$ \\
Elderly & $22.05 \%$ & $51.03 \%$ \\
Total & $15.99 \%$ & $39.39 \%$ \\
\hline
\end{tabular}

state such as Kerala. However, households need access to health services in order to incur CHE. The lower rates of CHE in Bihar could partially be a reflection of lower availability of hospital beds and doctors in the state (Central Bureau of Health Intelligence 2010a; Central Bureau of Health Intelligence 2010b). As well, households need a minimum amount of income in order to incur CHE. Given the higher levels of poverty in Bihar (41\%) than in Kerala (14\%) (author's calculations with NSSO data), it is likely that Biharis often do not have the available income to spend on healthcare. 
A few other factors can explain the differences between elderly households in Kerala and Bihar. For one, Bihar is much more rural and many of the elderly in Bihar are still working in agriculture while, in Kerala, many of the elderly are retired and in urban areas (Naik 2009). The larger urban population in Kerala means many households have a much better geographical access to health services. As well, Kerala is well known for its high quality public health services despite the recent increase in private care (Institute of Applied Manpower Research (India) 2011; Kutty 2000). Good quality care at a reasonable price leads to higher utilization and thus more CHE. While households in Kerala are incurring more CHE, it is not necessarily comparable to the CHE in Bihar. The threshold for CHE that we have retained for this analysis is $10 \%$ of household expenditure whether the household is rich or poor, and it is clear that $10 \%$ of the expenditure of a middle income household is not the same as $10 \%$ of a household that is below the poverty line (BPL). Our data shows that $41 \%$ of households in Bihar are poor while only $14 \%$ are poor in Kerala (using state-specific poverty lines). As such, the higher level of CHE in Kerala should not be interpreted as completely negative; rather, it should be an indication that households in Kerala are spending an important part of their income to receive much-needed healthcare. As an analogy, Sen notes that healthcare utilization rates are much higher in the United States than in India and much higher in Kerala than Bihar, but this does not mean that Americans are in worse health than Indians. Similarly, the lower utilization rates do not mean that Biharis are in better health than Keralites (Sen 2002). The lower utilization is likely due to the inability to use health services, not due to a lack of need.

In the following sections we address our hypotheses regarding the causes of higher CHE in Kerala (increased elderly, chronic disease, and use of private healthcare).

\subsection{Level of CHE in Kerala: Is it the elderly or the chronic disease?}

Our bivariate analyses suggest that the presence of elderly people in the household was a significant factor affecting the likelihood of incurring CHE (see table 7-II). However, we also know that chronic disease leads to more CHE, due to the extended periods of treatment, and this is confirmed in our analysis (table 6-I). 
Given that the elderly are more likely to have a chronic disease, we examined whether the impact of the elderly remained in the multivariate analysis.

Once we added the impact of chronic disease to our model, the impact of the presence of the elderly became insignificant, indicating that it is not the presence of elderly in and of itself that causes CHE, but the fact that elderly people have more chronic diseases that causes the CHE in households with elderly. The table below shows the distribution of elderly and non-elderly households with chronic disease. Table 7-III Distribution of households with chronic disease

\begin{tabular}{llllll}
\hline Households & $\begin{array}{l}\text { Bihar } \\
\text { disease })\end{array}$ & with chronic $\%$ & $\begin{array}{l}\text { Kerala } \\
\text { disease })\end{array}$ & \\
\hline without elderly & $17.75 \%$ & $54.18 \%$ & with chronic \\
with elderly & $58.95 \%$ & $80.40 \%$ & \\
\hline
\end{tabular}

This indicates that households with elderly are more likely to have a chronic disease. The repetitive treatments associated with chronic disease make them more costly than acute diseases. Given that households with elderly are more likely to have a chronic disease and that chronic diseases are more expensive to treat than acute ones, the increased CHE in elderly households is likely linked to the increased presence of chronic diseases. Without the increased presence of chronic disease, it is unlikely that the presence of elderly, in and of itself, would lead to higher CHE. It is possible that some elderly choose more expensive care and that the presence of elderly does lead to higher health expenditure directly. However, the impact of the elderly on CHE is largely via chronic disease.

Chronic disease is likely not a confounding variable as it is in the causal pathway between elderly and CHE. Being elderly leads to a higher likelihood of having a chronic disease, which in turn leads to a higher likelihood of CHE.

\subsection{Did private healthcare use lead to increased CHE?}

We hypothesized that private treatment would lead to more CHE than public treatment. Our preliminary analyses indicated that private healthcare was more strongly associated with CHE in the bivariate analysis. 
However, the results of our multivariate analysis were much less clear. We break the discussion of this analysis into two main sections. The first addresses the multivariate analysis using all households in each state, while the second consists of the multivariate analysis stratified by presence of elderly.

\subsubsection{Impact of using private healthcare on CHE (all households combined)}

Our regressions showed that households using private healthcare for inpatient services were more likely to incur CHE when elderly and non-elderly households were analyzed as one group. It also showed that using private healthcare for outpatient services had no impact on the likelihood to incur CHE. This applies in both Kerala and Bihar. Private inpatient treatment costs roughly twice as much as public inpatient treatment according to our analyses so our results are unsurprising. It is slightly more surprising that private outpatient treatment did not lead to more CHE than public treatment, given the fact that private outpatient treatment also costs about twice as much as public outpatient treatment. The most likely explanation for this result relates to our methodology. We multiplied 2-week outpatient expenditure by 26 to obtain yearly outpatient expenditure, despite the limitations of this method. As we can see in table 6-II, the amounts spent for public and private outpatient healthcare are more similar than public and private inpatient expenditure. Given that our mean yearly consumption expenditure (a proxy for income) is close to 33000 rupees, it seems likely that the difference in public and private inpatient spending is enough to cause a noticeable difference in CHE. On the other hand, public outpatient spending of 6053 rupees is substantially more than $10 \%$ of 33000 rupees (our threshold for CHE) and so outpatient spending is likely leading to CHE regardless of whether it occurs in the public or private sector.

Our analysis seems to indicate a threshold effect, where having any outpatient expenditure is strongly associated with CHE. Of households with any outpatient expenditure 67\% had CHE, while households without outpatient expenditure only incurred CHE at a rate of 4\%. Comparatively, households with any inpatient expenditure incurred CHE 43\% of the time, while households without inpatient expenditure incurred $\mathrm{CHE}$ at a rate of $57 \%$. Therefore, the presence of 
outpatient expenditure seems strongly linked with CHE, while inpatient expenditure does not. Households with any outpatient expenditure, whether public or private, thus seem more likely to incur CHE and this could explain the lack of impact of the private sector. It would be interesting to test this by using other methods to calculate yearly healthcare expenditure (e.g. a regression) or simply to measure yearly health expenditure directly in a survey. This would allow us to understand if this result is merely a reflection of our methodology or if there is an underlying cause that could be explored.

Next, we analyzed the impact of private treatment separately for households with and without elderly to see whether the elderly created an additional burden on their households.

\subsubsection{Impact of using private healthcare on CHE (stratified by presence of elderly)}

Tables 6-III and 6-V show the impact of private care on health expenditure for inpatient and outpatient services separately. The tables are the results of our multivariate analysis and so control for factors such as chronic diseases, household size, and others.

In Bihar, private inpatient treatment only causes non-elderly households to incur more CHE while in Kerala, private treatment only causes elderly households to incur more CHE. It appears that elderly households in Bihar are protected from CHE, while elderly households in Kerala are particularly affected by CHE if they use private facilities. This is somewhat surprising, as we would expect private inpatient treatment to lead to more CHE for all households.

Two factors to consider are the type of private healthcare in each state and the type of disease.

First, the choice of public or private healthcare is an important one in the Indian context. There is free healthcare at some hospitals, though availability is often limited and quality at government hospitals is often questionable. The use of private healthcare is very widespread, accounting for $82 \%$ of outpatient visits and $58 \%$ of inpatient expenditure (Sengupta \& Nundy 2005).The private sector has also grown considerably since the end of British rule in 1947, when private care 
provided only $5-10 \%$ of inpatient care. Growth of the private sector has been especially strong in Kerala in recent decades, partially to control government spending (Kutty 2000). Table 6-IV confirms that the widespread use of private healthcare for inpatient services in both states.

We would expect that, despite some variability, private healthcare facilities would tend to be of better quality in Kerala than Bihar. In Kerala public treatment (2400 INR) costs about half as much as private treatment (4959 INR). Given that private treatment is more expensive than public treatment in Kerala and that the elderly use this more expensive private care more often than non-elderly (table 6IV), we would expect that private treatment would have an impact on CHE in elderly households in Kerala.

However, in Bihar, public and private treatments have similar average costs (public - 8315 INR, private - 7422 INR) yet we still notice the impact of private treatment in non-elderly households. This could be due to the type of disease. Given that certain diseases are more expensive to treat than others, it could be that that an increased prevalence of a more expensive disease among the non-elderly population is leading to these results (more CHE in non-elderly households in Bihar than in elderly ones). While a full analysis of disease-specific costs was not carried out in this research, this would be an interesting area to explore.

These high costs of treatment in Bihar also suggest that treatment is being sought mostly for expensive diseases. This could be due to under-utilization of treatment in Bihar. Further, the lack of impact of private care amongst the elderly also suggests under-utilization by the elderly, in particular. If the elderly were using health services (public and private) for cheaper diseases as well, we might notice a difference between the costs.

In Kerala in particular, the impact of private care on CHE could be linked to the growing problem of mental health. The 2001 census shows that mental illness affects $5.87 \%$ of people in Kerala compared to only $2 \%$ nationally. It should be noted that awareness of mental health issues is likely much higher in Kerala than in Bihar and so the prevalence measured might well differ from the actual prevalence. Similarly, the stigma associated with mental illness likely contributes to less 
accurate prevalence rates. The suicide rates in Kerala are the highest in the country at 27.7 per 100,000 compared with 0.6 per 100,000 in Bihar (Soman et al. 2009). Mental health can impact CHE in the following way.

Economic development and urbanization are leading to more nuclear families in many households in India. Our data showed that average household size in Kerala was 4.4 while it was 5.6 in Bihar. These changes combined with diminished productivity of elderly people often lead to increased isolation and feelings of inadequacy making the elderly more prone to depression (Pilania et al. 2013). As well, a study of elderly in India showed that female sex and lack of family care and affection were linked to increased mental health concerns (Kamble et al. 2012). This is relevant in Kerala where, according to the 2001 census the femalemale ratio in the elderly was 1254:1000 compared with 1029:1000 for the country as a whole (Kumar \& Devi 2010). The increase in mental health issues is compounded by the fact that depression is often co-morbid with other chronic diseases and worsens their outcomes (Moussavi et al. 2007). Households with depressed elderly will thus spend even more on healthcare (World Health Organisation 2001), which could contribute to higher levels of CHE, particularly if private treatment is being used. Private inpatient care is about twice the cost of public inpatient care (table 6-V). In a private healthcare facility, this increased expenditure due to comorbidities could lead to increased CHE. This is a hypothesis that could partially explain why private care leads to CHE for elderly in Kerala but not for elderly in Bihar. However, no analysis to verify this was carried out for this research and it would be interesting to explore the idea further.

Finally, it is still difficult to explain why non-elderly households in Kerala would not have increased CHE due to using private inpatient services, given that we are controlling for other factors such as the presence of chronic disease. One possibility is the length of treatment. Elderly often have longer stays in hospital than the non-elderly. Private treatment is very widespread in Kerala and many clinics have one or two beds, should they need to keep a patient overnight. While intended as outpatient treatment, this type of visit would be recorded as inpatient treatment due to the overnight stay. However, the short period of stay (more likely among 
non-elderly) would lower the cost of private inpatient care that we calculated. This would make the cost of private outpatient care more similar to public care. Therefore, this short-term hospitalization could mask the difference between private and public treatment for inpatient services. Alternatively, this could simply be a type-2 error (i.e. our data does not show the impact of private care even though it should).

In our previous analysis, use of private outpatient services did not lead to any more CHE. However, once we stratify our analysis by presence of elderly, we reveal a more complicated picture (table 6-V). Use of private services for outpatient care has no impact on CHE (or any of our other dependent variables) in Bihar. Private outpatient care seems to be a concern only for non-elderly households in Kerala. This is the opposite result of private inpatient care in Kerala, where the impact of private care on CHE was seen only in households with elderly. This leads us to consider the way households choose private or public providers for outpatient services as compared to inpatient services. It has been shown that households tend to choose their healthcare provider based on the cost and the perceived quality of care (Mukherjee \& Levesque 2012). Suppose private treatment costs twice as much as public treatment. An outpatient service might cost 50 INR in the public and 100 INR in the private. However, an inpatient service might cost 500 INR in the public and 1000 INR in the private. This difference will permit some households to utilize private care for outpatient services while only using public care for more expensive inpatient services. This difference in spending pattern for inpatient and outpatient services might then explain why there is a different impact of outpatient and inpatient services. However, it is still difficult to explain why exactly private care leads to more CHE for elderly households using inpatient care in Kerala and also leads to more CHE for non-elderly households using outpatient care in Kerala.

An important caveat is the wide range in quality and prices of private providers. In the Indian context in particular, there is an interesting diversity of private providers, ranging from state-of-the-art facilities drawing in medical tourists to private providers with no formal training. For example, a study of rural Madhya Pradesh showed that up to $65 \%$ of people identified as doctors had no formal 
medical training (Das 2011). Alternative medicine is a huge industry worldwide, estimated at 2.3 AUD\$ in Australia and 34 billion USD\$ in the United States (MacLennan et al. 2002). In India, this industry is widespread as it is often integrated in the culture of care. There is a wide range of alternative medicines such as ayurveda, acupuncture, aromatherapy, herbal therapy, meditation, and naturopathy. A study of hypertensive patients in Chandigarh showed that $63.9 \%$ of patients used some sort of complementary or alternative medicine, the most common one being ayurveda (Shafiq et al. 2003). Alternative medicine is often cheaper than modern medicine so poorer populations (such as in Bihar) would be expected to use alternative medicine more often. It has been shown that the quality of health services used by the poor (whether public or private) are of less good quality than those used by the rich in Delhi (Das \& Hammer 2007). Therefore private care is not likely to be equivalent in Kerala and Bihar nor would private care received by the rich be the same as that received by the poor. Using private alternative medicine in Bihar might cost a similar amount to public care and so the impact of private care on CHE would not be seen in our data. Our data showed that the mean cost of public outpatient care in non-elderly households in Bihar is 745 INR while private care costs 429 INR, on average. Similarly, in elderly households in Bihar, public care costs 590 INR on average while private care was cheaper at 545 INR. Since we expect use of alternative care to be higher in Bihar, the lower cost associated with private care could be linked to more informal treatment or alternative care. Comparatively, in Kerala, private health services are very widespread, part of the formal sector and so often, more expensive than public healthcare. Mean cost of public outpatient use in Kerala amongst the non-elderly was 175 INR, while it was 303 INR in the private sector. Amongst elderly it was 234 INR for public use, and 425 INR for private use. We thus expect private care to lead to more CHE and we see that this is the case with non-elderly households. However we don't see this with the elderly and that is difficult to explain. One possibility is that since the absolute cost of treatment for both public and private care is more expensive amongst the elderly, elderly households might be incurring CHE regardless of whether they use public or private health services while, non-elderly 
households might only incur CHE when they use private care. Future studies could explore the use of alternative care by distinguishing between different types of private health services.

Returning to our hypotheses, we saw that there was more CHE in Kerala than Bihar. Next, we saw that households with elderly had more CHE than households without elderly, but that much of this was due to households with elderly having more chronic disease. Finally, our analysis showed that the impact of private treatment varied substantially based on state, presence of elderly people and the type of treatment (inpatient or outpatient).

Having examined our hypotheses, in this second part of the discussion, we consider other variables from our conceptual framework that could have an impact on CHE and its related consequences, namely insurance, gender, household size, education and socio-religious status. As these variables either were not significant in our multivariate analysis, or were individual level rather than household level variables, the next points are based on the analysis of our secondary dependent variables (loss of income, avoidance of treatment, alternative sources of funding). They provide further information to understand the context in which CHE takes place.

\subsection{Lack of insurance}

Estimates of the rate of health insurance coverage in India range from about 1.6\% to 25\% (Mahal et al. 2005; Joglekar 2008; Ellis et al. 2000; Reddy et al. 2011; Balarajan et al. 2011). Our data (from 2004) shows the rate of insurance at 3.09\% in Kerala and only $0.18 \%$ in Bihar. If we include all those who received any sort of reimbursement for their healthcare, this increases very slightly to $4.04 \%$ in Kerala and $0.30 \%$ in Bihar. Insurance coverage is very low and so almost all households pay for healthcare out-of-pocket. In Bihar, the amount of insurance coverage was so small that it was impossible to include in the logistic regressions. In Kerala, insurance had no impact on the amount of catastrophic health expenditure. This is somewhat surprising given that the goal of insurance is to protect households from financial shocks. A study of health insurance in China has shown that, contrary to 
expectations, health insurance increased CHE (Li et al. 2012). This was due to the fact that many diseases were not covered by the insurance program being studied. This program caused an increase in utilization without providing adequate coverage. It is clear that higher utilization is a key factor causing CHE. Our analysis shows that utilization in Kerala is almost 5 times higher than Bihar and CHE is more than twice as prevalent in Kerala. Similarly, in India the government has increased the breadth of health insurance coverage (the number of people covered in the country) from 75 million people in 2007 to 302 million people in 2010. However, the depth of coverage (the number and types of diseases and medications covered) is still insufficient. Most health insurance schemes such as Rashtriya Swasthya Bima Yojna (RSBY), an insurance scheme for the poor, only cover inpatient services (K. Srinath Reddy et al. 2011). Outpatient services and the cost of medication are also important contributors to health expenditure (Li et al. 2012). RSBY is a particularly good initiative in that it targets below poverty line (BPL) households, but its limited depth of coverage (limited to 30000 INR) and large breadth of coverage could lead to a situation similar to that of China, as mentioned above. Nonetheless, this will likely improve the health of the population, but the cost must be taken into account. For example, if the depth of insurance coverage is not sufficient, it will lead to more out-of-pocket expenditure leading to consequences such increased debt, the sale of assets, or impoverishment (Wagstaff \& Doorslaer 2003). Both Kerala and Bihar likely need better health insurance, though Bihar in particular would also benefit from improvement in its public health facilities. Without improved public healthcare, the impact of the ageing population will likely be much harder to cope with in Bihar than it has been in Kerala.

\subsection{Women in Bihar}

The plight of women in Bihar is a problem that stands out in the analysis of the data. Women generally have better life expectancy at birth than men, in most of the world as well as in India (Jeyalakshmi et al. 2011). Women also have higher utilization rates of health services(Bertakis et al. 2000) though this does vary with age (Macintyre et al. 1996). Table 6-VI and chart 6-I compare utilization in Kerala 
and Bihar amongst elderly and non-elderly for males and females. It shows lower utilization rates than expected for elderly females in Bihar.

Of particular interest in this table is the plight of Bihari women. The data shows that non-elderly females and males in Bihar use healthcare at almost the same rate, though females are expected to use it more. Further, when we examine the elderly in Bihar, we can see that females use healthcare less than males. Elderly females in Bihar thus have three levels of burden. The first is the disadvantage suffered by being Bihari ( 5 times less utilization than Kerala). The second is the disadvantage of being a woman in Bihar (equal utilization compared with males). The third is the disadvantage of being an elderly woman in Bihar (less utilization compared to males). How does this occur? As access is not purely a factor of demand issues, we must also consider the availability of health services, which is much better in Kerala. Doctors are more readily available in Kerala where there are 7060 patients per government doctor while in Bihar there are 23174 patients per government doctor. Further, there are 1089 and 4163 people per government hospital bed in Kerala and Bihar, respectively (Central Bureau of Health Intelligence 2010a; Central Bureau of Health Intelligence 2010b). Availability of services is thus much better in Kerala. We must also consider the impact of economic status. Our data indicates that there are many more households below the poverty line in Bihar (41\%) than in Kerala (14\%). Households struggling to pay for food will not consider healthcare a priority as is the case in Bihar, while in Kerala, households have the leeway to pay for healthcare should the need arise.

Data also shows that $50 \%$ of elderly females are widows while only $15 \%$ of elderly males are widowers, a situation that puts females at risk of lacking support in old-age (Dey et al. 2012). Women also often have difficulty retaining land upon the death of their husbands, in much of India, though this is less of a concern in Kerala (Jensen 2005). In rural areas in particular, many potential jobs involve difficult physical labor. However, the impact of these jobs involving physical labor can vary from region to region as some think that the types of crop have an influence on women's status. Wheat is the dominant crop in the north while rice is dominant in the south. Since cultivating rice is much less strength intensive, women 
from the south, such as in Kerala, are more able to contribute, giving them greater economic value and potentially a better status in society (Jensen 2005). With regards to physical access, many of Bihar's elderly live in rural areas, away from urban centers that tend to have better health infrastructure (Dey et al. 2012). These are potential explanations that could be explored further to better understand the mechanism behind decreased utilization by elderly women in Bihar.

What is the impact of these multiple layers of disadvantage? Data shows that life expectancy in Kerala is higher for females (76.8) than males (72.0), similar to most developed countries. On the other hand, in Bihar, life expectancy for females (66.7) is lower than it is for males (67.1) (Institute of Applied Manpower Research (India) 2011). Our data on utilization, combined with data on poor life expectancy, suggests that women in Bihar, and elderly women in particular, are not receiving the treatment they need.

On the other hand, our measure of avoidance of treatment does not show that women in Bihar avoid treatment more often than males. We suspect that the primary reason for this is that our measure of avoidance only includes those who went to the doctor and then did not receive treatment. It does not include all of those who never visited a doctor at all. However, our data does show that when women in Bihar avoid treatment it is due to financial reasons $31 \%$ of the time, while financial reasons are only a concern $22 \%$ of the time for men. Comparing the states more generally, our data shows that a lack of medical facilities is the reason for avoidance about $10 \%$ of the time in Bihar, while in Kerala a lack of medical facilities is a factor less than $1 \%$ of the time. This is in line with our knowledge about the availability of doctors and hospital beds in Kerala. This is indicative of the cultural barriers faced by women in Bihar. A traditionally patrilineal society in which few women own land or have a paying job leaves these women in a vulnerable position (Dey et al. 2012).

Some of the explanation for this difference in the treatment of women lies in Kerala's past. For one, certain matrilineal communities emphasized the importance of women, allowing them to own land and to have decision-making power as a head of household. As well, female literacy amongst the elderly is much higher in Kerala 
(58\%) than Bihar (12\%) (Jeyalakshmi et al. 2011). This education empowers elderly women in Kerala. Kerala also has a history of investing in education and the gender gap in education is almost nil. Further encouraging girls' education is the increasing number of female teachers in Kerala (68\%) while Bihar has less than $20 \%$ of female teachers (Chakraborty 2005). Bihar is not actively discriminating against women, but in a context of poverty, elderly women seem to be neglected especially when compared with the elderly women of Kerala.

\subsection{Household size}

Household size is an interesting factor as it can have both and negative impacts on health expenditure. For example, in a larger household, more people can fall sick. However, there are also potentially more people in the household who receive an income or who can stay home to care for the person that has fallen sick. Household size had an impact on two of our secondary dependent variables and the results are summarized in the table below.

Summarized in the table 6-VII are the variables on which household size had an impact, namely, avoidance of treatment and source of funding for treatment. Household size had no impact on catastrophic health expenditure or on loss of income.

First we notice that in non-elderly households in Bihar, household size has no impact on either avoidance or source of treatment. In elderly households in Bihar, we see that larger households fund their treatment more through their income and savings than smaller households. Why is it that in elderly households, larger households seem to fund their treatment more through income and savings and less through borrowing? This could be due to the type of people in the households. Larger households without elderly might have many children who don't earn an income, while large households with elderly would tend to have more savings from multiple adults in the household. Many elderly in India cannot afford to retire due to a lack of savings and pensions. Only about $10 \%$ of workers in India were covered by a formal pension scheme (Institute of Applied Manpower Research (India) 2011). Up to $40 \%$ of elderly in India were still working in 1991 (Prakash 1999) and this

trend continued through 2001 up to 2008 (Jeyalakshmi et al. 2011). This is 
particularly present in a poor state such as Bihar where the informal sector makes up a much larger part of the workforce (94\%) than in Kerala (63\%) (Naik 2009; Ekman 2004), and this work in the informal sector is more likely to lead to poverty amongst elderly (Shepherd 2011).

Second, we examine Kerala, and notice that, again, household size has no impact on avoidance or source of treatment amongst households without elderly. Here we notice that amongst households with elderly, large households avoid treatment more often than small ones. This could be due to the availability of elderly people at home to care for the sick person. In households without elderly, the head of household would likely have to continue working. This merits further exploration as it is not clear why large households with elderly in Kerala avoid treatment more often that small ones.

Why don't large elderly households in Bihar avoid treatment more often than small ones? This could be due to the fact that Bihar is a poorer state and as such, the elderly people are still working, while in Kerala, they are more likely to be retired. We also see that smaller households require more contributions from friends and family than larger households amongst households with elderly. Similarly to the case of Bihar, it seems that larger households with elderly have safer sources of funding, while smaller households with elderly don't have the same protection.

Changing family structure is also an important difference between Kerala and Bihar. As a more socially and economically developed state, Kerala has moved away from traditional joint households towards a more nuclear family (Gulati \& Rajan 1999). In support of this, our data shows that households in Bihar (5.6 people) are larger, on average, than in Kerala (4.4 people). An advantage of the joint family is the social support and financial support provided by the larger family. Kerala has compensated somewhat by increasing the number of nursing homes, (Rajan 2000) something Bihar may need to consider when their age structure approaches that of Kerala.

While household size does not have a significant impact on CHE, it does show that larger households tend to fund treatment more through income and savings and that they seem to have a better social support system. It should be noted that 
since the poor die at a younger age, on average, households with elderly tend to be richer (Pal \& Palacios 2011). Our data supports this showing that only amongst households with elderly is there a better source of funding for large households. This is an indication that the elderly would benefit from living in a joint family and that the trend away from this is not to their advantage.

\subsection{Return to our conceptual framework}

In this section, we return to our conceptual framework (figure 3-1) to understand the broad range of variables that can have an impact on access. Some of these were possible to measure with our data set, and some were not. First we discuss the measured variables. Then we discuss the potential implications of not including some of these variables in our analysis.

Our conceptual framework shows a pathway from healthcare needs to healthcare consequences. We are only partially able to measure healthcare needs. For example, we know that there are increased healthcare needs due to the presence of acute and chronic disease. On the other hand, we are not able to measure the real healthcare needs of a household. We measured avoidance of treatment though this was only avoidance of households that first went to a healthcare professional and then chose to avoid treatment. We did not measure all those who never made a decision to seek treatment. Further, wealthier households are likely better at identifying their healthcare needs. This means that the increased prevalence of CHE amongst the rich is likely skewed by the fact the poor are not seeking treatment. Given that CHE is only a concern for people that can afford treatment, a better understanding of healthcare needs would help build a more complete picture of the amount and type of households that are not incurring CHE, but are still suffering consequences of falling sick.

Regarding approachability and the ability to perceive, we did not have data examining people's health literacy or health beliefs, nor did we have data on screening or the availability of health information. We were, however, able to examine the level of education. Education did not have a significant impact on CHE, though better educated households lost more income due to illness, avoided 
treatment less often, and were able to fund treatment through income and savings rather than borrowing. For households, understanding the need for treatment is an important variable determining utilization and this is not something we were able to analyze directly. As well, understanding health beliefs could explain the use of alternative medicine in more detail.

Regarding acceptability and the ability to seek, we did not have data on specific cultural differences. Some of our results, such as the low levels of utilization amongst elderly females in Bihar, suggest cultural differences though we don't have a direct measure of this. We were able to measure the caste, and found that there were benefits to being in higher castes. ST and SC households, in particular, would be expected to have more barriers to seeking care. It is therefore possible that fewer of these households are seeking treatment and so the impact of being from those castes would not be felt in the measure of CHE.

Availability, accommodation, and the ability to reach include a few important factors to consider.

First, geographic access is an important determinant of access. We saw that availability of services was better in Kerala than Bihar, and better in urban rather than rural areas. However, we did not have a direct measure of distance to a health facility for every household. Our data did include distance as a reason for not seeking care, but only amongst those who did not receive care. While difficult logistically, including a variable measuring distance to health facility might show a significant impact of geographical access, despite the fact that our sector variable (urban/rural) did not show a significant impact in the multivariate analysis. The availability of transport, combined with distance to health facility would likely be a good indicator of avoidance. Again, this is likely to affect poorer and more rural population disproportionately.

Second, the ability to reach also includes social support. Having support in the household allows sick people to seek treatment with more ease. While we did not measure this directly, household size and source of funding (contributions from friends) are linked to social support. This can be a determinant of access and thus, of utilization. 
Affordability and the ability to pay are the concepts that we measured most directly in this analysis. We had measures of household expenditure (a proxy for income) as well as the cost of healthcare utilization. We analyzed how this affected utilization and then CHE. We also discussed avoidance of treatment as well as longterm consequences that were a result of losing income or paying for health care through borrowing. We were also somewhat able to measure the opportunity cost through our measure of loss of income. While the cost of treatment is, in theory, the same for everyone, it is also possible that healthcare providers are providing certain health services at a lower cost for poorer populations in order to ensure some income. Insurance was not something we were able to analyze due to its very small prevalence. While we expect it to prevent CHE, we saw in the literature review that it had caused increased CHE in China. The prevalence of insurance has increased since this data was collected in 2004, and so the next iteration of this survey might be better able to analyze the impact of insurance.

Appropriateness and ability to engage are related to the treatment received and the follow up of this treatment. This has an impact on healthcare consequences. For example, the type of treatment can lead to more costs but it can also lead to better outcomes. We did not discuss health outcomes, though they can have a feedback effect on healthcare needs. An illness that is not treated properly will mean healthcare needs do not diminish and the person will have to seek treatment again. Poorer populations likely tend to use less qualified and cheaper healthcare providers. This might have the effect of protecting them from CHE in the short term, though this might lead to more health problems and eventually more health expenditure in the long term.

Access is multifaceted, and in our analysis we discussed mostly affordability and ability to pay, while touching on ability to perceive (cultural access), and ability to reach (geographic access, social support). However, the scope of our analysis does not allow us to consider all the potential explanatory variables of CHE. Further research, incorporating the many components of access, mentioned above, would permit us to develop a more complete understanding of the factors affecting access and CHE. 


\subsection{Strength and Limitations}

\subsubsection{Limitations: Avoidance, recall period for health expenditure.}

\subsubsection{Definition of $\mathrm{CHE}$}

\subsection{Choice of threshold}

The threshold for CHE is necessarily somewhat arbitrary. It is supposed to indicate an amount at which a household would be forced to give up other essential items or services should they spend more than that amount of healthcare. Our threshold of $10 \%$ of monthly household expenditure is common in the literature and recognized as a threshold at which households are forced to cut back (Ghosh 2010; Wagstaff \& Doorslaer 2003). Using the same threshold allows for some comparability between studies. To ensure that our results are not dependent on the threshold, we have carried out a sensitivity analysis, in which we ran our regressions using thresholds of 10\% and 15\% (see appendix I). We then compared the odds ratio and their significance. The models are relatively stable. The one variable that varies slightly is the income level. The variation of income level as a significant independent variable is not unexpected given that our dependent variable is a direct function of income (as measured by expenditure).

\subsection{Capacity to pay}

Some authors use capacity to pay as the denominator for CHE instead of total household expenditure (Wagstaff \& Doorslaer 2003; Gotsadze et al. 2009; Su et al. 2006). Capacity to pay is defined as household expenditure minus essential expenditure, such as food. The reason for using capacity to pay is to include poor households that might spend almost all their income on food and so never have $10 \%$ of total expenditure to spend on healthcare. We have not used this method for a technical reason. One way to define capacity to pay is to take the household expenditure and subtract the poverty line from this (since the poverty line could be considered equivalent to a minimum essential expenditure). However, since many of the households in our sample are below the poverty line, subtracting the poverty line from their expenditure implies that any health expenditure at all would be 
considered catastrophic since their capacity to pay would be zero. In poorer states such as Bihar, this causes huge increases in the number of households with CHE. Using our original method (denominator is total household expenditure) results in $16 \%$ and 39\% of households incurring CHE in Bihar and Kerala, respectively. Interestingly, when using the capacity to pay method, $50 \%$ and $40 \%$ of households incur CHE in Bihar and Kerala, respectively (see table 7-IV). Using the capacity to pay method, Bihar has more CHE, while using our original method leads to more CHE in Kerala.

Table 7-IV Comparison of definitions of CHE (Households that incurred CHE)

\begin{tabular}{lll}
\hline CHE definition & Bihar & Kerala \\
\hline $\mathbf{1 0} \%$ of total expenditure & $15.99 \%$ & $39.39 \%$ \\
$\mathbf{4 0 \%}$ of capacity to pay & $49.92 \%$ & $40.02 \%$ \\
\hline
\end{tabular}

This is directly related to the income distribution in the states. In a poor state the capacity to pay method will lead to large amounts of CHE. Further, the Indian literature has levels of CHE similar to what we get using our original method (Mondal et al. 2010; George 2005). The primary purpose of our analysis is not to examine the total amount of CHE. Rather, the goal is to determine what factors influence CHE in the context of an ageing population. As such, we have decided to use total expenditure as our denominator, while keeping in mind that this method leads to more CHE in more affluent states.

\subsection{Anything above $10 \%$ is considered catastrophic}

Another limitation of our analysis is that we don't distinguish between households that have spent $10 \%$ or $80 \%$ of their income on healthcare. All of these households are simply classified as having incurred CHE in our analysis. However, households that have to spend a much larger percentage of their income on healthcare will likely have more trouble coping with the expenses than households only spending $10 \%$.

\subsection{Alternative methodologies for calculating CHE}

The analysis in this research brought to light some challenges in measuring CHE. In our case, it was required to combine health expenditure that had been 
measured over different time periods. Other researchers studying CHE from surveys such as the one used for this study, that were not specifically designed with the measurement of CHE in mind, might encounter similar methodological challenges. While we multiplied health expenditure to changes the reference period to one year, this is not ideal as this will likely lead to changes in the measurement of the prevalence of CHE. As an alternative, it would be interesting to use a regression to predict how much health expenditure a given household would incur and then to impute this value to households that did not have any health expenditure in the time period measured. One challenge of this method would be to determine the variables that most accurately predict a household's health expenditure. A second difficulty in using this method, that is context specific, is the very low income of our sample. Imputing any value to a very poor household, might lead us to believe that they incurred CHE, while they might have avoided treatment instead. This is particularly relevant if CHE is defined as a percentage of capacity to pay where capacity to pay is defined as household expenditure minus the poverty line. In this case, any health expenditure whatsoever for households below the poverty line would be defined as CHE. Despite some limitations, and its lack of use in the literature to date, we think it could be valuable to explore this regression method to adjust for different reference periods when calculating CHE.

Another alternative is to define different thresholds of CHE for different income groups. For example, a poor household might need to spend only $5 \%$ of their total household expenditure, a middle-income household might need $10 \%$ and a rich household might require a threshold of $20 \%$ for it to be considered catastrophic. This would help avoid results such as ours where the richer populations seem to have more $\mathrm{CHE}$, despite the fact that the catastrophe is probably more challenging for the poorer households. The difficulty in using different thresholds is to choose the threshold at which payment becomes catastrophic for each income group.

Two other alternatives can also improve our measurements. First one could use household income as a denominator instead of household expenditure, which is simply a proxy for income. However, total income might be hard to measure directly, particularly in low and middle-income countries where income might not be directly 
measurable through a paycheck. Second, a more ideal measurement would be a longitudinal one, where households are followed over a few years and the impact of health expenditure on their quality of life is measured repeatedly.

It is of importance to realize that the results of analysis are dependent on the definition of CHE and that this definition can vary considerably. Further, the definition that is chosen will likely depend on the context and data available, as was this case in our research. These various definitions also imply that comparing research on CHE, particularly when trying to measure prevalence, should be done with the strengths and limitations of various definitions in mind.

\subsubsection{Avoidance of treatment}

The interpretation of this variable needs to be done with caution for two reasons.

First, the data set only includes information about people that went to a doctor, discovered they needed treatment and then chose to not receive it for whatever reason. It would not include an individual who felt ill but decided never to seek treatment. This is important in our interpretation of the variable. This means that people who avoided treatment probably did it because it was too expensive or possible because they did not think it was important despite the recommendations of the healthcare professional. It also means that it is unlikely that these people would avoid treatment because of prior experience with the healthcare system and its costs. Those households with prior experience would be more likely to avoid the healthcare professional altogether and so our variable would not capture them.

Second, avoidance of treatment in our context refers only to avoidance of treatment in an outpatient context. Households were not asked if they avoided treatment in an inpatient context. Once a patient arrives at a hospital, it is likely that he has a disease that needs treatment and will have to pay for it somehow. Outpatient care is very different in that a patient could seek medical advice and then decide that the treatment or medication is too expensive. Avoidance is more likely in the outpatient context because treatment is often not as essential as it is for inpatient care. Regardless, it was not possible to examine avoidance at an inpatient level because this information was not provided in the data. 


\subsubsection{Survey data}

All of this data is from a survey and despite being an NSSO survey, using a two stage stratified sampling methodology to ensure representation by all relevant groups, the data suffers from the risk of recall-bias like any other survey.

\subsubsection{Over analysis}

Another limitation is the possibility of over-analysis. By stratifying households by elderly and non-elderly, we might be creating differences in groups that have no real meaning. By examining whether each of our dependent variables varied in relation to each of our independent variables, we are likely to find some significant differences, simply from having considered so many possibilities. Type-1 error is thus a possibility in some of these analyses.

\subsubsection{Strengths}

\subsubsection{3 secondary dependent variables}

A main strength of our methodology is the inclusion of three secondary dependent variables (avoidance of treatment, loss of income, and source of funding) as a way to better understand CHE. Most of the previous research on CHE simply examines the level of CHE and the factors that can influence it. While other studies often acknowledge the limitations of the definition, few studies address the limitations directly. The usual methods used to calculate CHE mean that some households affected by illness are likely not included. Our additional measures identified certain groups (e.g. SC and Muslim households) that might be particularly vulnerable despite socio-religious group not being a significant factor in our multivariate analysis.

\subsubsection{Future analyses}

Looking forward, our data is from the NSSO, which repeats surveys regularly. Therefore, the same analysis can be done using data from the next round of the survey to examine changes in CHE over time. 


\subsection{Summary of discussion}

In this discussion we examined the factors leading to higher CHE in Kerala than Bihar. We found that households with elderly were more likely to incur CHE but that this was likely largely due to these households having more chronic diseases. We also saw that the impact of private treatment was not clear, and that there was variation by state, presence of elderly and type of treatment (inpatient/outpatient). We suggested that some of the unexpected variations were due to alternative medicine use, similar cost of public and private services in Bihar, increased mental health concerns in Kerala, and short durations of stay in some private clinics. Analysis of our secondary dependent variables revealed some interesting results. While insurance coverage is increasing in India, this can sometimes lead to increased CHE. Elderly women in Bihar were at a disadvantage with regards to use of health services. Certain SC and Muslim households were more likely to borrow to fund their treatment. Larger households, particularly amongst the elderly were shown to have a certain amount of protection from the long-term consequences of health spending by funding through income and savings.

Some factors affecting CHE were the elderly, chronic disease, and private care, in some cases. Other factors, such as caste, religion, and gender did not show an impact in our multivariate analysis. However, our secondary analysis suggests that some of these groups do suffer from the costs of healthcare, even though our measure does not include them. The potential for long-term consequences (e.g.: debt, inability to pay for essential items such as education) on these groups should not be ignored, and this is a reminder of the advantage of studying CHE longitudinally. 


\section{Conclusion}

\subsection{Goal}

As a very large country with an ageing population, India is facing the challenges that this population entails. Chronic diseases are a growing problem (Chatterji et al. 2008) and the expenses they entail are an increasing burden on households (Selvaraj \& Karan 2009). Expensive illnesses can also lead to loss of income, avoidance of essential treatment, or force households to sell valuable assets (Kabir et al. 2000; Russell 1996; R. Sauerborn et al. 1996). Our goal was to examine the impact of an ageing population on households, through an analysis of the economic consequences of falling sick. We chose two states (Bihar and Kerala) at two very different levels of development. We hoped that the analysis would both inform us on the current impact of an ageing population as well as provide useful information to help Bihar cope with the challenges of a large elderly population when their demographic structure changes.

\subsection{Data}

We have used data from the National Sample Survey $60^{\text {th }}$ round survey on health care, morbidity, and the aged. This national level survey carried out in 2004, provided information on health needs, health care use, and the cost of treatment. This allowed us to calculate the rates of catastrophic health expenditure and the impact of the elderly on these rates. We also calculated the loss of income for all households, examined the source of all expenditure, and examined avoidance of treatment amongst all households that had healthcare needs.

\subsection{Findings}

First we examined the difference in CHE in Kerala and Bihar. We found that households with elderly had more CHE than households without. However, our multivariate analysis suggested that this was likely due to the increased prevalence of chronic disease in households with elderly. Next we examined the impact of private care on both inpatient and outpatient spending. Inpatient spending showed 
more CHE in households with elderly in Kerala but not in Bihar. This could be due the increased prevalence of mental health issues in Kerala. Mental health problems can worsen other disease and in an expensive private setting, might lead to more CHE. The lack of impact of private care on CHE in non-elderly households in Kerala might be due to short durations of stay in private clinics by the non-elderly. These short stays could cost a similar amount to a public visit and so not show an impact on CHE. Private outpatient use only showed an impact in non-elderly households in Kerala. We suggested that this might be due to increased use of alternative care in Bihar and in the elderly in Kerala. There is diversity in the range of private providers in India, in terms of quality, ranging from those with formal biomedical training, to those with formal training in alternative medicine, and to those without any formal training (Das \& Hammer 2007). The private sector accounts for $82 \%$ of outpatient visits and 58\% of inpatient expenditure care (Sengupta \& Nundy 2005). A study of alternative medicines showed that a main reason for the use of alternative care was its low cost, that they were preferred for common rather than serious ailments and that they were used more commonly in rural (40\%) rather than urban areas (30\%) (Singh et al. 2005). Further, a study of cancer patients showed older patients were more likely to use traditional, complementary or alternative medicines (Broom et al. 2009). If alternative care is cheaper, used more by the elderly (such as in Kerala) and used more in rural areas (such as Bihar), it is possible that the cheap cost of alternative care is masking the economic impact of using private rather than public healthcare in Bihar and amongst the elderly in Kerala. Finally the disease distribution might have an impact on the effect of using private treatment on CHE. Certain diseases are more prevalent amongst the non-elderly and if these are cheap in the private sector, our results might show that private care has no impact on CHE.

Next we examined our secondary dependent variables to understand the impact of other factors potentially not revealed by our analysis of CHE.

Gender was difficult to examine at a household level, but it was possible to examine the rates of utilization of males and females. Our analysis revealed the disadvantage of elderly women in Bihar with regards to utilization. We also found 
that financial concerns lead to avoidance more often in females than in males in Bihar.

Household size had an impact on the source of funding and avoidance. Larger households with elderly in Kerala avoid treatment more often, and we suggested that this could be due to the increased prevalence of elderly working in Bihar. The lack of social security would mean elderly in Bihar would be less likely to be able to stay home to care for sick household members. With regards to source of funding, large households with elderly tended to be able to fund their treatment through income and savings and less by borrowing, indicating the benefit of the joint family model.

Finally, poorly educated households and some Muslim, ST, and SC households avoided treatment or were required to borrow more often. This shows us that despite the lack of impact seen in our regression analysis, that education and caste likely can be indicators of discrimination.

\subsection{Measurement of Catastrophic Health Expenditure}

The mathematical definition of CHE is important in understanding results from different contexts. Our results showed higher levels of CHE (defined as health expenditure exceeding $10 \%$ of total households expenditure) in Kerala than in Bihar. Intuitively, one would expect a poorer state such as Bihar to incur more CHE. However, in practice, one needs a certain amount of income in order to purchase health services and incur CHE. Households that are too poor are less likely to incur CHE when it is defined in this way. This leads us to the unexpected result of a richer state with more CHE than a poorer one. It should be noted that the results of the analysis are very dependent on the definition of CHE. This definition can change considerably and so comparison of CHE from different studies should keep this in mind.

\subsection{Implications for policy and research}

The impact of chronic disease on health expenditure in India is a growing concern. Healthy lifestyles through fitness and nutrition could be promoted to help cope with the ageing population. While the impact of private care is less clear, a 
strengthening of public system and clear regulation on the cost in the private sector could reduce the burden on households. Emphasis should also be put on ensuring females are receiving the care they need, particularly in less developed states, such as Bihar. The trend away from the joint family model is also likely problematic for the elderly, as it removes a layer of social support. Finally, a lack education and social disadvantage did not have a direct impact on CHE, but might have long-term financial effects through alternative sources of funding, or long-term health impacts through avoidance of treatment.

With regards to future research, we think it would be interesting to examine the impacts of alternative treatment on the costs and outcomes of healthcare. The impact of mental health concerns on states transitioning from developing to developed status would also be of value. Finally, a longitudinal study of the impact of health expenditure on households would be an ideal way to help us understand the full range of factors that have an impact on CHE, in order to consider both the short and long-term financial effects of illness.

We have set out to improve our understanding of the impact of an ageing population on the economic consequences of healthcare. We believe that this thesis sheds some light on the impact of an ageing population in Kerala and Bihar and hope that this knowledge can contribute to improved policy or further research. We hope that a pro-active approach, building on these and other results, will help states such as Bihar in their demographic and epidemiological transition. 


\section{References:}

Balarajan, Y., Selvaraj, S. \& Subramanian, S.V., 2011. Health care and equity in India. Lancet, 377(9764), pp.505-515.

Bandyopadhyay, K.R., 2010. Poverty in India: A Chronological Review on Measurement and Identification, Asian Institute of Transport Development. Available at: http://mpra.ub.unimuenchen.de/25691/1/MPRA_paper_25691.pdf [Accessed June 30, 2013].

Bertakis, K.D. et al., 2000. Gender differences in the utilization of health care services. The Journal of family practice, 49(2), pp.147-152.

Bhat, R., 1999. Characteristics of private medical practice in India: a provider perspective. Health policy and planning, 14(1), pp.26-37.

Bhattacharjya, A.S. \& Sapra, P.K., 2008. Health Insurance In China And India: Segmented Roles For Public And Private Financing. Health Affairs, 27(4), pp.1005-1015.

Bhattacharjya, P., 2005. Implications of an Ageing population in India: Challenges and Opportunities. In Living to 100 and Beyond Symposium. Orlando, Florida, USA: Society of Actuaries. Available at: http://www.silverinnings.com/docs/Ageing\%20Indian/Implication $\% 20$ of $\%$ 20Ageing\%20population\%20in\%20India.pdf.

Bhaumik, S., 2013. Increase to India's health budget is not enough, say doctors. $B M J$, 346(mar04 4), pp.f1428-f1428.

Bloom, D.E., 2011. Population dynamics in India and implications for economic growth. The WDA-HSG Discussion Paper Series on Demographic Issues, (2011/1). Available at: http://www.harvardschoolofpublichealth.org/pgda/WorkingPapers/2011/ PGDA_WP_65.pdf [Accessed November 27, 2012].

Broom, A. et al., 2009. Indian Cancer Patients' use of Traditional, Complementary and Alternative Medicine (TCAM) and delays in presentation to Hospital. Oman Medical Journal, 24(2), pp.99-102.

Central Bureau of Health Intelligence, 2010a. Health Infrastructure 2010. In National Heath Profile of India. Office of the Registrar General and Census Commissioner, Government of India. Available at: http://cbhidghs.nic.in/writereaddata/mainlinkFile/Health\%20Infrastructur e.pdf [Accessed November 26, 2012].

Central Bureau of Health Intelligence, 2010b. Human Resources in Health Sector 2010. In National Heath Profile of India. Office of the Registrar General and Census Commissioner, Government of India. Available at: 
http://cbhidghs.nic.in/writereaddata/mainlinkFile/Human\%20Resources\% 20in\%20Health\%20Sector\%202010.pdf [Accessed November 26, 2012].

Chacko, E., 2003. Marriage, development, and the status of women in Kerala, India. Gender \& Development, 11(2), pp.52-59.

Chakraborty, A., 2005. Kerala's Changing Development Narratives. Economic and Political Weekly, 40(06).

Chatterji, S. et al., 2008. The Health Of Aging Populations In China And India. Health Affairs, 27(4), pp.1052-1063.

Chuma, J. \& Maina, T., 2012. Catastrophic health care spending and impoverishment in Kenya. BMC Health Services Research, 12(1), p.413.

Corbett, J., 1989. Poverty and Sickness: The High Costs of III - Health. IDS Bulletin, 20(2), pp.58-62.

Das, J., 2011. The Quality of Medical Care in Low-Income Countries: From Providers to Markets. PLoS Med, 8(4), p.e1000432.

Das, J. \& Hammer, J., 2007. Location, Location, Location: Residence, Wealth, And The Quality Of Medical Care In Delhi, India. Health Affairs, 26(3), pp.w338-w351.

Datta, A. \& Rustagi, P., 2012. Status of Women in Bihar: Exploring Transformation in Work and Gender Relations, New Delhi: Institute for Human Development.

Devadasan, N. et al., 2007. Indian community health insurance schemes provide partial protection against catastrophic health expenditure. BMC Health Services Research, 7(1), p.43.

Dey, S. et al., 2012. Health of the Elderly in India: Challenges of Access and Affordability. In Aging in Asia: Findings From New and Emerging Data Initiatives. Washington, DC: The National Academies Press.

Dogra, B., 1988. The'Other Epidemics'. Economic and Political Weekly, pp.2627-2628.

Van Doorslaer, E. et al., 2006. Effect of payments for health care on poverty estimates in 11 countries in Asia: an analysis of household survey data. The Lancet, 368(9544), pp.1357-1364.

Ekman, B., 2004. Community-based health insurance in low-income countries: a systematic review of the evidence. Health Policy and Planning, 19(5), pp.249270.

Ellis, R.P., Alam, M. \& Gupta, I., 2000. Health insurance in India: prognosis and prospectus. Economic and Political Weekly, pp.207-217. 
Ensor, T. \& San, P.B., 1996. Access and payment for health care: the poor of Northern Vietnam. The International journal of health planning and management, 11(1), pp.69-83.

Evashwick, C. et al., 1984. Factors explaining the use of health care services by the elderly. Health Services Research, 19(3), pp.357-382.

Feldstein, M., 1971. A New Approach to National Health Insurance. The Public Interest, 23(Spring).

George, A.T., 2005. Good Health at Low Cost. Economic and Political Weekly, pp.2488-2491.

Ghosh, S., 2010. Catastrophic Payments and Impoverishment Due to Out-of-Pocket Health Spending: The Effects of Recent Health Sector Reforms in India. SSRN eLibrary. Available at:

http://papers.ssrn.com/sol3/papers.cfm?abstract_id=1658573 [Accessed May 18, 2012].

Ghuman, B.S. \& Mehta, A., 2009. Health Care Services in India: Problems and Prospects. In International Conference on The Asian Social Protection in Comparative Perspective. Singapore.

Gotsadze, G., Zoidze, A. \& Rukhadze, N., 2009. Household catastrophic health expenditure: evidence from Georgia and its policy implications. BMC Health Serv Res, 9, p.69.

Government of India, Ministry of Health and Family Welfare, 2009. National Health Accounts India 2004-05,

Government of Kerala, 2001. Women in Kerala, Thiruvananthapuram, Kerala: Government State Press.

Grosse, R.N. \& Auffrey, C., 1989. Literacy and Health Status in Developing Countries. Annual Review of Public Health, 10(1), pp.281-297.

Gulati, L. \& Rajan, S.I., 1999. The Added Years: Elderly in India and Kerala. Economic and Political Weekly, 34(44), pp.WS46-WS51.

Gupta, I., 2009. Out-of-pocket Expenditures and Poverty: Estimates From NSS 61st Round, Delhi: Institute of Economic Growth.

Hjortsberg, C., 2003. Why do the sick not utilise health care? The case of Zambia. Health economics, 12(9), pp.755-770.

Institute of Applied Manpower Research (India), 2011. India human development report, 2011: towards social inclusion 1st ed., New Delhi: Institute of Applied Manpower Research, Planning Commission, Govt. of India : Oxford University Press. 
Jensen, R.T., 2005. Caste, Culture, and the Status and Well-Being of Widows in India. In Analyses in the Economics of Aging. University of Chicago Press, pp. 357372. Available at: http://papers.nber.org/books/wise05-1.

Jeyalakshmi, S., Chakrabarti, S. \& Gupta, N., 2011. Situation Analysis of The Elderly in India. Available at: mospi.nic.in/mospi_new/upload/elderly_in_india.pdf [Accessed July 4, 2012].

Joglekar, R., 2008. Can Insurance Reduce Catastrophic Out-of-Pocket Health Expenditure?, East Asian Bureau of Economic Research. Available at: http://ideas.repec.org/p/eab/laborw/22367.html [Accessed May 18, 2012].

Jolliffe, D., 2002. Whose Education Matters in the Determination of Household Income? Evidence from a Developing Country. Economic Development and Cultural Change, 50(2), pp.287-312.

Kabir, M.A. et al., 2000. Sickness among the urban poor: a barrier to livelihood security. Journal of International Development, 12(5), pp.707-722.

Kamble, S.V. et al., 2012. Mental Health status of elderly pesons in rural area of India. Indian Journal of Basic \& Applied Medical Research, 1(4), pp.309-312.

Kannan, K.P. \& Hari, K.S., 2002. Kerala's Gul Connection: Emigration, Remittances and their Macroeconomic Impact 1972-2000 Working paper 328., Centre for Development Studies Thiruvananthapuram.

Kinsella, K. \& He, W., 2009. An Aging World: 2008 International Population Reports, Washington, DC: U.s. Census Bureau. Available at: http://www.cardi.ie/publications/anagingworld2008internationalpopulatio nreports [Accessed November 27, 2012].

Knaul, F. et al., 2007. Impoverishing and Catastrophic Household Health Spending Among Families with Older Adults in Mexico: A Health Reform Priority. In J. Angel \& K. Whitfield, eds. The Health of Aging Hispanics. Springer New York, pp. 237-262. Available at: http://dx.doi.org/10.1007/978-0-387-472089_18.

Knaul, F.M. et al., 2011. Household catastrophic health expenditures: a comparative analysis of twelve Latin American and Caribbean Countries. Salud Publica Mex, 53 Suppl 2, pp.s85-95.

Kumar, N.A. \& Devi, D.R., 2010. Health of Women in Kerala: Current Status and Emerging Issues, Centre for Socio-economic \& Environmental Studies.

Kumar, S., Sathyanarayana, K. \& Omer, A., 2011. Living Arrangements of Elderly in India: Trends and Differentials. Available at: http://nationalacademies.org/AgingInAsia/Presentations/Kumar.pdf [Accessed November 29, 2012]. 
Kurian, N.J., 2007. Widening economic \& social disparities: implications for India. The Indian journal of medical research, 126(4), pp.374-380.

Kutty, V.R., 2000. Historical analysis of the development of health care facilities in Kerala State, India. Health policy and planning, 15(1), pp.103-109.

Levesque, J.-F. et al., 2013. Measuring the prevalence of chronic diseases using population surveys by pooling self-reported symptoms, diagnosis and treatments: results from the World Health Survey of 2003 for South Asia. International Journal of Public Health, 58(3), pp.435-447.

Levesque, J.-F., Harris, M.F. \& Russell, G., 2013. Patient-centred access to health care: conceptualising access at the interface of health systems and populations. International Journal for Equity in Health, 12(1), p.18.

Li, Y. et al., 2012. Factors affecting catastrophic health expenditure and impoverishment from medical expenses in China: policy implications of universal health insurance. Bulletin of the World Health Organization, 90(9), pp.664-671.

Macintyre, S., Hunt, K. \& Sweeting, H., 1996. Gender differences in health: Are things really as simple as they seem? Social Science \& Medicine, 42(4), pp.617-624.

MacLennan, A.H., Wilson, D.H. \& Taylor, A.W., 2002. The Escalating Cost and Prevalence of Alternative Medicine. Preventive Medicine, 35(2), pp.166-173.

Mahal, A. et al., 2005. Health Insurance in India. In Financing and Delivery of Health Care Services in India. Ministry of Health and Family Welfare, Government of India. Available at: http://www.who.int/macrohealth/action/Background\%20Papers\%20repor t.pdf.

McIntyre, D. et al., 2006. What are the economic consequences for households of illness and of paying for health care in low- and middle-income country contexts? Social Science \& Medicine, 62(4), pp.858-865.

McPake, B., Hanson, K. \& Mills, A., 1993. Community financing of health care in Africa: an evaluation of the Bamako initiative. Social science \& medicine (1982), 36(11), pp.1383-1395.

Mehta, A.K. \& Shah, A., 2001. Chronic Poverty in India: Overview Study, Rochester, NY: Indian Institute of Public Administration. Available at: http://papers.ssrn.com/abstract=1754532 [Accessed June 27, 2013].

Mock, C.N. et al., 2003. Economic consequences of injury and resulting family coping strategies in Ghana. Accident Analysis \& Prevention, 35(1), pp.81-90. 
Mohindra, K.S., Haddad, S. \& Narayana, D., 2006. Women's health in a rural community in Kerala, India: do caste and socioeconomic position matter? Journal of Epidemiology and Community Health, 60(12), pp.1020-1026.

Mondal, S. et al., 2010. Catastrophic out-of-pocket payment for health care and its impact on households: Experience from West Bengal, India. In Ten years of war against poverty. Available at:

http://www.chronicpoverty.org/publications/details/catastrophic-out-ofpocket-payment-for-health-care-and-its-impact-on-households.

Moussavi, S. et al., 2007. Depression, chronic diseases, and decrements in health: results from the World Health Surveys. Lancet, 370(9590), pp.851-858.

Mukherjee, S., Haddad, S. \& Narayana, D., 2011. Social class related inequalities in household health expenditure and economic burden: evidence from Kerala, south India. International Journal for Equity in Health, 10(1), p.1.

Mukherjee, S. \& Levesque, J.-F., 2012. Morbidity and Outpatient Care for the Elderly in Kerala, South India: Evidence from a National Population based Survey. Journal of Population Ageing, 5(3), pp.177-192.

Nahar, S. \& Costello, A., 1998. The hidden cost of "free" maternity care in Dhaka, Bangladesh. Health policy and planning, 13(4), pp.417-422.

Naik, A.K., 2009. Informal Sector and Informal Workers in India. In IARIW-SAIM Conference on Measuring the Informal Economy in Developing Countries. Kathmandu, Nepal. Available at: http://www.iariw.org/papers/2009/5a\%20naik.pdf.

National Sample Survey Organisation, 2005. Household Consumer Expenditure in India, NSS (60th round), 2004, Ministry of Statistics and Programme Implementation, Government of India.

O'Donnell, O. et al., 2005. Explaining the incidence of catastrophic health expenditures on health care: Comparative evidence from Asia. EQUITAP Project: Working Paper \#5.

Office of the Registrar General and Census Commissioner, India, 2011. Census 2011, Available at: http://www.census2011.co.in/literacy.php [Accessed August 7, 2013].

Pal, R., 2010. Analysing Catastrophic OOP Health Expenditure in India: Concepts, Determinants and Policy Implications, Indira Gandhi Institute of Development Research.

Pal, S. \& Palacios, R., 2011. Understanding Poverty among the Elderly in India: Implications for Social Pension Policy. Journal of Development Studies, 47(7), pp.1017-1037. 
Penchansky, R. \& Thomas, J.W., 1981. The Concept of Access: Definition and Relationship to Consumer Satisfaction. Medical Care, 19(2), pp.127-140.

Pilania, M. et al., 2013. Elderly depression in India: An emerging public health challenge. The Australasian Medical Journal, 6(3), pp.107-111.

Planning Commission, 2013. Press Note on Poverty Estimates, 2011-12, New Delhi: Government of India, Press Information Bureau.

Prakash, B.A., 1998. Gulf Migration and Its Economic Impact: The Kerala Experience. Economic and Political Weekly, 33(50), pp.3209-3213.

Prakash, I.J., 1999. Ageing in India.

Pryer, J., 1989. When breadwinners fall ill: preliminary findings from a case study in Bangladesh. IDS Bulletin, 20(2), pp.49-57.

Pryer, J.A., Rogers, S. \& Rahman, A., 2004. The epidemiology of good nutritional status among children from a population with a high prevalence of malnutrition. Public health nutrition, 7(2), pp.311-317.

Rajan, S.I., 2000. Home away from home: A survey of oldage homes and inmates in Kerala, Centre for Development Studies, Trivendrum, India. Available at: http://econpapers.repec.org/paper/indcdswpp/306.htm [Accessed May 2, 2013].

Reddy, K.S. et al., 2011. A Critical Assessment of the Existing Health Insurance Models in India.

Reddy, K.S. et al., 2005. Responding to the threat of chronic diseases in India. Lancet, 366(9498), pp.1744-1749.

Roy, K. \& Howard, D.H., 2007. Equity in out-of-pocket payments for hospital care: Evidence from India. Health Policy, 80(2), pp.297-307.

Russell, S., 1996. Ability to pay for health care: concepts and evidence. Health Policy and Planning, 11(3), pp.219-237.

Sahn, D.E., 2012. Health, Poverty and Economic Growth: An Introduction. African Development Review, 24(4), pp.267-269.

Saksena, P., Xu, K. \& Durairaj, V., 2010. The Drivers of Catastrophic expenditure: outpatient services, hospitalization or medicines?, World Health Organization.

Sauerborn, R. et al., 1996. Seasonal variations of household costs of illness in Burkina Faso. Social science \& medicine (1982), 43(3), pp.281-290.

Sauerborn, R., Adams, A. \& Hien, M., 1996. Household strategies to cope with the economic costs of illness. Social Science \& Medicine, 43(3), pp.291-301. 
Selvaraj, S. \& Karan, A.K., 2009. Deepening Health Insecurity in India: Evidence from National Sample Surveys since 1980s. Economic and Political Weekly, XLIV(40), pp.55-60.

Sen, A., 2002. Health: perception versus observation. BMJ, 324(7342), pp.860-861.

Sengupta, A. \& Nundy, S., 2005. The private health sector in India. BMJ : British Medical Journal, 331(7526), pp.1157-1158.

Shafiq, N. et al., 2003. Prevalence and pattern of use of complementary and alternative medicine (CAM) in hypertensive patients of a tertiary care center in India. International journal of clinical pharmacology and therapeutics, 41(7), pp.294-298.

Shepherd, A., 2011. Tackling Chronic poverty, Chronic Poverty Research Centre. Available at:

http://www.chronicpoverty.org/uploads/publication_files/Tackling\%20chr onic\%20poverty\%20webcopy.pdf.

Singh, P., Yadav, R.J. \& Pandey, A., 2005. Utilization of indigenous systems of medicine \& homoeopathy in India. The Indian journal of medical research, 122(2), pp.137-142.

Soman, C.R. et al., 2009. Suicide in South India: A community-based study in Kerala. Indian Journal of Psychiatry, 51(4), pp.261-264.

Su, T.T., Kouyaté, B. \& Flessa, S., 2006. Catastrophic household expenditure for health care in a low-income society: a study from Nouna District, Burkina Faso. Bulletin of the World Health Organization, 84(1), pp.21-27.

Thuan, N.T.B. et al., 2006. Household out-of-pocket payments for illness: Evidence from Vietnam. BMC Public Health, 6(1), p.283.

Tibaijuka, A.K., 1997. AIDS and economic welfare in peasant agriculture: Case studies from Kagabiro village, Kagera region, Tanzania. World Development, 25(6), pp.963-975.

Uppal, S. \& Sarma, S., 2007. Aging, Health and Labour Market Activity: The Case of India. World Health \& Population, 9(4), pp.79-97.

Wagstaff, A. \& Doorslaer, E. van, 2003. Catastrophe and impoverishment in paying for health care: with applications to Vietnam 1993-1998. Health Economics, 12(11), pp.921-933.

Whitehead, M., Dahlgren, G. \& Evans, T., 2001. Equity and health sector reforms: can low-income countries escape the medical poverty trap? The Lancet, 358(9284), pp.833-836. 
World Bank, 1999. Consultations with the Poor: Participatory Poverty Assessment in the Kyrgyz Republic, Bishkek. Available at: http://siteresources.worldbank.org/INTPOVERTY/Resources/3356421124115102975/1555199-1124138866347/kyrgyz.pdf.

World Health Organisation, 2001. Conquering Depression, New Delhi: WHO Regional Office for South-East Asia. Available at: http://whqlibdoc.who.int/searo/2001/SEA_Ment_120.pdf [Accessed July 15, 2013].

$\mathrm{Wu}, \mathrm{Y} ., 1997$. China's health care sector in transition: resources, demand and reforms. Health Policy, 39(2), pp.137-152.

Wyszewianski, L., 1986. Families with Catastrophic Health Care Expenditures. Health Services Research, 21(5), pp.617-34.

Xu, K., Evans, D.B., et al., 2003. Household catastrophic health expenditure: a multicountry analysis. The Lancet, 362(9378), pp.111-117.

$\mathrm{Xu}, \mathrm{K} ., \mathrm{Klavus,} \mathrm{J.,} \mathrm{et} \mathrm{al.,} \mathrm{2003.} \mathrm{Household} \mathrm{health} \mathrm{system} \mathrm{contributions} \mathrm{and} \mathrm{capacity} \mathrm{to}$ pay: definitional, empirical and technical challenges. Murray C, Evans D. Health System Performance Assesment. Washington, DC: Organización Mundial de la Salud. 


\section{Appendices}

Appendix I Sensitivity analysis (logistic regression)

Table 9-I Bihar, no elderly

\begin{tabular}{|c|c|c|c|c|}
\hline \multirow{2}{*}{$\begin{array}{l}\text { Independent } \\
\text { Variable }\end{array}$} & \multicolumn{2}{|c|}{$10 \%$ threshold } & \multicolumn{2}{|c|}{$15 \%$ threshold } \\
\hline & $\begin{array}{l}\text { Odds ratio } \\
(95 \% \mathrm{CI})\end{array}$ & $p>z$ & $\begin{array}{l}\text { Odds ratio } \\
\text { (95\% CI) }\end{array}$ & $p>z$ \\
\hline $\begin{array}{l}\text { Middle } \\
\text { income }\end{array}$ & $\begin{array}{l}0.57(0.19- \\
1.72)\end{array}$ & 0.318 & $\begin{array}{l}0.66(0.25- \\
1.78)\end{array}$ & 0.417 \\
\hline Rich & $\begin{array}{l}0.17(0.01- \\
2.08)\end{array}$ & 0.166 & $\begin{array}{l}0.04(0.00- \\
0.49)\end{array}$ & 0.011 \\
\hline $\begin{array}{l}\text { Chronic } \\
\text { disease }\end{array}$ & $\begin{array}{l}1.87(0.96- \\
3.72)\end{array}$ & 0.067 & $\begin{array}{l}1.74(0.96- \\
3.17)\end{array}$ & 0.068 \\
\hline $\begin{array}{l}\text { Private } \\
\text { treatment } \\
\text { (inpatient) }\end{array}$ & $\begin{array}{l}11.62(1.60- \\
84.52)\end{array}$ & 0.015 & $\begin{array}{l}9.31(1.61- \\
53.79)\end{array}$ & 0.013 \\
\hline $\begin{array}{l}\text { Private } \\
\text { treatment } \\
\text { (outpatient) }\end{array}$ & $\begin{array}{l}0.83(0.10- \\
6.73)\end{array}$ & 0.860 & $\begin{array}{l}0.84(0.11- \\
6.26)\end{array}$ & 0.869 \\
\hline sub-round & $\begin{array}{l}1.06(0.32- \\
3.54)\end{array}$ & 0.920 & $\begin{array}{l}1.55(0.52- \\
4.65)\end{array}$ & 0.431 \\
\hline
\end{tabular}

Table 9-II Bihar, elderly

\begin{tabular}{|c|c|c|c|c|}
\hline \multirow[t]{2}{*}{ Variable } & \multicolumn{2}{|c|}{ 10\% threshold } & \multicolumn{2}{|c|}{ 15\% threshold } \\
\hline & $\begin{array}{l}\text { Odds ratio } \\
(95 \% \mathrm{CI})\end{array}$ & $p>z$ & $\begin{array}{l}\text { Odds ratio } \\
(95 \% \mathrm{CI})\end{array}$ & $\mathbf{p}>\mathbf{z}$ \\
\hline $\begin{array}{l}\text { Middle } \\
\text { income }\end{array}$ & $\begin{array}{l}0.31(0.05- \\
2.16)\end{array}$ & 0.241 & $\begin{array}{l}0.93(0.23- \\
3.84)\end{array}$ & 0.925 \\
\hline Rich & $\begin{array}{l}\text { Omitted by } \\
\text { stata }\end{array}$ & & $\begin{array}{l}\text { Omitted by } \\
\text { stata }\end{array}$ & \\
\hline $\begin{array}{l}\text { Chronic } \\
\text { disease }\end{array}$ & $\begin{array}{l}0.57(0.32- \\
1.00)\end{array}$ & 0.051 & $\begin{array}{l}1.06(0.59- \\
1.92)\end{array}$ & 0.836 \\
\hline $\begin{array}{l}\text { Private } \\
\text { treatment } \\
\text { (inpatient) }\end{array}$ & $\begin{array}{l}0.53(0.10- \\
2.74)\end{array}$ & 0.448 & $\begin{array}{l}1.69(0.35- \\
8.15)\end{array}$ & 0.514 \\
\hline $\begin{array}{l}\text { Private } \\
\text { treatment } \\
\text { (outpatient) }\end{array}$ & $\begin{array}{l}3.33(0.78- \\
14.16)\end{array}$ & 0.103 & $\begin{array}{l}1.02(0.18- \\
5.79)\end{array}$ & 0.979 \\
\hline sub-round & $\begin{array}{l}0.12(0.02- \\
0.81)\end{array}$ & 0.030 & $\begin{array}{l}0.39(0.11- \\
1.41)\end{array}$ & 0.151 \\
\hline
\end{tabular}


Table 9-III Kerala, no-elderly

\begin{tabular}{|c|c|c|c|c|}
\hline \multirow[t]{2}{*}{ Variable } & \multicolumn{2}{|c|}{$10 \%$ threshold } & \multicolumn{2}{|c|}{$15 \%$ threshold } \\
\hline & $\begin{array}{l}\text { Odds ratio } \\
(95 \% \mathrm{CI})\end{array}$ & $p>z$ & $\begin{array}{l}\text { Odds ratio } \\
(95 \% \mathrm{CI})\end{array}$ & $p>z$ \\
\hline $\begin{array}{l}\text { Middle } \\
\text { income }\end{array}$ & $\begin{array}{l}1.10(0.48- \\
2.51)\end{array}$ & 0.826 & $\begin{array}{l}1.03(0.50- \\
2.13)\end{array}$ & 0.936 \\
\hline Rich & $\begin{array}{l}0.31(0.10- \\
0.92)\end{array}$ & 0.035 & $\begin{array}{l}0.41(0.15- \\
1.14)\end{array}$ & 0.088 \\
\hline $\begin{array}{l}\text { Chronic } \\
\text { disease }\end{array}$ & $\begin{array}{l}1.38(1.06- \\
1.78)\end{array}$ & 0.015 & $\begin{array}{l}1.54(1.24- \\
1.91)\end{array}$ & $<0.001$ \\
\hline $\begin{array}{l}\text { Private } \\
\text { treatment } \\
\text { (inpatient) }\end{array}$ & $\begin{array}{l}1.08(0.55- \\
2.10)\end{array}$ & 0.823 & $\begin{array}{l}0.88(0.48- \\
1.58)\end{array}$ & 0.662 \\
\hline $\begin{array}{l}\text { Private } \\
\text { treatment } \\
\text { (outpatient) }\end{array}$ & $\begin{array}{l}2.94(1.50- \\
5.73)\end{array}$ & 0.002 & $\begin{array}{l}2.12(1.17- \\
3.85)\end{array}$ & 0.013 \\
\hline sub-round & $\begin{array}{l}1.09(0.60 \text { - } \\
1.97)\end{array}$ & 0.781 & $\begin{array}{l}0.85(0.51- \\
1.40)\end{array}$ & 0.518 \\
\hline
\end{tabular}

Table 9-IV Kerala, elderly

\begin{tabular}{|c|c|c|c|c|}
\hline \multirow[t]{2}{*}{ Variable } & \multicolumn{2}{|c|}{$10 \%$ threshold } & \multicolumn{2}{|c|}{ 15\% threshold } \\
\hline & $\begin{array}{l}\text { Odds ratio } \\
(95 \% \mathrm{CI})\end{array}$ & $p>z$ & $\begin{array}{l}\text { Odds ratio } \\
(95 \% \mathrm{CI})\end{array}$ & $p>z$ \\
\hline $\begin{array}{l}\text { Middle } \\
\text { income }\end{array}$ & $\begin{array}{l}0.78(0.38- \\
1.58)\end{array}$ & 0.486 & $\begin{array}{l}0.68(0.36- \\
1.29)\end{array}$ & 0.238 \\
\hline Rich & $\begin{array}{l}0.50(0.18- \\
1.37)\end{array}$ & 0.178 & $\begin{array}{l}0.38(0.16- \\
0.91)\end{array}$ & 0.031 \\
\hline $\begin{array}{l}\text { Chronic } \\
\text { disease }\end{array}$ & $\begin{array}{l}1.21(1.02- \\
1.44)\end{array}$ & 0.027 & $\begin{array}{l}1.32(1.13- \\
1.55)\end{array}$ & 0.001 \\
\hline $\begin{array}{l}\text { Private } \\
\text { treatment } \\
\text { (inpatient) }\end{array}$ & $\begin{array}{l}3.01(1.60- \\
5.64)\end{array}$ & 0.001 & $\begin{array}{l}2.42(1.38- \\
4.26)\end{array}$ & 0.002 \\
\hline $\begin{array}{l}\text { Private } \\
\text { treatment } \\
\text { (outpatient) }\end{array}$ & $\begin{array}{l}0.97(0.50- \\
1.87)\end{array}$ & 0.927 & $\begin{array}{l}1.12(0.62- \\
2.03)\end{array}$ & 0.702 \\
\hline sub-round & $\begin{array}{l}1.08(0.64- \\
1.81)\end{array}$ & 0.772 & $\begin{array}{l}1.17(0.74- \\
1.86)\end{array}$ & 0.495 \\
\hline
\end{tabular}


Appendix II - Bivariate Analyses

Table 9-V Percentage of households with CHE in Bihar $(10 \%$ of total household expenditure)

\begin{tabular}{|c|c|c|c|}
\hline & & Bihar No Elderly & Bihar Elderly \\
\hline \multirow[t]{3}{*}{$\begin{array}{l}\text { Sector } \\
(n=7003)\end{array}$} & Urban & $\begin{array}{l}13.64 \%(8.83- \\
20.49)\end{array}$ & $\begin{array}{l}25.15 \%(17.58- \\
34.6)\end{array}$ \\
\hline & Rural & $\begin{array}{l}14.16 \%(12.45- \\
16.06)\end{array}$ & $\begin{array}{l}21.67 \%(18.55- \\
25.15)\end{array}$ \\
\hline & & $\mathrm{p}=0.8674$ & $\mathrm{p}=0.4406$ \\
\hline \multirow{3}{*}{$\begin{array}{l}\text { Disease status } \\
\text { (n=3688 } \\
\text { households that } \\
\text { had chronic or } \\
\text { acute disease) }\end{array}$} & $\begin{array}{l}\text { Households } \\
\text { with anyone } \\
\text { that has a } \\
\text { chronic disease }\end{array}$ & $\begin{array}{l}69.15 \%(59.4- \\
77.45)\end{array}$ & $\begin{array}{l}66.49 \%(57.92- \\
74.09)\end{array}$ \\
\hline & $\begin{array}{l}\text { Households } \\
\text { with only acute } \\
\text { diseases }\end{array}$ & $50.86 \%(44.3-57.4)$ & $\begin{array}{l}61.4 \%(49.66- \\
71.96)\end{array}$ \\
\hline & & $\mathrm{p}=0.0022$ & $\mathrm{p}=0.4720$ \\
\hline \multirow[t]{5}{*}{$\begin{array}{l}\text { Socio-religious } \\
\text { status }(n=7002)\end{array}$} & Scheduled tribe & $\begin{array}{l}14.17 \%(3.76- \\
41.09)\end{array}$ & $6.2 \%(1.11-28.06)$ \\
\hline & Scheduled caste & $\begin{array}{l}11.32 \%(8.56- \\
14.82)\end{array}$ & $\begin{array}{l}21.11 \%(15.03- \\
28.83)\end{array}$ \\
\hline & Muslim & $\begin{array}{l}14.72 \%(10.42- \\
20.39)\end{array}$ & $\begin{array}{l}20.28 \%(12.85- \\
30.5)\end{array}$ \\
\hline & Other & $\begin{array}{l}15.17 \%(13.03- \\
17.58)\end{array}$ & $\begin{array}{l}22.76 \%(19.2- \\
26.76)\end{array}$ \\
\hline & & $\mathrm{p}=0.3988$ & $p=0.6689$ \\
\hline \multirow{5}{*}{$\begin{array}{l}\text { Household level } \\
\text { education } \\
(n=7001)\end{array}$} & $\begin{array}{l}\text { Secondary and } \\
\text { above }\end{array}$ & $\begin{array}{l}14.27 \%(11.47- \\
17.62)\end{array}$ & $\begin{array}{l}27.17 \%(21.78- \\
33.32)\end{array}$ \\
\hline & Middle & $\begin{array}{l}13.93 \%(10.09- \\
18.93)\end{array}$ & $26.19 \%(17.9-36.6)$ \\
\hline & $\begin{array}{l}\text { Primary and } \\
\text { below (literate) }\end{array}$ & $\begin{array}{l}15.46 \%(12.26- \\
19.3)\end{array}$ & $\begin{array}{l}18.03 \%(12.58- \\
25.17)\end{array}$ \\
\hline & Illiterate & $\begin{array}{l}12.85 \%(10.11- \\
16.19)\end{array}$ & $\begin{array}{l}17.4 \%(13.32- \\
22.42)\end{array}$ \\
\hline & & $p=0.7065$ & $\mathrm{p}=0.0374$ \\
\hline \multirow{3}{*}{$\begin{array}{l}\text { Reimbursement } \\
\text { or Insurance } \\
(n=158)\end{array}$} & $\begin{array}{l}\text { Reimbursement } \\
\text { or Insurance }\end{array}$ & $\begin{array}{l}30.06 \%(7.84- \\
68.48)\end{array}$ & $8.22 \%(1.06-42.75)$ \\
\hline & $\begin{array}{l}\text { No } \\
\text { Reimbursement } \\
\text { or Insurance }\end{array}$ & $\begin{array}{l}14.05 \%(12.41- \\
15.86)\end{array}$ & $\begin{array}{l}22.07 \%(19.13- \\
25.31)\end{array}$ \\
\hline & & $\mathrm{p}=0.2260$ & $p=0.2630$ \\
\hline \multirow{2}{*}{$\begin{array}{l}\text { Source of } \\
\text { treatment } \\
\text { (Inpatient) }\end{array}$} & Public & $\begin{array}{l}46.97 \%(35.15- \\
59.15)\end{array}$ & $\begin{array}{l}73.85 \%(61.41- \\
83.36)\end{array}$ \\
\hline & Any Private & $66.94 \%$ (62.01 - & $73.22 \%(67.16-$ \\
\hline
\end{tabular}




\begin{tabular}{|c|c|c|c|}
\hline \multirow[t]{2}{*}{$(n=2629)$} & & $71.52)$ & $78.52)$ \\
\hline & & $\mathrm{p}=0.0021$ & $\mathrm{p}=0.9217$ \\
\hline \multirow{3}{*}{$\begin{array}{l}\text { Source of } \\
\text { treatment } \\
\text { (Outpatient) } \\
(n=2564)\end{array}$} & Public & $\begin{array}{l}89.16 \%(72.46- \\
96.26)\end{array}$ & $\begin{array}{l}74.11 \%(50.17- \\
89.06)\end{array}$ \\
\hline & Any Private & $\begin{array}{l}69.52 \%(62.0- \\
76.12)\end{array}$ & $\begin{array}{l}77.83 \%(69.07- \\
84.66)\end{array}$ \\
\hline & & $p=0.0243$ & $\mathrm{p}=0.7254$ \\
\hline \multirow[t]{3}{*}{$\begin{array}{l}\text { Children under } \\
5(n=7003)\end{array}$} & $\begin{array}{l}\text { Children under } \\
5\end{array}$ & $\begin{array}{l}14.2 \%(12.04- \\
16.67)\end{array}$ & $\begin{array}{l}19.74 \%(14.95- \\
25.6)\end{array}$ \\
\hline & $\begin{array}{l}\text { No Children } \\
\text { under } 5\end{array}$ & $\begin{array}{l}13.96 \%(11.62- \\
16.68)\end{array}$ & $\begin{array}{l}23.86 \%(20.5- \\
27.59)\end{array}$ \\
\hline & & $\mathrm{p}=0.8913$ & $\mathrm{p}=0.2202$ \\
\hline \multirow[t]{4}{*}{$\begin{array}{l}\text { Economic } \\
\text { status }(n=7003)\end{array}$} & Poor & $\begin{array}{l}14.47 \%(11.96- \\
17.41)\end{array}$ & $\begin{array}{l}15.79 \%(11.83- \\
20.77)\end{array}$ \\
\hline & Middle income & $\begin{array}{l}14.01 \%(11.89- \\
16.45)\end{array}$ & $\begin{array}{l}25.98 \%(22.03- \\
30.35)\end{array}$ \\
\hline & Rich & $6.27 \%(2.2-16.58)$ & $\begin{array}{l}31.26 \%(14.79- \\
54.39)\end{array}$ \\
\hline & & $p=0.4266$ & $p=0.0016$ \\
\hline \multirow[t]{3}{*}{$\begin{array}{l}\text { Household size } \\
(n=7003)\end{array}$} & 1 to 4 & $\begin{array}{l}13.75 \%(11.08- \\
16.93)\end{array}$ & $\begin{array}{l}19.6 \%(16.06- \\
23.71)\end{array}$ \\
\hline & 5 or more & $\begin{array}{l}14.32 \%(12.31- \\
16.59)\end{array}$ & $\begin{array}{l}23.32 \%(19.35- \\
27.83)\end{array}$ \\
\hline & & $\mathrm{p}=0.7574$ & $\mathrm{p}=0.2012$ \\
\hline \multirow[t]{3}{*}{$\begin{array}{l}\text { Sub-round } \\
(n=7003)\end{array}$} & Sub-round 1 & $\begin{array}{l}15.92 \%(13.5- \\
18.69)\end{array}$ & $\begin{array}{l}23.46 \%(19.37- \\
28.11)\end{array}$ \\
\hline & Sub-round 2 & $\begin{array}{l}12.14 \%(10.08- \\
14.55)\end{array}$ & $\begin{array}{l}20.74 \%(16.72- \\
25.44)\end{array}$ \\
\hline & & $p=0.0296$ & $\mathrm{p}=0.3896$ \\
\hline
\end{tabular}

Table 9-VI Percentage of households with CHE in Kerala (10\% of total household expenditure)

\begin{tabular}{|c|c|c|c|}
\hline & & Bihar No Elderly & Bihar Elderly \\
\hline \multirow[t]{3}{*}{$\begin{array}{l}\text { Sector } \\
(n=7003)\end{array}$} & Urban & $\begin{array}{l}25.09 \%(20.96- \\
29.73)\end{array}$ & $\begin{array}{l}46.41 \%(41.17 \text { - } \\
51.74)\end{array}$ \\
\hline & Rural & $\begin{array}{l}34.7 \% \text { (31.38 - } \\
38.18)\end{array}$ & $\begin{array}{l}52.58 \%(49.02- \\
56.12)\end{array}$ \\
\hline & & $p=0.0011$ & $\mathrm{p}=0.0587$ \\
\hline \multirow[t]{2}{*}{$\begin{array}{l}\text { Disease status } \\
\text { (n=3688 } \\
\text { households that } \\
\text { had chronic or } \\
\text { acute disease) }\end{array}$} & $\begin{array}{l}\text { Households } \\
\text { with anyone } \\
\text { that has a } \\
\text { chronic disease }\end{array}$ & $\begin{array}{l}56.04 \%(50.55- \\
61.38)\end{array}$ & $\begin{array}{l}64.02 \%(60.29- \\
67.59)\end{array}$ \\
\hline & $\begin{array}{l}\text { Households } \\
\text { with only acute }\end{array}$ & $\begin{array}{l}40.89 \%(35.39- \\
46.63)\end{array}$ & $\begin{array}{l}56.6 \% \text { (48.65 - } \\
64.23)\end{array}$ \\
\hline
\end{tabular}




\begin{tabular}{|c|c|c|c|}
\hline & diseases & & \\
\hline & & $\mathrm{p}=0.0002$ & $\mathrm{p}=0.0873$ \\
\hline \multirow[t]{5}{*}{$\begin{array}{l}\text { Socio-religious } \\
\text { status }(n=7002)\end{array}$} & Scheduled tribe & $\begin{array}{l}39.61 \%(19.64- \\
63.78)\end{array}$ & $\begin{array}{l}60.04 \%(26.61- \\
86.16)\end{array}$ \\
\hline & Scheduled caste & $\begin{array}{l}34.69 \%(26.71- \\
43.64)\end{array}$ & $\begin{array}{l}42.52 \%(33.37- \\
52.22)\end{array}$ \\
\hline & Muslim & $\begin{array}{l}40.92 \%(34.87 \text { - } \\
47.26)\end{array}$ & $\begin{array}{l}55.17 \%(48.2- \\
61.93)\end{array}$ \\
\hline & Other & $\begin{array}{l}28.91 \%(25.74- \\
32.31)\end{array}$ & $\begin{array}{l}51.26 \%(47.74- \\
54.76)\end{array}$ \\
\hline & & $\mathrm{p}=0.0118$ & $\mathrm{p}=0.1913$ \\
\hline \multirow{5}{*}{$\begin{array}{l}\text { Household level } \\
\text { education } \\
(n=7001)\end{array}$} & $\begin{array}{l}\text { Secondary and } \\
\text { above }\end{array}$ & $\begin{array}{l}30.66 \%(27.11- \\
34.45)\end{array}$ & $\begin{array}{l}51.63 \%(47.77- \\
55.47)\end{array}$ \\
\hline & Middle & $\begin{array}{l}35.47 \%(30.86- \\
40.37)\end{array}$ & $\begin{array}{l}51.02 \%(45.43- \\
56.58)\end{array}$ \\
\hline & $\begin{array}{l}\text { Primary and } \\
\text { below (literate) }\end{array}$ & $\begin{array}{l}27.25 \%(19.47- \\
36.72)\end{array}$ & $\begin{array}{l}52.43 \%(42.38- \\
62.3)\end{array}$ \\
\hline & Illiterate & $\begin{array}{l}25.31 \%(7.24- \\
59.53)\end{array}$ & $\begin{array}{l}34.7 \%(21.00- \\
51.52)\end{array}$ \\
\hline & & $\mathrm{p}=0.3605$ & $\mathrm{p}=0.3070$ \\
\hline \multirow{3}{*}{$\begin{array}{l}\text { Reimbursement } \\
\text { or Insurance } \\
(\mathrm{n}=158)\end{array}$} & $\begin{array}{l}\text { Reimbursement } \\
\text { or Insurance }\end{array}$ & $\begin{array}{l}27.72 \%(16.77- \\
42.2)\end{array}$ & $\begin{array}{l}56.07 \%(42.01- \\
69.21)\end{array}$ \\
\hline & $\begin{array}{l}\text { No } \\
\text { Reimbursement } \\
\text { or Insurance }\end{array}$ & $\begin{array}{l}32.12 \%(29.37- \\
35.01)\end{array}$ & $\begin{array}{l}50.79 \%(47.74- \\
53.84)\end{array}$ \\
\hline & & $\mathrm{p}=0.5299$ & $\mathrm{p}=0.4721$ \\
\hline \multirow{3}{*}{$\begin{array}{l}\text { Source of } \\
\text { treatment } \\
\text { (Inpatient) } \\
(n=2629)\end{array}$} & Public & $\begin{array}{l}54.39 \%(46.73- \\
61.85)\end{array}$ & $\begin{array}{l}58.54 \%(50.35- \\
66.28)\end{array}$ \\
\hline & Any Private & $\begin{array}{l}65.07 \%(59.36- \\
70.37)\end{array}$ & $\begin{array}{l}75.73 \% \text { (70.78 - } \\
80.08)\end{array}$ \\
\hline & & $\mathrm{p}=0.0252$ & $\mathrm{p}=0.0002$ \\
\hline \multirow{3}{*}{$\begin{array}{l}\text { Source of } \\
\text { treatment } \\
\text { (Outpatient) } \\
(n=2564)\end{array}$} & Public & $\begin{array}{l}45.86 \%(38.27 \text { - } \\
53.64)\end{array}$ & $\begin{array}{l}59.96 \%(52.87- \\
66.66)\end{array}$ \\
\hline & Any Private & $\begin{array}{l}60.07 \%(54.84- \\
65.07)\end{array}$ & $\begin{array}{l}69.49 \%(65.61- \\
73.12)\end{array}$ \\
\hline & & $\mathrm{p}=0.0028$ & $\mathrm{p}=0.0150$ \\
\hline \multirow[t]{3}{*}{$\begin{array}{l}\text { Children under } \\
5(n=7003)\end{array}$} & $\begin{array}{l}\text { Children under } \\
5\end{array}$ & $\begin{array}{l}41.71 \%(36.93- \\
46.65)\end{array}$ & $\begin{array}{l}50.16 \%(45.04- \\
55.28)\end{array}$ \\
\hline & $\begin{array}{l}\text { No Children } \\
\text { under } 5\end{array}$ & $\begin{array}{l}28.81 \%(25.69- \\
32.13)\end{array}$ & $\begin{array}{l}51.43 \%(47.77- \\
55.07)\end{array}$ \\
\hline & & $\mathrm{p}<0.0000$ & $p=0.6943$ \\
\hline \multirow[t]{2}{*}{$\begin{array}{l}\text { Economic } \\
\text { status }(n=7003)\end{array}$} & Poor & $\begin{array}{l}38.73 \%(31.53- \\
46.45)\end{array}$ & $\begin{array}{l}55.88 \%(48.58- \\
62.93)\end{array}$ \\
\hline & Middle income & $\begin{array}{l}33.46 \%(30.22- \\
36.86)\end{array}$ & $\begin{array}{l}50.37 \%(46.85- \\
53.88)\end{array}$ \\
\hline
\end{tabular}




\begin{tabular}{|l|l|l|l|}
\hline & Rich & $\begin{array}{l}19.45 \%(14.25- \\
25.98)\end{array}$ & $\begin{array}{l}48.5 \%(39.85- \\
57.23)\end{array}$ \\
\hline & & $p=0.0002$ & $\mathrm{p}=0.3494$ \\
\hline \multirow{2}{*}{$\begin{array}{l}\text { Household size } \\
\text { (n=7003) }\end{array}$} & \multirow{2}{*}{ to 4} & $28.62 \%(25.49-$ & $50.23 \%(45.63-$ \\
& & $31.97)$ & $54.83)$ \\
\cline { 2 - 4 } & \multirow{2}{*}{ or more } & $\begin{array}{l}39.91 \%(34.9- \\
45.13)\end{array}$ & $\begin{array}{l}51.63 \%(47.72- \\
55.52)\end{array}$ \\
\cline { 2 - 4 } & & $\mathrm{p}=0.0002$ & $\mathrm{p}=0.6505$ \\
\hline \multirow{2}{*}{$\begin{array}{l}\text { Sub-round } \\
\text { (n=7003) }\end{array}$} & Sub-round 1 & $33.53 \%(29.68-$ & $48.87 \%(44.71-$ \\
& & $37.61)$ & $53.05)$ \\
\cline { 2 - 4 } & Sub-round 2 & $30.35 \%(26.66-$ & $53.46 \%(49.2-$ \\
& & $34.31)$ & $57.67)$ \\
\cline { 2 - 4 } & & $\mathrm{p}=0.2597$ & $\mathrm{p}=0.1313$ \\
\hline
\end{tabular}


Xviii 